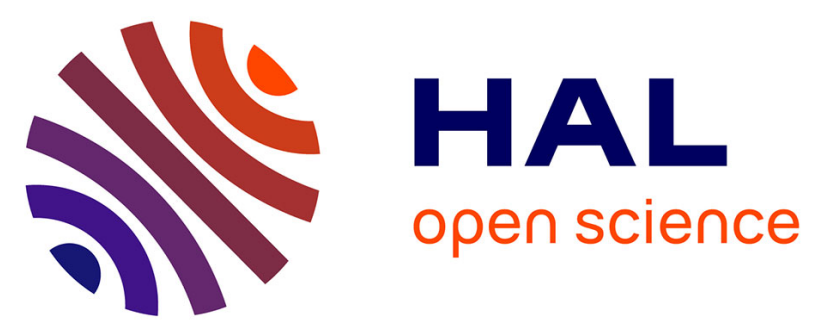

\title{
New data and perspectives on the early stages of the Neolithic in the Middle Kura River Valley (South Caucasus). The 2017-2019 excavations at Kiçik Tepe, Western Azerbaijan
}

Giulio Palumbi, Farhad Guliyev, Laurence Astruc, Emmanuel Baudouin, Rémi Berthon, Maria Bianca d'Anna, Alexia Decaix, Bernard Gratuze, Caroline Hamon, Modwene Poulmarc'H, et al.

\section{To cite this version:}

Giulio Palumbi, Farhad Guliyev, Laurence Astruc, Emmanuel Baudouin, Rémi Berthon, et al.. New data and perspectives on the early stages of the Neolithic in the Middle Kura River Valley (South Caucasus). The 2017-2019 excavations at Kiçik Tepe, Western Azerbaijan. Archaeological Research in Asia, 2021, 27, pp.100308. 10.1016/j.ara.2021.100308 . hal-03432319

\author{
HAL Id: hal-03432319 \\ https://hal.science/hal-03432319
}

Submitted on 17 Nov 2021

HAL is a multi-disciplinary open access archive for the deposit and dissemination of scientific research documents, whether they are published or not. The documents may come from teaching and research institutions in France or abroad, or from public or private research centers.
L'archive ouverte pluridisciplinaire HAL, est destinée au dépôt et à la diffusion de documents scientifiques de niveau recherche, publiés ou non, émanant des établissements d'enseignement et de recherche français ou étrangers, des laboratoires publics ou privés. 


\title{
New data and perspectives on the early stages of the Neolithic in the Middle Kura River Valley (South Caucasus). The 2017-2019 excavations at Kiçik Tepe, Western Azerbaijan
}

\author{
Giulio Palumbi ${ }^{\mathrm{a}}$, , Farhad Guliyev ${ }^{\mathrm{b}}$, Laurence Astruc ${ }^{\mathrm{c}}$, Emmanuel Baudouin ${ }^{\mathrm{d}}$, Rémi Berthon ${ }^{\mathrm{e}}$, \\ Maria Bianca D'Anna ${ }^{\mathrm{f}}$, Alexia Decaix ${ }^{\mathrm{a}}$, Bernard Gratuze ${ }^{\mathrm{g}}$, Caroline Hamon ${ }^{\mathrm{h}}$, \\ Modwene Poulmarc'h ${ }^{\mathrm{i}}$, Andrea Ricci ${ }^{\mathrm{j}}$, Valeh Alakbarov ${ }^{\mathrm{k}}$ \\ ${ }^{a}$ Laboratoire CEPAM (UMR 7264), CNRS/Université Côte d'Azur, 24, avenue des Diables Bleus, 06300 Nice, France \\ ${ }^{\mathrm{b}}$ Institute of Archaeology and Ethnography by the Azerbaijan National Academy of Sciences (ANAS), Huseyin Cavid Propspekti, Baku, Azerbaijan \\ ${ }^{\mathrm{c}}$ Equipe VEPMO, Laboratoire ArScan (UMR 7041), CNRS, Maison de l'Archéologie et de l'Ethnologie, 21 allée de l'université, 92023 Nanterre Cedex, France \\ ${ }^{\mathrm{d}}$ Université Toulouse Jean Jaurès, Laboratoire TRACES (UMR 5608) CNRS, Maison de la Recherche, 5, allées Antonio Machado, 31058 Toulouse, France \\ e Laboratoire Archéozoologie - Archéobotanique. Sociétés, pratiques et environnements (UMR 7209), CNRS/MNHN, Muséum national d'Histoire naturelle CP 56 - 57 rue \\ Cuvier, 75005 Paris, France \\ ${ }^{\mathrm{f}}$ Institut für vorderasiatische Archäologie, Freie Universität Berlin, Fabeckstr. 23-25, 14195 Berlin, Germany \\ ${ }^{\mathrm{g}}$ Institut de Recherche sur les Archéomatériaux, Centre Ernest-Babelon (UMR 5060), CNRS/Université d' Orléans (France), 3D, Rue de la Férollerie, 45071 Orléans, CEDEX \\ 2, France \\ ${ }^{\mathrm{h}}$ Laboratoire Trajectoires (UMR 8215), CNRS/Université de Paris 1, Maison de l'Archéologie \& Ethnologie, 21 allée de l'Université, 92023 Nanterre, CEDEX, France \\ ${ }^{\mathrm{i}}$ Laboratoire Archéorient (UMR 5133), CNRS/Université Lyon, 2. 7, rue Raulin, 69365 Lyon, Cedex 7, France \\ ${ }^{\mathrm{j}}$ Cluster of Excellence ROOTS, Kiel University, Leibniztstr. 3, 24118 Kiel, Germany \\ ${ }^{\mathrm{k}}$ Institute of Archaeology and Ethnography by the Azerbaijan National Academy of Sciences (ANAS), Huseyin Cavid Propspekti, Baku, Azerbaijan
}

\section{A R T I C L E I N F O}

\section{Keywords:}

Kiçik Tepe

Kura river valley

Azerbaijan

South Caucasus

South West Asia

Neolithisation

Neolithic

Shomu-Shulaveri culture

6th millennium BCE

\begin{abstract}
A B S T R A C T
The factors and dynamics that initiated the Neolithisation process in the South Caucasus between the very end of the 7th and the beginning of the 6th millennium BCEare still unclear and hotly debated. It is within this framework that the excavations at Kiçik Tepe, in the middle Kura river valley of Western Azerbaijan, aim to offer new data and new perspectives on the complex interplay of environmental, social and cultural factors that contributed to this process. Excavations at Kiçik Tepe uncovered two main phases of occupation consisting of circular buildings dating to the first centuries of the 6th millennium. Architectural remains allowed us to highlight an evolutionary architectural trajectory hinting at social and productive changes in the role and structure of the households. The subsistence strategies that rely on species domesticated elsewhere show at once a series of specificities highlighting adaptation to the local environment and the exploitation of wild species possibly resulting from previous Mesolithic practices. Simultaneously, while the almost aceramic way of life at Kiçik Tepe outlines a local dialectic between Mesolithic and Neolithic cooking practices, lithic and macrolithic tools pinpoint broadly shared regional elements as well as very localised traits framed into both long and short distance contacts. As a whole the new evidence from Kiçik Tepe highlights that the Neolithisation in the South Caucasus was not a straightforward process that consisted of the abrupt and homogenous adoption of an exogenous 'package' but most probably of a gradual and complex process of change resulting from dynamics of resistance and innovation between old and new socio-economic and cultural models.
\end{abstract}

\section{Introduction}

During the last 15 years, archaeological excavations and research in South Caucasus produced important results that have significantly ad- vanced our understanding of the process and dynamics of the Neolithisation in the region. We define the Neolithic in the South Caucasus as a homogenous phenomenon marked by the adoption of a new model of subsistence based on a food production economy simultaneously asso-

\footnotetext{
* Corresponding author.

E-mail address: giulio.palumbi@cepam.cnrs.fr (G. Palumbi).
} 
ciated with the appearance, as early as the very beginning of the 6th millennium BCE, ${ }^{1}$ of small and multistratified settlements presumably standing for a process of increasing sedentarisation in the region. However, we still know very little about the mechanisms resulting from the complex dialectic between environmental, human and cultural factors that activated this process in the South Caucasus (Chataigner et al., 2014a). Environmental data from lacustrine and sedimentological archives attest to an increase in humid conditions after the dry 8200 kyr/a event (Ollivier et al., 2018; Leroyer et al., 2016; Messager et al., 2013; Joannin et al., 2014) with changes in seasonal precipitation regimes, possibly also influenced by the Black Sea effect (Messager et al., 2017) and the beginning of a climatic optimum (Kvavadze and Connor, 2005) which could have created the conditions that favoured the adoption of a new economic model of food-production in the region.

Archaeological data shows the appearance and co-existence, as early as the beginning of the 6th millennium BCE, of several clusters of settlements in different areas of the South Caucasus along the Middle Kura River valley, in the Ararat plain and along the valley of the Araxes River (Fig. 1). These data highlight that fertile plains and river valleys were the most favourable environments for these new food-producing communities, even though the widespread exploitation of obsidian sources located on high elevations clearly shows that the highlands were also used, possibly seasonally, by these populations (Chataigner and Gratuze, 2014a). Botanical and faunal data also converge on the fact that plants and animals exploited since the beginning of the 6th millennium BCE and that the subsistence strategies of the earliest $\mathrm{Ne}$ olithic communities relied largely on domestic species (Benecke, 2012; Decaix, 2016; Akashi et al., 2018).

So-far, there is no evidence supporting the hypothesis of a process of pre-domestication among the local Mesolithic communities or forms of indigenous domestication undertaken by the Caucasian Neolithic communities that might be considered autonomous from those that had developed at least two millennia before in the neighbouring regions of Anatolia and Iran (Nishiaki et al., 2019). Conversely, recent botanical and animal aDNA analyses strengthen the hypothesis that some domestic species of emmer wheat (Triticum dicoccum, whose wild ancestors were not present in South Caucasus) might have been introduced from the neighbouring Near Eastern regions (Chataigner et al., 2014a). Preliminary aDNA analysis on Aruchlo samples of sheep and cattle showed a high genetic variability, pointing to "a close proximity to the areas of domestication" for these samples (Benecke, 2012: 155). Consistently, recent analysis on goat samples from Göy Tepe and Hacı Elamxanlı shows that these samples are genetically related to goats domesticated in Eastern Anatolia and North-West Iran (Kadowaki et al., 2017: 254). Furthermore, the sporadic finds of imported painted ceramics of the typical Halaf and Samarra horizons such as those excavated at Aknashen and Aratashen in the Ararat plain, at Kültepe in Nakhchevan and finally at Hacı Elamxanlı in the Kura River valley strengthen the hypothesis of contact and exchange with the Neolithic communities from East Anatolia and Upper Mesopotamia (Palumbi, 2007; Harutyunyan, 2014; Abibullaev, 1982; Nishiaki et al., 2013). Finally, recent analyses carried out on human aDNA have highlighted a genetic cline stretching from Anatolia to the Southern Caucasus and resulting from a process of human admixture thus suggesting dynamics of interaction and mobility between the populations of these regions as early as the mid-7th millennium BCE (Skourtanioti et al., 2020).

As pointed out by Chataigner et al. (2014a) different theoretical models, already developed to explain Neolithisation in Europe (e.g. Zvelebil, 2001; Özdoğan, 2011), could also fit the dynamics of the Neolithisation in the South Caucasus. However, beyond abstract models, a multiplicity of interactions with the neighbouring regions (Anatolia, North Mesopotamia, Iran), encompassing human mobility as well as

\footnotetext{
${ }^{1}$ In this article we adhere to a calibrated calendar year chronology (BCE).
}

cultural dynamics, may have played a fundamental role in the Neolithisation of the South Caucasus. For this reason, material cultural data is fundamental in order to define the details of this process and highlight its variegated expressions in the region.

The earliest Neolithic communities of the South Caucasus shared a series of new material cultural traits radically different from those of the Mesolithic communities, and that implied an innovation of both conceptual and practical notions. Among these shared traits, a new concept of "house" is seen, with the widespread use of a model of circular architecture which, in the earliest stages, includes so-called "snowman shaped" buildings (Nishiaki et al., 2015a; Baudouin, 2019). Simultaneously, a new type of lithic industry, mainly using obsidian, predominantly blade-oriented and produced using pressure techniques (Chataigner et al., 2014a), appeared, alongside a distinctive set of macrolithic artefacts including grinding stones, pestles, axes and grooved stones, representing another common feature of the Early Neolithic communities of the region. Furthermore, the earliest ceramic containers of the region share a series of technical traits: they were all handmade with coils and the repertoire's morphology was rather homogenous mainly consisting of holemouth jars.

Since the earliest attempts to characterise the South Caucasian Neolithic (Kiguradze, 1986), there has been a general consensus to foreground the commonalities of these material traits as they are considered to express a broadly shared cultural horizon, the so-called "Shomu Tepe - Shulaveri Culture" (or Shulaveri-Shomu Tepe Culture) after the eponym sites first excavated in Azerbaijan and Georgia along the Kura river valley. However, as research progressed, it was clear that this cultural horizon developed also in the Ararat plain in Armenia (Badalyan et al., 2007; Badalyan et al., 2004) and along the Araxes river (Abibullaev, 1982; Marro et al., 2019). Furthermore, new and increasingly detailed data shows that the SSC is in fact characterised by a diachronic regional evolution, as is visible, for instance, in the architectural (with an evolution from snowman shaped to circular compounds) and ceramic traditions (diversification of the morphological range and appearance of regionalised decorative repertoires). Moreover, since the early developments of this - postulated as homogenous - cultural horizon it is possible to identify significant regional or even site-specific differences. These differences can be seen not only with the adoption of different architectural techniques and building materials (Baudouin, 2019; Hamon et al., 2016), but also different manufacturing traditions in the ceramic production and bone tool assemblages. They also mark crucial preferences in the strategies of subsistence (Berthon, 2014) as well as regional networks of exchange and modalities of procurement of raw materials; chief among them obsidian. These different choices and strategies pursued simultaneously by the earliest farming communities of the South Caucasus reflect the complex dynamics of the Neolithisation in the region. It has been hypothesised that the latter could have mirrored the key role played by the pre-existing cultural traditions of the indigenous Mesolithic populations (Chataigner et al., 2014a; Nishiaki et al., 2019) in the spread and re-adaptation of an exogenous $\mathrm{Ne}-$ olithic model introduced in the South Caucasus.

Archaeological evidence shows that the valley of the Kura river in modern Western Azerbaijan certainly represented one of the crucial regions undergoing this process from its earliest stages. Archaeological investigations of the Neolithic period started in this region in the early 1960s with the excavations of Shomu Tepe (Narimanov, 1987; Akhundov, 2012) and later on of the settlements of Toiretepe and Gargalar Tepesi (Narimanov, 1987). Surveys carried out during the 1970s by I. Narimanov (1987) identified numerous settlements dating to the Neolithic period, and over the last ten years, excavations at the settlements of Göy Tepe (Nishiaki et al., 2018), Mentesh Tepe (Lyonnet et al., 2012; Lyonnet et al., 2016; Lyonnet et al., 2017) and Hacı Elamxanlı (Nishiaki et al., 2013; Nishiaki et al., 2015a) in the district of Tovuz have shed new light on the developments of the Neolithic communities in this region. The combination of partially overlapping phases of occu- 


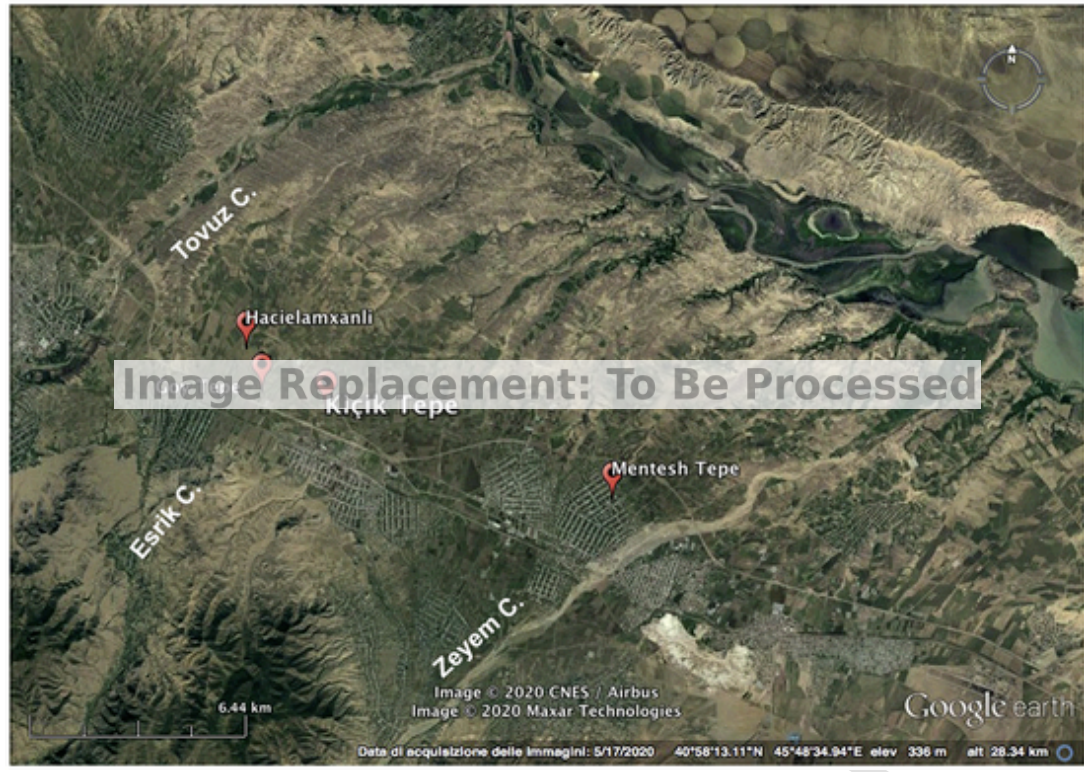

Fig. 1. Map showing the location of the Kiçik Tepe and of the main geographical clusters of Neolithic settlements in the South Caucasus. In the inset, the study area in broader geographical perspective (Map elaborated and drawn by E. Baudouin).

pation of these settlements allows us to reconstruct a long sequence of cultural and socio-economic developments starting from the very beginning of the 6th millennium BCE with levels 3 and 4 at Hacı Elamxanlı (Nishiaki et al., 2015b), followed by Period I at Mentesh Tepe (covering approximately the 5750-5650 BCE time-span) (Lyonnet et al., 2017) and ending with the dense stratigraphic sequence at Göy Tepe that terminates around 5450 BCE (Nishiaki et al., 2018). To complete this picture, recent excavations at the Damjili cave in the district of Kazakh provides new information on the latest stages of the Mesolithic dating to the end of the 7th millennium BCE and on the still very problematic transition between Mesolithic and Neolithic (Nishiaki et al., 2019). It is within this framework that the excavations at Kiçik Tepe aim to build new perspectives on the complex interplay of environmental, social and cultural factors that contributed to the process of Neolithisation in the Kura river valley of Western Azerbaijan.

\section{The excavations 2017-2019 at Kiçik Tepe}

\subsection{Location of the settlement}

The settlement of Kiçik Tepe (4057'49.85”N; 4543'49.32"E; 390 m asl) is a small anthropic mound of approximately $70 \mathrm{~m}$ in diameter and less than $2 \mathrm{~m}$ of elevation over the surrounding plain, nearby the modern village of Qovlar in the district of Tovuz. Unfortunately, we are not able to reconstruct the ancient dimensions of the settlement, as the mound was heavily re-shaped and flattened by agricultural works in Soviet times, and more recently further damaged by an illegal waste dump dug into its eastern flank. Situated about $11 \mathrm{~km}$ South-West of the present bed of the Kura River, Kiçik Tepe lies at the intersection of the alluvial fans of the Tovuz-Arenji, Esrik and Zeyem Cay rivers (Fig. 2), all right bank tributaries of the Kura River, on the same silty and clayey deposit area as other nearby prehistoric settlements (Ollivier et al., 2016). Probably, owing to the severe damages suffered by the settlement, Kiçik Tepe was not identified during the surveys carried out by Narimanov in the region (1987), even though it is located in close proximity to the Neolithic settlements of Goy Tepe and Hacı Elamxanlı (respectively 2 and $3 \mathrm{~km}$ to the south) and at about $9 \mathrm{~km}$ north of Mentesh Tepe (Fig. 2) that he identified.

Kiçik Tepe was identified in 2013 by F. Guliyev and F. Huseynov of the Institute of Archaeology and Ethnography of the Academy of Sciences of Azerbaijan. Two test trenches opened in 2014 revealed the re-

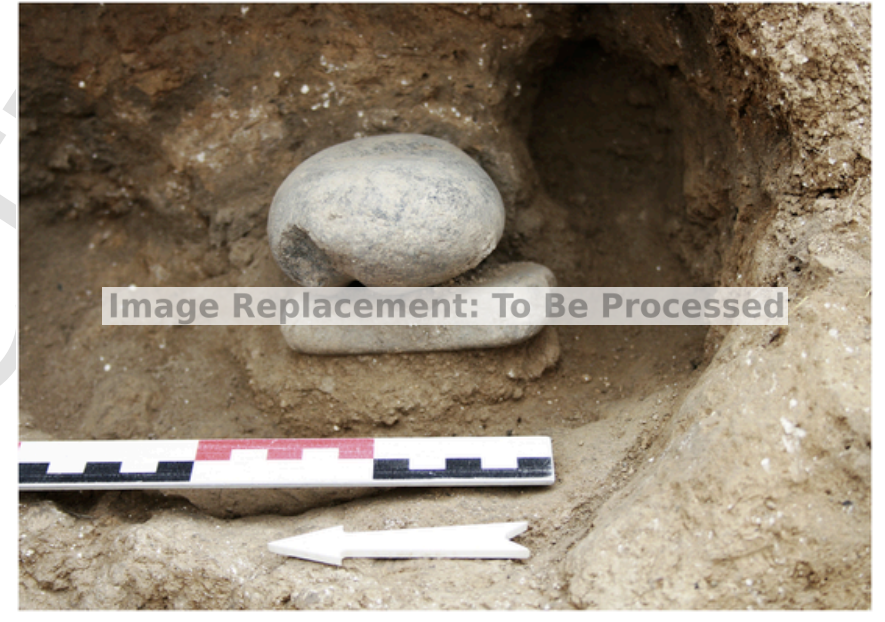

Fig. 2. Location of Kiçik Tepe in relation to the neighbouring Neolithic settlements (Map elaborated after Google earth).

mains of circular architecture. The first systematic surface collection carried out in 2016 only revealed the presence of vegetal-tempered ceramics dating to the Chalcolithic period. Excavations began in 2017 as part of the activities of the "Mission Boyuk Kesik" (French Ministry of Foreign Affairs and CNRS), in collaboration with the Institute of Archaeology and Ethnography of the Academy of Sciences of Azerbaijan.

\subsection{Stratigraphy and architecture}

Stratigraphic, architectural and material cultural data as well as 14C determinations show that Kiçik Tepe was occupied during the Neolithic and Chalcolithic periods (Fig. 3). The latter occupation - Phase 1 - is heavily disturbed by modern agricultural activity; fragmentary remains of various features (kilns, pits, clay-lined bins and fireplaces) cut into the underlying levels are the only evidence of occupation radiocarbondated to the second half of the 5th millennium BCE. The presence of vegetal-tempered, obsidian-tempered wares, mangals, bitumen-painted bowls as well incised 'Sioni-like' jars typical of the Chalcolithic ceramic horizon of the region well fit this absolute chronology (Lyonnet, 2018). 


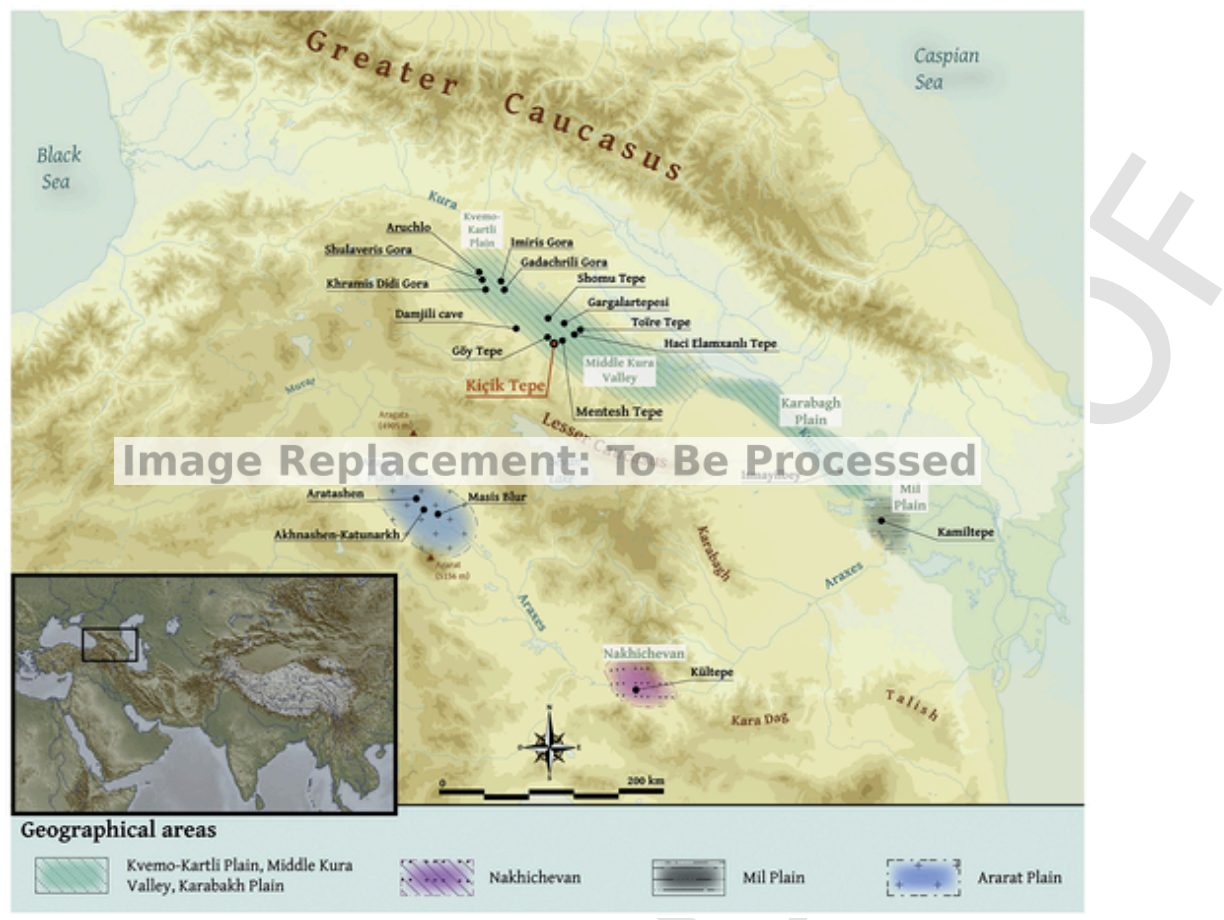

Fig. 3. Drone photo of Kiçik Tepe taken at the end of the 2019 season showing chalcolithic features and Neolithic buildings (Mission Boyuk Kesik MEAE).

Immediately under Phase 1, excavations brought to light a substantial archaeological deposit dating to the Neolithic period that we subdivided in two main phases.The earliest occupation is Phase 3; this lies on a homogenous bed of clay devoid of anthropic materials that appears to be the natural substrate. Buildings belonging to Phase 3 were identified and excavated in squares F-G/8-9 (Fig. 4) and, in spite of the damages caused by the modern waste dump, were in a remarkable state of preservation.

The southernmost building is Structure 2 (Fig. 5), a large circular mud-brick dwelling (diameter of approximately $4.2 \mathrm{~m}$ and a total area of $14 \mathrm{~m}^{2}$ ), its eastern part was preserved, to more than $1.4 \mathrm{~m}$ in height. Structure 2 (hereafter Structure $=$ STR) was destroyed by a fire, as is indicated by the heavily burnt floor covered by a layer of mixed ashes and charcoal sealed, in turn, by a $60 \mathrm{~cm}$-thick layer of collapsed mudbricks. In the southern sector, a short partition wall divided the internal space in two activity areas. No internal features were identified in the western sector of the building, though it was only partially preserved, while a significant number of features was concentrated along the perimeter wall of the structure's eastern sector. These included a large clay silo (USC 19), that contained significant amounts of charred cereal seeds, and located to the east of the partition wall and at least five shallow pits, some of which (Fy5 and Fy6) contain substantial traces of fire. These could have been fire-pits or pit-ovens possibly related to cooking activities. Similar features have already been identified at other $\mathrm{Ne}-$ olithic settlements in the region including Hacı Elamxanlı (Nishiaki et al., 2015a), Mentesh Tepe (Lyonnet et al., 2017) and Kültepe I (Marro et al., 2019). Four bone-tools (three awls and one spatula) and one obsidian core-tablet were also found in situ in proximity to these features.

North of STR 2, another building (STR 21) with an elliptical plan ( $3.3 \mathrm{~m}$ in diameter max and $6.6 \mathrm{~m}^{2}$ internal surface area) was preserved to about $1.6 \mathrm{~m}$ in height (Fig. 6).

Structure 21 was also destroyed by a fire as was clearly indicated by a fill consisting of a $30 \mathrm{~cm}$ layer of charred branches and beams belonging to its roof (Fig. 7) that was in turn sealed by a thick layer of collapsed mudbricks.

Apart from one circular hollowed clay feature on the central-eastern sector of the floor which held one of the roof-posts (Fig. 6), no other features were identified within STR 21. However, this lack of internal structures was counterbalanced by an abundance of bone tools (several awls and one spatula), perforated animal scapulae with traces of usewear and a significant concentration of obsidian artefacts. To the north of STR 21, two smaller circular buildings were discovered. Structure 1, heavily damaged, was equipped with a sort of storage area on its eastern sector, south of which a green stone axe, a bone shaft and several stone-pellets were found in situ. Structure 3 was not only rich in bone tools, but also was noteworthy due to two concentrations of knapped flint located just outside (Fig. 8).

These two concentrations of flint raw material were accumulated in two small circular depressions (of about $10 \mathrm{~cm}$ in diameter and $10 \mathrm{~cm}$ in depth), one group included green flint knapped out of a large nucleus (USC 6) (Fig. 9), and the second (USC7) included only purple flint flakes.

Technological analysis (cf. 6.4) suggests that the accumulated flint resulted from knapping activities that must have taken place in this, presumably external, area. Still related to some type of craft production that could have taken place nearby, is the exceptional in situ find, just north of STR 1, of two grooved polishers (cf. 7.6) standing one on the top of the other (Fig. 10).

The, architectural remains from Phase 3 are too limited to allow us to reconstruct the spatial layout of the settlement; however, it is possible to make some functional considerations on the spatial distribution of some activities. For instance, STR 2, which is the largest, is also the only one containing features that could have been related to activities of food storage, transformation and preparation over the fire. Conversely, the other smaller buildings lack of this type of installations and seem to be more univocally related to craft-production activities. Although the evidence is limited, we might hypothesise a certain degree of segregation of different activities, namely those linked to subsistence and those to the production of more or less utilitarian artefacts.

The following Phase 2 can be subdivided in a series of different stratigraphic sub-phases and architectural levels. The earliest one (Phase 2A) follows the abrupt destruction of the previous structures; it includes a series of pits and fire-pits cutting into the walls and collapsed mudbricks of the underlying structures of Phase 3. It is possible that these features were also associated with circular mud-brick buildings as is the case with STR 19, partially brought to light in square H8. The 


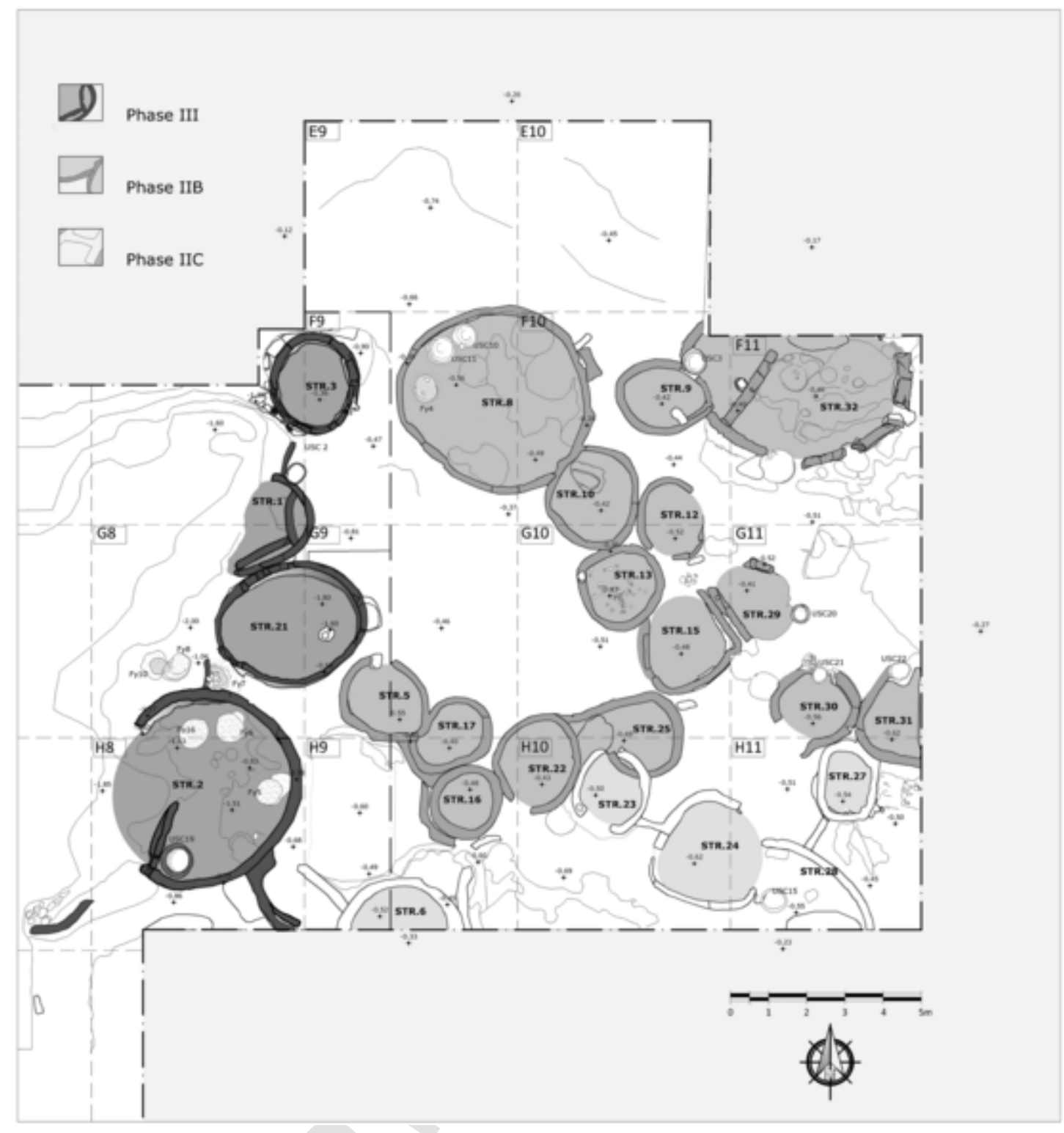

Fig. 4. Architectural plan of Phase 3 buildings and partial plan of Phase 2 buildings (plan elaborated and drawn by E. Brunacci).

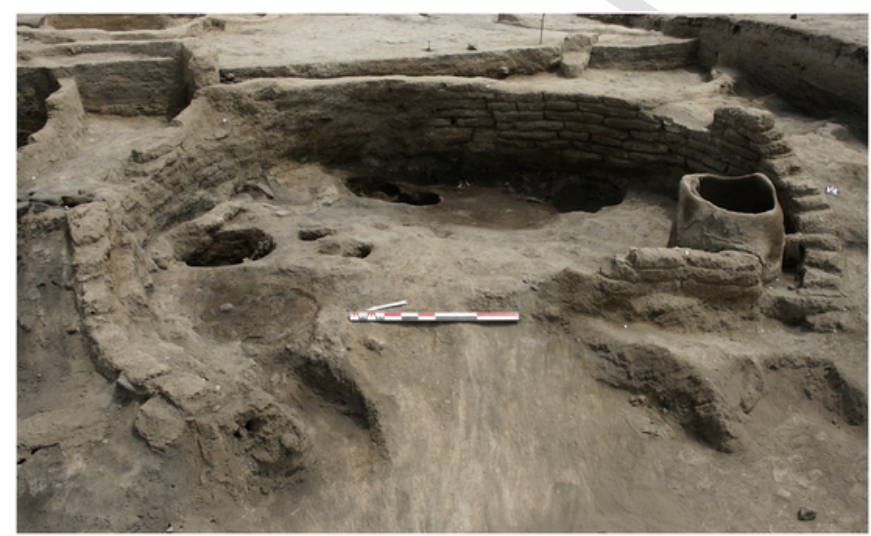

Fig. 5. The burnt floor of STR 2 (Phase 3) brought to light at the end of the 2018 excavations (Mission Boyuk Kesik MEAE). structures of Phase 2A were sealed by a deposit consisting of a series of layers of green clay alternating with layers of ash; this deposit followed a steep inclination towards the depressions created by the collapsed buildings of the underlying Phase 3 . These deposits contain very few archaeological remains suggesting that they accumulated during a period of abandonment of the settlement.

The following Phases $2 \mathrm{~B} / \mathrm{C}$ are the most extended architectural horizon (about $225 \mathrm{~m}^{2}$ ) brought to light at Kiçik Tepe and comprise about 20 circular structures, preserved, unfortunately, to no more than $30 \mathrm{~cm}$ in height, as they were disturbed by the Chalcolithic occupation and by modern agricultural activities. Not all of the structures that we discovered under the Chalcolithic occupation are contemporary, as some were built one on the top of others, thus indicating the existence of at least two overlapping architectural levels (2B and 2C) (Fig. 11). However, owing to modern disturbance, we were not always able to distinguish between the two phases. Unlike Phase 3 structures, Phase 2B/C buildings were not destroyed by fire.

In Phase 2B buildings can be clustered in two main dimensional groups possibly mirroring complementary functions. Small buildings (category 1), measuring less than $5 \mathrm{~m}^{2}$, are more numerous (75\%) and 


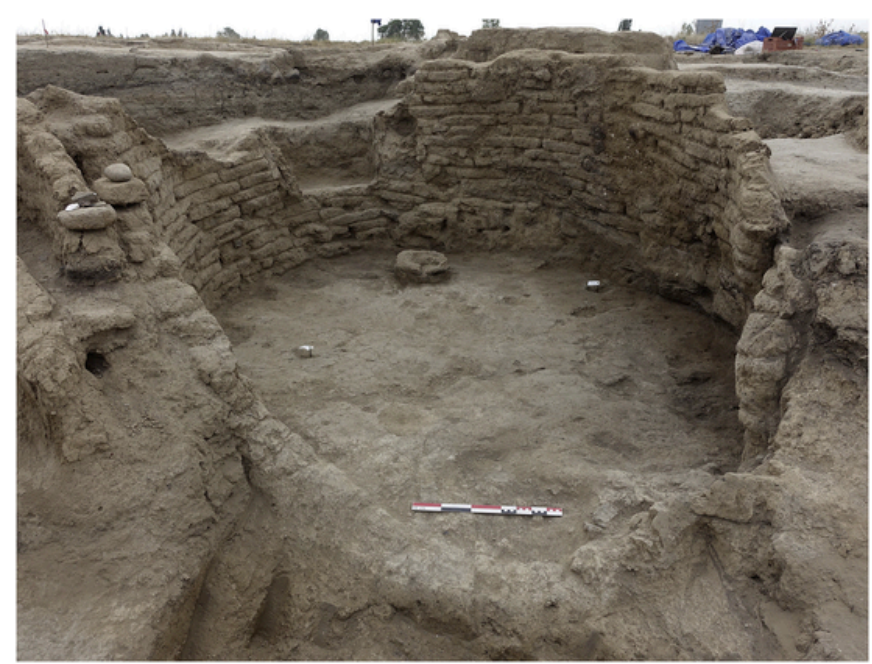

Fig. 6. STR21 (Phase 3) with exceptional preservation of the walls and the hollowed clay feature at the rear of the building (Mission Boyuk Kesik MEAE).

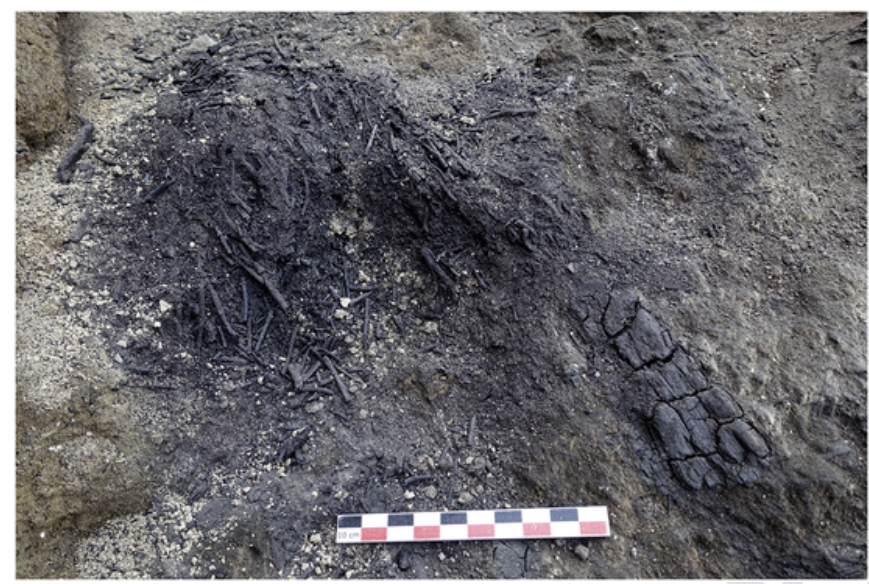

Fig. 7. Charred branches and beam belonging to the roofing of STR 21 (Mission Boyuk Kesik MEAE).

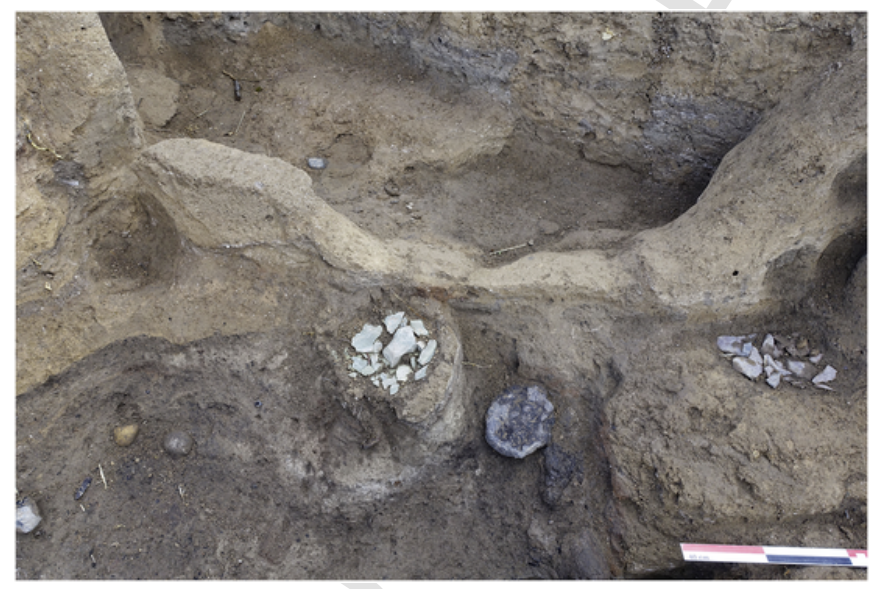

Fig. 8. The two concentrations of flint (USC 6 and USC 7) outside of STR 3 (Mission Boyuk Kesik MEAE).

were in use at the same time as the larger buildings (category 3) measuring more than $15 \mathrm{~m}^{2}$ (Fig. 12).

The larger buildings are characteristic of the most ancient Neolithic settlements of the region, and often contained fireplaces and storage facilities. Large STR 8 (Fig. 13a-b) contains the remains of a fireplace as

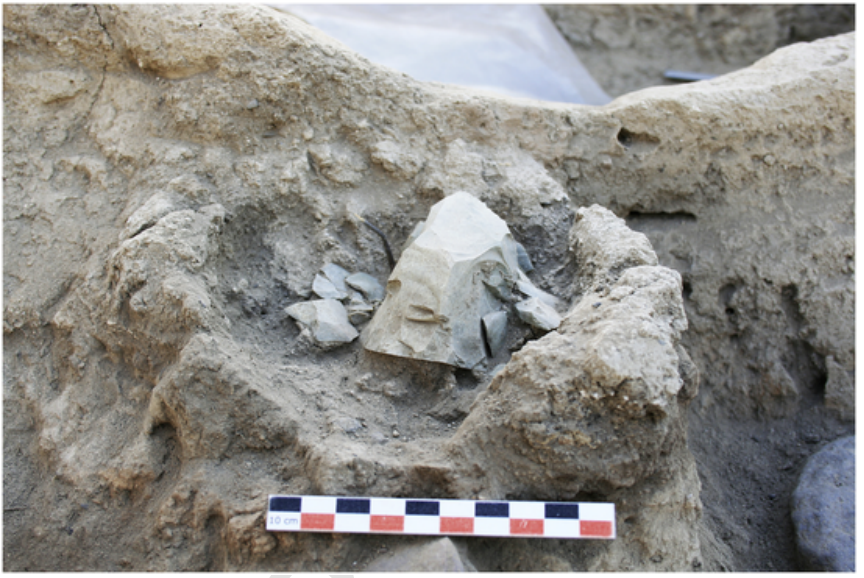

Fig. 9. The nucleus in green flint retrieved at the bottom of feature USC 6 (Mission Boyuk Kesik MEAE). (For interpretation of the references to colour in this figure legend, the reader is referred to the web version of this article.)

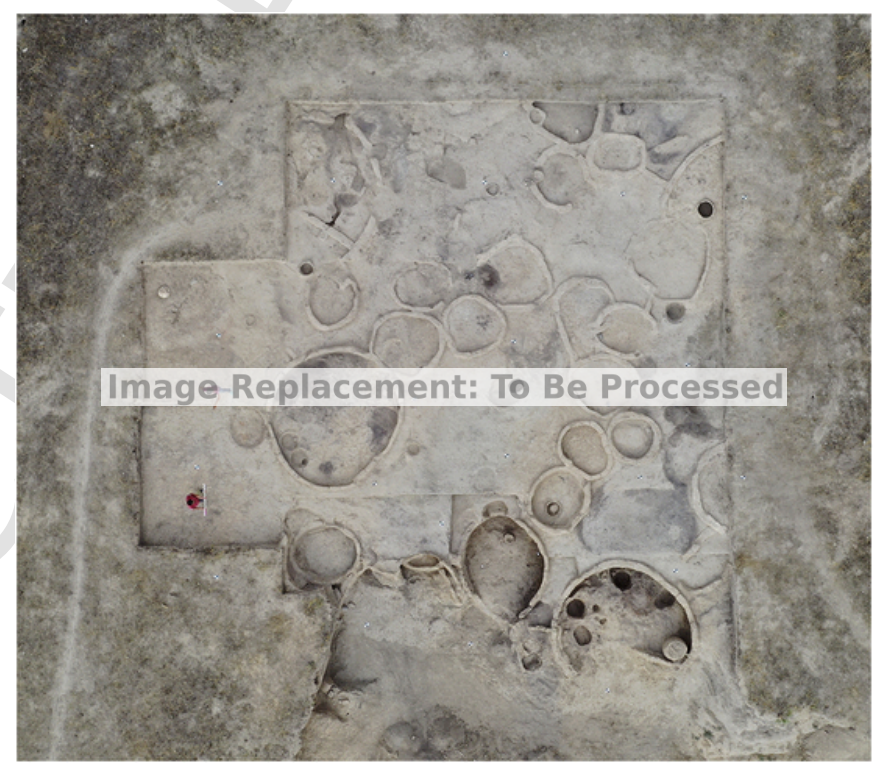

Fig. 10. The two grooved polishers retrieved in connection with STR 1 (Mission Boyuk Kesik MEAE).

well as of two silos containing charred cereal grains, thus pointing (as seen in STR 2 during Phase 3) to activities related to food storage and preparation.

STR 32 (Fig. 11) which was unfortunately heavily damaged, contained a partition wall, again recalling that of STR 2, and possibly a clay-lined bin on its western sector (though we cannot exclude that the latter could be intrusive from the Chalcolithic occupation). The smaller buildings do not have cooking installations and could have worked as auxiliary spaces for activities which differed from those carried out in the larger buildings.

The two larger buildings STR 8 (Fig. 13) and STR 32 (Fig. 11) are both joined to another smaller circular building (STR 10 and STR 9, respectively), thus featuring a composite plan recalling the so-called snowman shaped buildings already observed at the nearby settlement of Hac1 Elamxanl throughout its sequence (Levels 1-4) (Nishiaki et al., 2015a; Baudouin, 2019). However, in contrast with the evidence from Hacı Elamxanlı, data from Kiçik Tepe may show a further development from the "simple" bicellular snowman shaped plan. This is because the 'snowman' building STR 8-STR 10 seems to be part of a circular cluster composed of a series of densely spaced adjoining smaller buildings in 


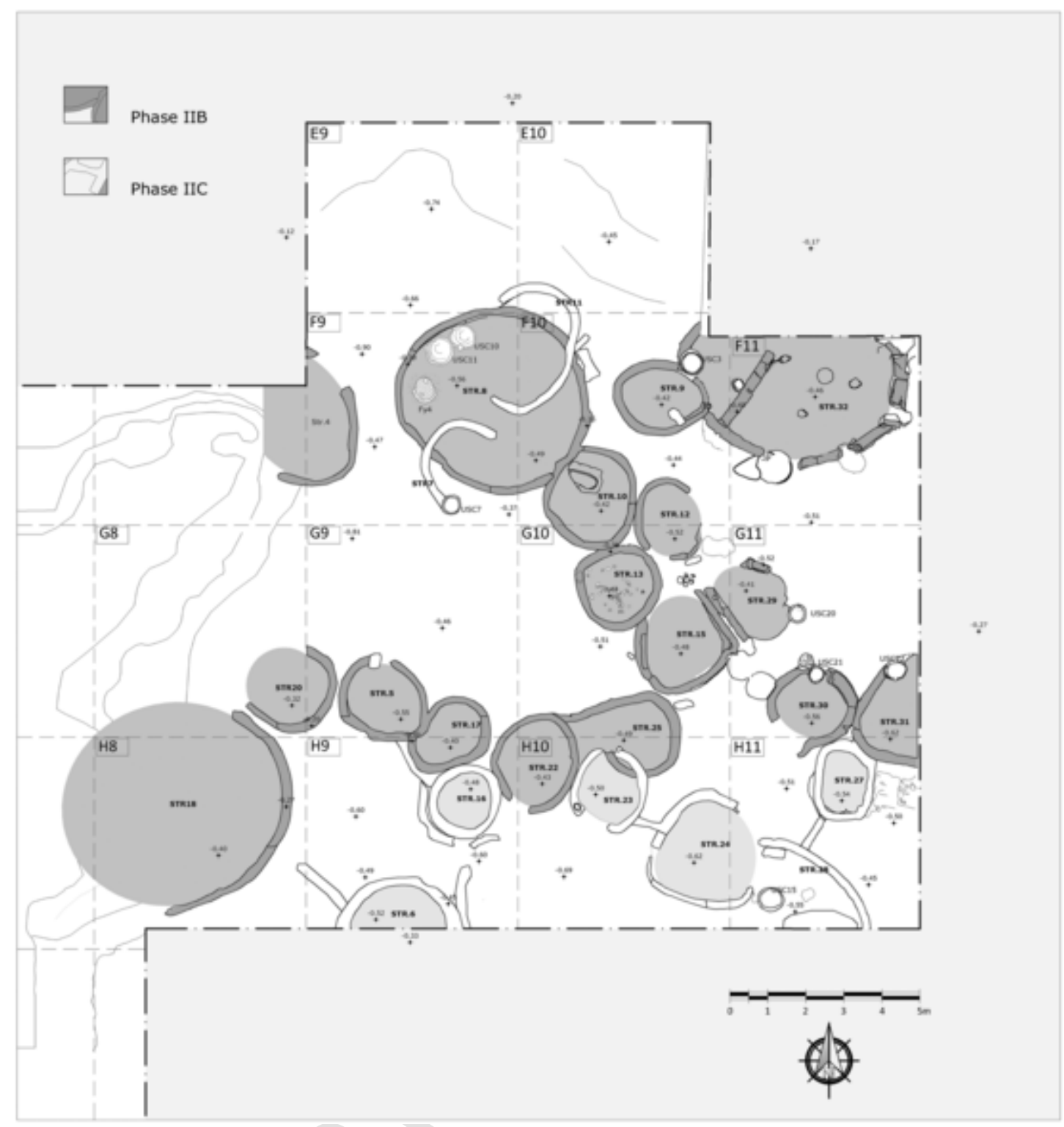

Fig. 11. Architectural plan of the buildings of Phases $2 B$ and $2 C$ (plan drawn and elaborated by E. Brunacci).

squares G9, G10 and F9 creating a circular compound around a central area (Figs. 11 and 14).

Though incomplete and fragmentary, also the 'snowman' building STR 32-STR 9, to the east of the former, could have been part of a second circular cluster of smaller adjoining buildings (Fig. 15). This "proto" type of circular spatial organisation around a central court, with snowman shaped buildings, may hint at the walled circular compounds of the second and third quarter of the 6th millennium BCE discovered in the valley of the Kura River in both Azerbaidjan, such as Göy Tepe (Guliyev and Nishiaki, 2014: 13, Fig. 3), and Georgia, such as Khramis Didi Gora and Shulaveris Gora (Dzhavakhishvili and Dzhaparidze, 1975: 17, pl. III) and that mark the mature and late phases of the architectural traditions of the Shomu-Shulaveri horizon (Nishiaki et al., 2015a).

In these later cases, both larger and smaller structures were joined by bent walls that clearly defined the perimeters of each compound. According to Baudouin (2019), the appearance of these multicellular compounds could indicate an enlargement of the members of each household as a result of the emergence of new aggregative social dynamics.

Going back to Kiçik Tepe, while there are no perimetral walls at the "proto-compounds" of Phase $2 \mathrm{~B}$, these perimetral walls could be identi- fied at another cluster of buildings discovered in the southern sector of the trench (squares H9-H11) that we propose to assign to Phase 2C. These bent-walls have been identified in the long circular wall which emerges from the southern baulk in square H11 extending to STR 33 and also in the segment of wall connecting STR 33 and 23 (Fig. 15). The fact that STR 23 sits on the top of STR 25, which belongs to the "snowman proto-compound", is crucial stratigraphic evidence of the posteriority of 'bent walls' compounds in relation with the "proto-compounds" of the Phase 2B.

A common trait among Phases $2 \mathrm{~B}-\mathrm{C}$ buildings is a lack of artefacts and materials in situ. With the exception of STR 8, where a series of stone tools were found (among which a polished stone axe) and a clay bin, USC 15, in STR 28 which contained another stone axe and its bone shaft, the rest of the buildings were mainly empty. A similar scarcity of in situ finds at Gadachrili Gora and Aruchlo has been interpreted as a result of deliberate abandonments of the settlement (Hamon et al., 2016: 168; Hansen and Ullrich, 2017) in the frame of short life-cycles of occupations and reoccupations such as those documented at Göy Tepe (Nishiaki et al., 2018). It can be hypothesised that the near total absence of finds in the buildings of Phases $2 \mathrm{~B}-\mathrm{C}$ compared to the relatively abundance of tools and materials in the early levels of the $\mathrm{Ne}-$ 


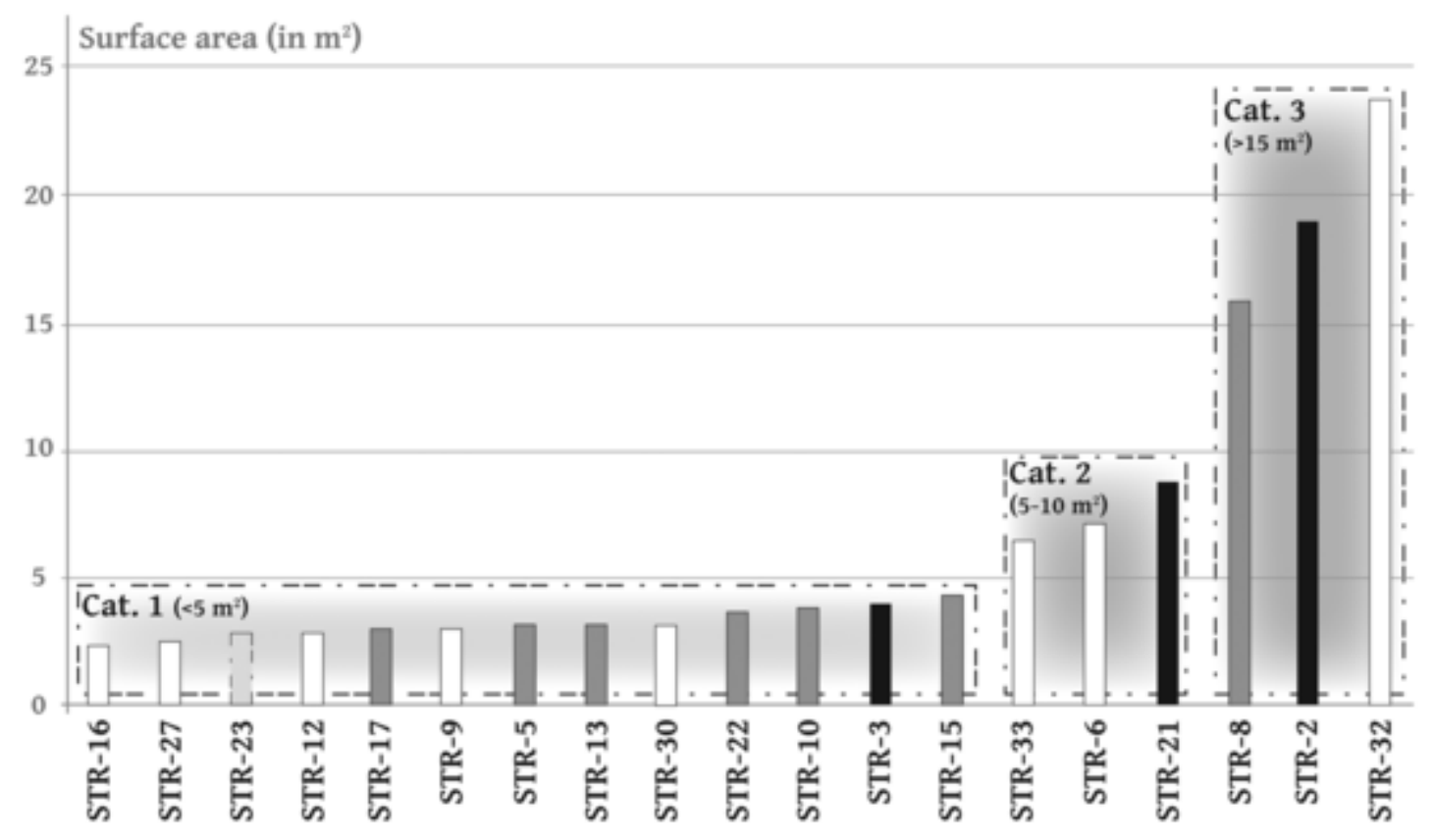

\begin{tabular}{lllll}
\hline$[+\cdots$ & Phase 2A \\
$\square$ & Phase 2 (A or B) $\quad \square$ Phase 2B 3
\end{tabular}

Fig. 12. Diagram with surface areas of buildings from Phase 3 to $2 \mathrm{C}$ (E. Baudouin).

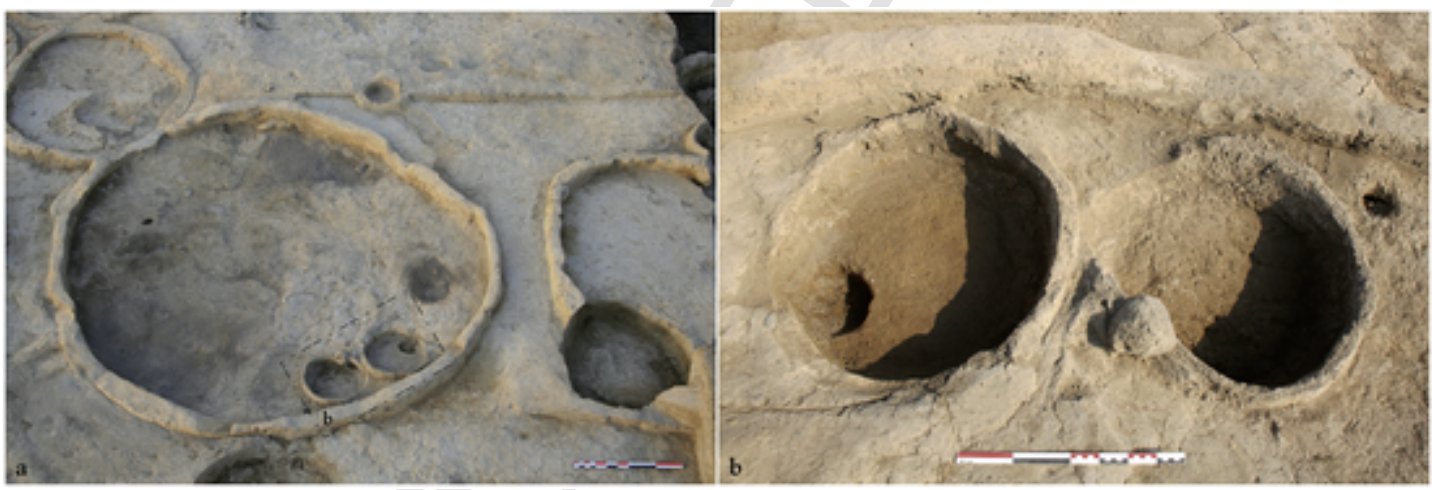

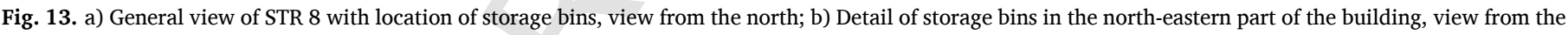
south (Mission Boyuk Kesik MEAE).

olithic Phase 3, left behind, no doubt, due to the fire, could actually mirror practices of planned abandonment of the settlement analogous to those observed at other Neolithic settlements of the Kura River valley.

\subsection{Building materials and techniques}

In Phases 3 and 2, sun-dried mud-bricks are always used for the construction of buildings. The composition of mud-bricks is very consistent, a mixture of water, earth and organic temper, sometimes used in large quantities, and with charcoal as seen in STR 4 (Fig. 16a).

Morphologically, the sun-dried mud-bricks are elongated and flat. Rather characteristic of the Ararat Plain (Aknashen-Katunarkh, Aratashen) (Badalyan and Harutyunyan, 2014: 165; Badalyan et al., 2004: 402), this type of mud-bricks is also found in the Middle Kura Valley at Göy Tepe (Guliyev and Nishiaki, 2014: 5) and in the KvemoKartli Plain at Gadachrili Gora (Hamon et al., 2016: 160-161). However, a series of specific elements were also observed; some had curved faces, like those used for the construction of STR 18 (Fig. 16e), and sag- ging sides - evidence they had been placed in the wall before they were sufficiently dry. Some mud-bricks have straight edges which may suggest they were molded, especially in STR 21 (Fig. 17).

Importantly, there are no ridges on the upper and/or lower faces, unlike the molded mud-bricks at Mentesh Tepe (Baudouin, 2019: 129, Fig. 6) and Aruchlo (Ioseliani, 2017: 282, Fig. 2). Finally, the end of mud-bricks, often curved and thin, as seen in STR 4 (Fig. 16b) and 21 (Fig. 16c-d) suggests that they were hand-shaped. Sun-dried mudbricks are generally elongated, often exceeding $40 \mathrm{~cm}$, with a width of between 10 and $23 \mathrm{~cm}$ (Table 1 ).

Cases of unusual size were also observed, as for some mud-bricks of STR 2 measuring $65 \mathrm{~cm}$ in length. Compared to regional sizes (Fig. 18), the mud-bricks of Kiçik Tepe are characteristic of the beginning of the Neolithic in the Middle Kura Valley and can be classified in previously defined groups (such as group 3 in Baudouin, 2019: 128, Fig. 5; or in categories C and D in Nishiaki et al., 2020).

The circular buildings are generally built without foundations or cobble beds. Only STR 18 has a foundation trench that could have been used to lay the first courses of the wall in the eastern part of the building (Fig. 19). The stretcher bond consists of juxtaposing masonry ele- 


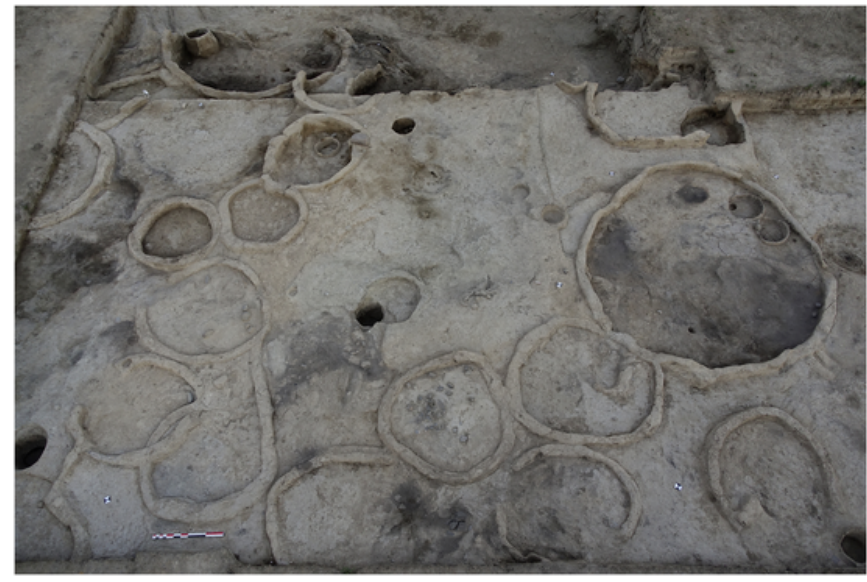

Fig. 14. The "protocompound" attached to the snowman shaped building STR 8- STR10 (Mission Boyuk Kesik MEAE). ments with the longest face of the mud-bricks along the axis of the wall. This type of bond is always used at Kiçik Tepe.

As concerns the "finishing" of the walls, interior and exterior faces were plastered with a mixture of earth, water and organic temper. The very good preservation of the walls of Phase 3 buildings allows for a series of architectural reconstructions. Considering that eleven courses of mud-bricks were preserved on STR 2 to a height of $1.4 \mathrm{~m}$ (Fig. 5), and twenty courses of STR 21 to a height of $1.6 \mathrm{~m}$ (Fig. 6), using archaeological (Margueron, 1987) and ethnographic datasets (Houben et al., 2006: 279), we can estimate that the overall height of these buildings was c. 3.1-3.4 m (Table 2).

As regards the covering and roofing, we can surmise that there was a system of supporting posts in STR 21. Here, a posthole, surrounded by a lump of clay was found in the eastern part of the building (Fig. 2), and a second one could be identified in the western part. The collapsed carbonized roof, covering the post-holes (Fig. 7), was found lying horizontally on the floor. These data suggests that there was a flat roof, with two supporting posts. The presence of a transverse master beam and other radial beams, with a diameter ca. 6-12 cm, can be hypothesised on the basis of wood imprints identified on earthen materials from the collapsed roof (Fig. 20a). The timber frame was then covered with

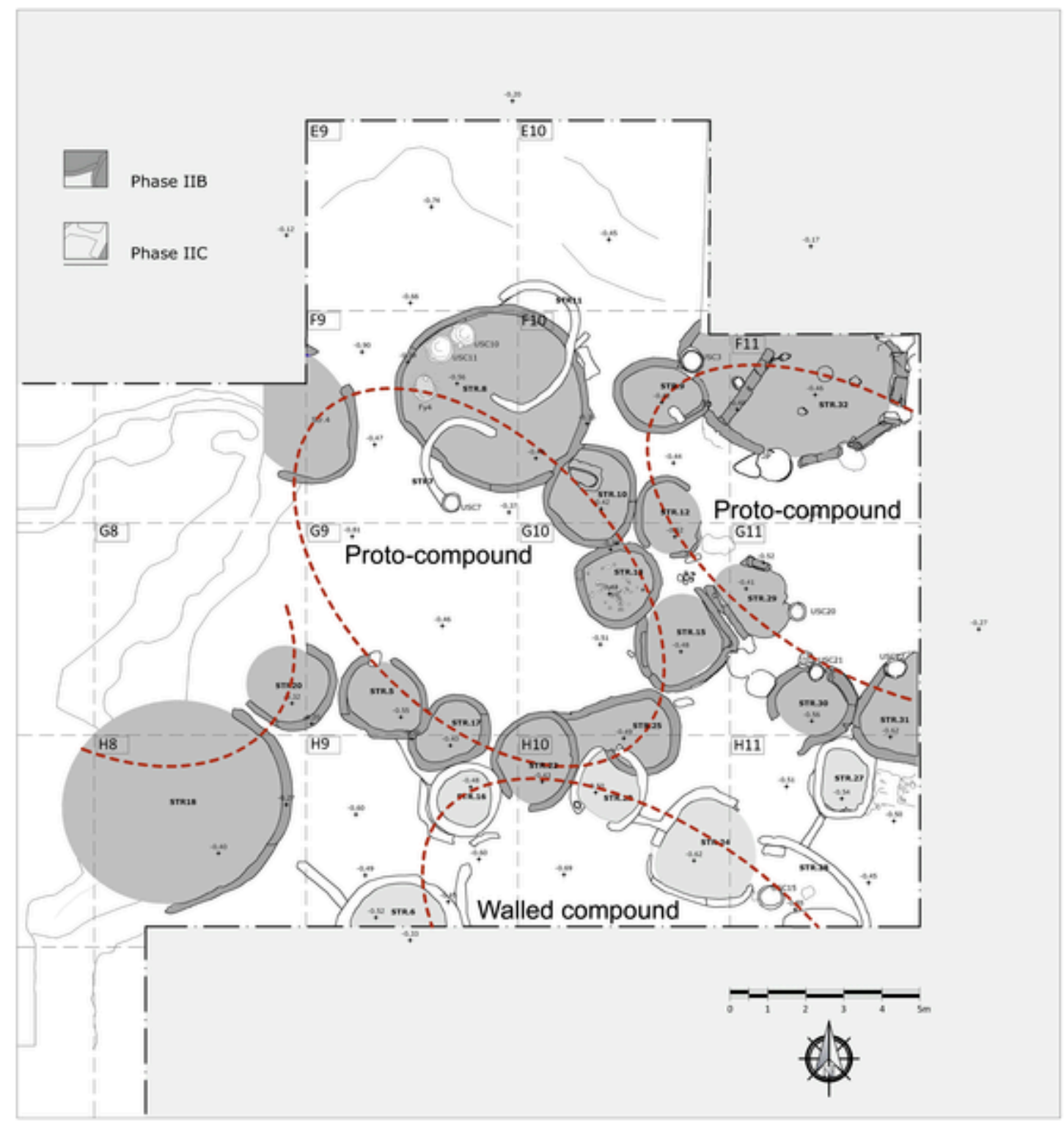

Fig. 15. "Proto-compounds" of Phase $2 \mathrm{~B}$ and the "walled compound" of Phase $2 \mathrm{C}$ (Plan drawn and elaborated by E. Brunacci). 

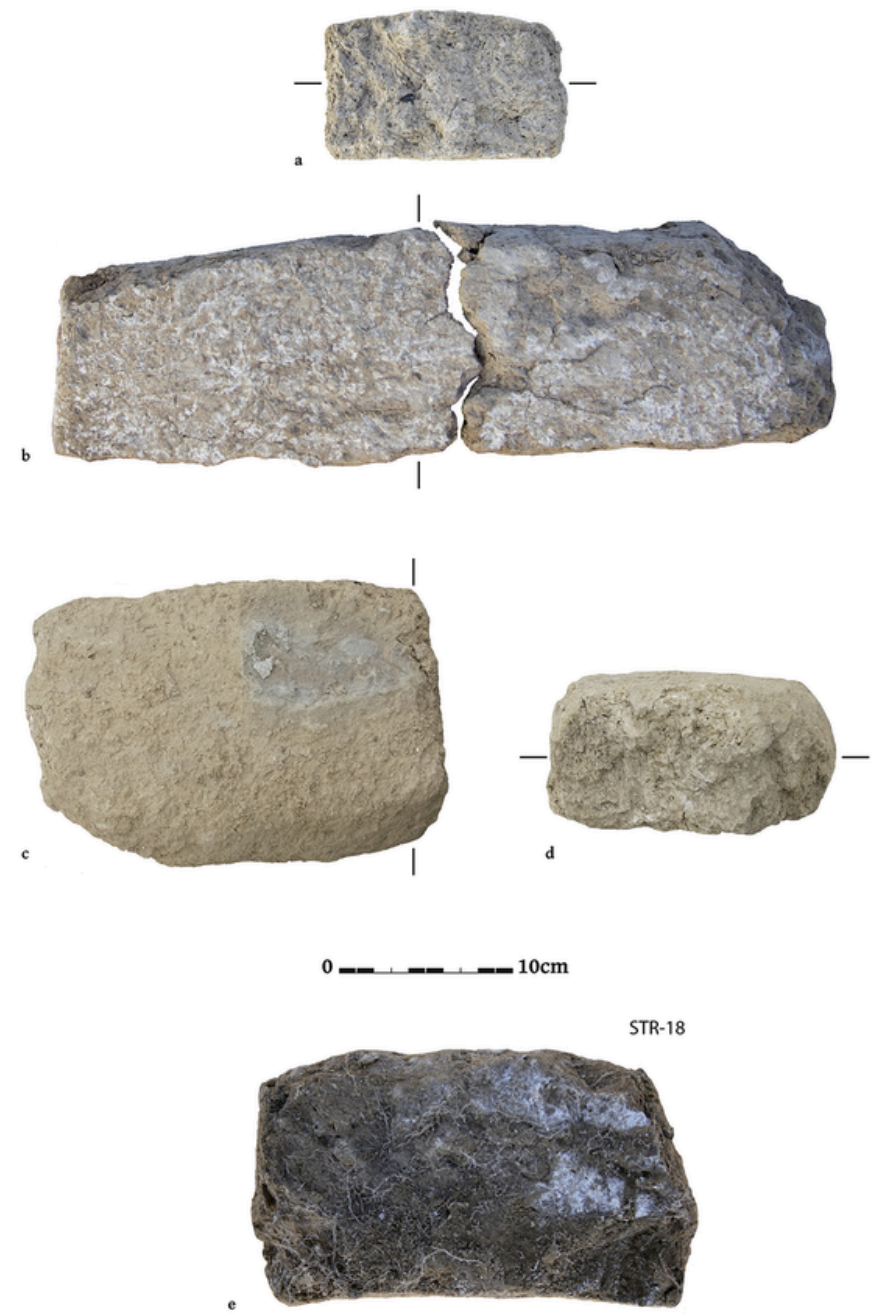

Fig. 16. Flat mud-bricks from Kiçik Tepe. Section (a) and overview (b) of a mud-brick, STR 4; Overview (c) and section (d) of a mud-brick, STR 21; e) Section of a mud-brick, STR 18 (E. Baudouin).

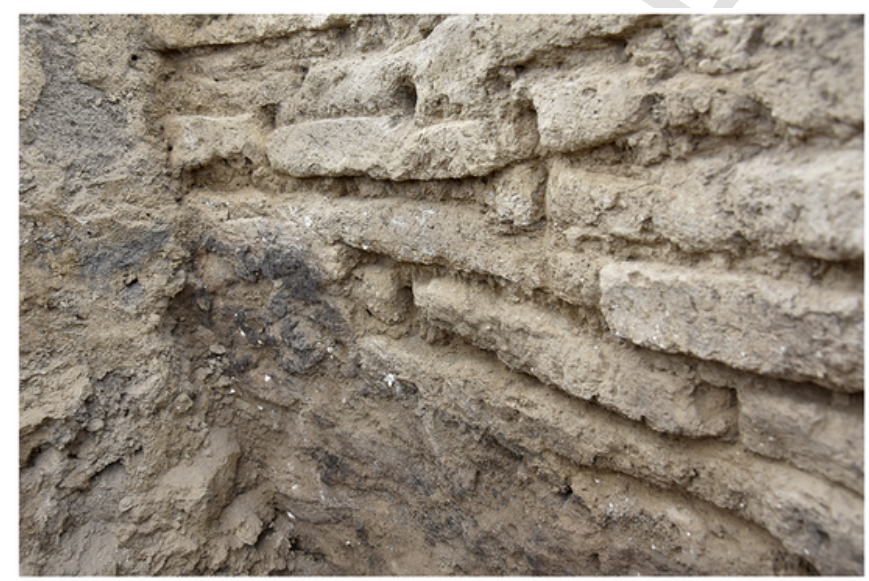

Fig. 17. Detail of the burnt coating and flat mud-bricks of STR 21, square G8, view from the north-west (Mission Boyuk Kesik, MEAE).
Table 1

Size of the mud-bricks from the different buildings of Phases 3 and 2 (E. Baudouin).

\begin{tabular}{llllll}
\hline Phase & Building & L (in cm) & W (in cm) & H (in cm) & Ratio L/1 \\
\hline 3 & STR-2 & 52 & 13 & $7-8$ & 4 \\
& & 65 & 12 & $7-8$ & 5,4 \\
& & $48-53$ & 23 & $8-9$ & $2.1-2.3$ \\
& STR-26 & 49 & 14 & 9 & 3.5 \\
& STR-21 & $39-44$ & $17-19$ & $6-8$ & $2.1-2.6$ \\
& STR-3 & 48 & $16-18$ & 8 & $2.7-3$ \\
2B & STR-20 & $?$ & 10 & 10 & $/$ \\
& STR-18 & 48 & 20 & 9 & 2.4 \\
& 2B & STR-4 & 46 & $10-13$ & $6-8$ \\
& STR-8 & 52 & 15 & 6 & 3.5 \\
& STR-17 & 50 & 15 & 8 & 3.3 \\
\hline
\end{tabular}

branches and straw (Fig. 7; Fig. 18b), in their turn covered with a thick layer of compacted mud.

\section{Radiocarbon dates}

A total of 17 radiocarbon dates, respectively N. 13 from Phase 3 and N. 4 from Phase 2B, were taken from the Neolithic occupation of Kiçik Tepe. Thirteen samples consist of charred cereal seeds (Table 3).

All of the samples were retrieved from the floors and filling layers that we consider to be related to the lifespan of use of the structures. The measures were carried out at two different laboratories (CEDAD and Tokyo University) and the results were calibrated by means of IntCal13 (Reimer et al., 2013) and OxCal v.4.3.2.

A Bayesian model was adopted for the interpretation of the dates (Fig. 21). These were modeled in consideration of both the absolute stratigraphic position and the local relative phases. The resulting model has good agreement (Amodel $=92$ ). The majority of the calibrated dates fall confidently within the first half of the 6th millennium BCE thus confirming that Phases 3 and 2 at Kiçik Tepe are contemporaneous with the Neolithic settlements of the Shomu-Shulaveri horizon. The model of Phase 3 and Phase 2B shows a coherent bipartite chronological sequence that matches the stratigraphic sequence where the date around $5800 \mathrm{cal} \mathrm{BC}$ seems to represent the chronological distinction between the two phases.

Specifically, the model estimates that phase 3 of Kiçik Tepe began c. 5870-5785 cal BC and lasted until c. 5840-5775 cal BC, at 2 sigma confidence. Ten samples well cluster within this time range, supporting this estimate. For this phase, three samples were excluded from the model as they resulted too old and the model was not reaching sufficient overall agreement (below 60; see Hamilton and Krus, 2018). Two of them (LTL18434A and LTL18433A) were obtained from charcoal samples retrieved at the very bottom of STR 1 . They both date to the last quarter of the 7th mill. BC (respectively c. $6210-6000$ cal BC and c. 6230$6050 \mathrm{cal} \mathrm{BC}$ ) and it is possible that this early dating is the result of an old wood effect. The third excluded measurement comes from a charred barley seed (LTL17878A) that dates later than the other two outliers of this phase (i.e. c. 6200-5920 cal BC). This date could represent the earliest occupation of the site; however this hypothesis needs further corroboration. As for phase 2, the model estimates its beginning at c. 58305755 cal BC and end at c. 5830-5720 cal BC with 2 sigma confidence, directly following Phase 3 and cluster in the 5820-5750 cal BC span of time, with three dates overlapping between 5830 and $5740 \mathrm{cal} \mathrm{BC}$. One sample (LTL17698A) dates to c. 6240-6065 cal BC and it was therefore defined as an outlier.

These results indicate that the Neolithic occupation of Kiçik Tepe was relatively short, lasting no more than 120-140 years in total. By comparing data from Phases 3 and 2, worth noticing is the almost complete overlap between the boundary end of Phase 3 and the boundary start of Phase 2B thus indicating that a very short span of time (stretching from a few years to a couple of decades) passed between the two 


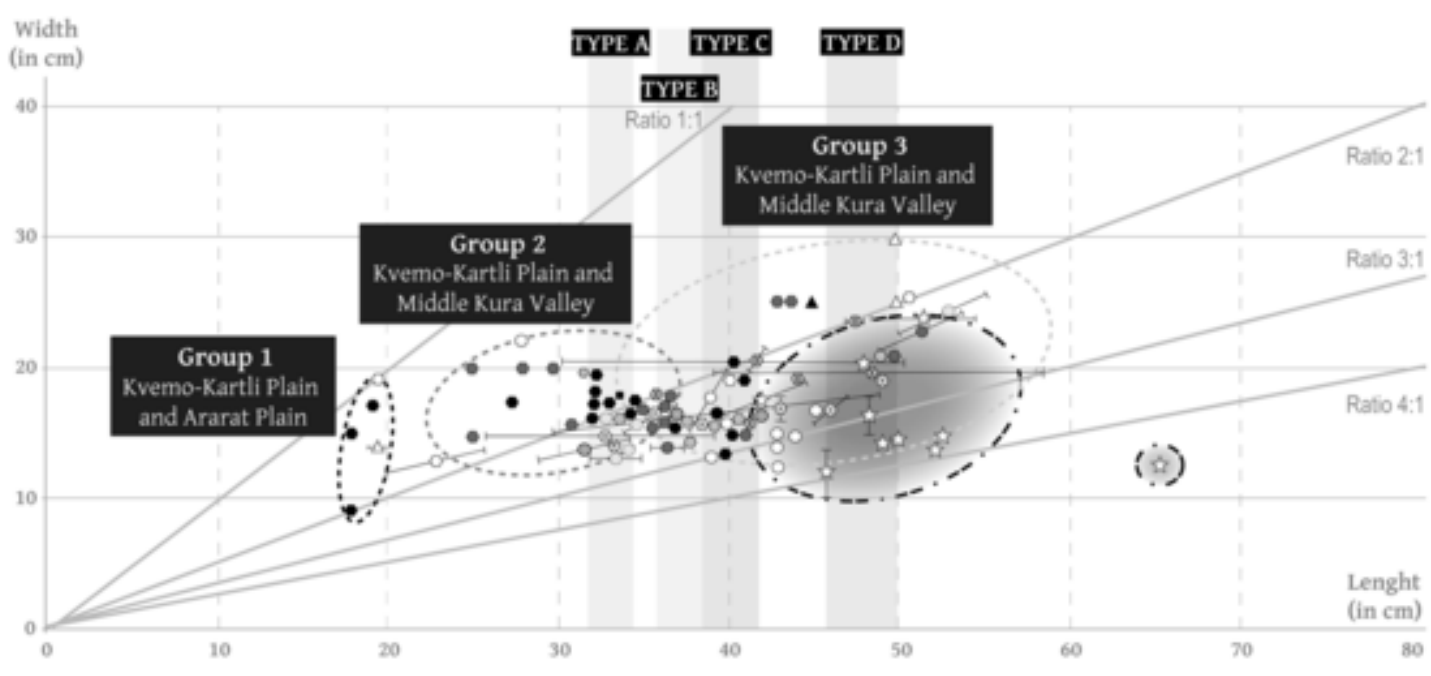

\begin{tabular}{|c|c|c|c|}
\hline \multicolumn{4}{|l|}{ Caption } \\
\hline$\Delta$ Aknashen-Katunarkh & - Göy Tepe & 0 & Haci Elamxanlı Tepe \\
\hline A Aratashen & - Imiris Gora & 0 & Mentesh Tepe \\
\hline - Aruchlo & - Kamiltepe & 0 & Shomu Tepe \\
\hline Gadachrili Gora & * Khramis Didi-Gora & $\bullet$ & Shulaveris Gora \\
\hline (6) Gargalar Tepesi & Aiçik Tepe & - & Toïre Tepe \\
\hline
\end{tabular}

$$
\begin{aligned}
& \text { Size's groups } \\
& \because: \text { Small bricks (group 1) } \\
& \because \quad \text { Medium bricks (group 2) } \\
& \therefore \text { Large bricks (group 3) }
\end{aligned}
$$

Fig. 18. Diagram summarizing the mud-brick sizes from Kiçik Tepe in comparison with other Neolithic sites in Southern Caucasus (E. Baudouin).

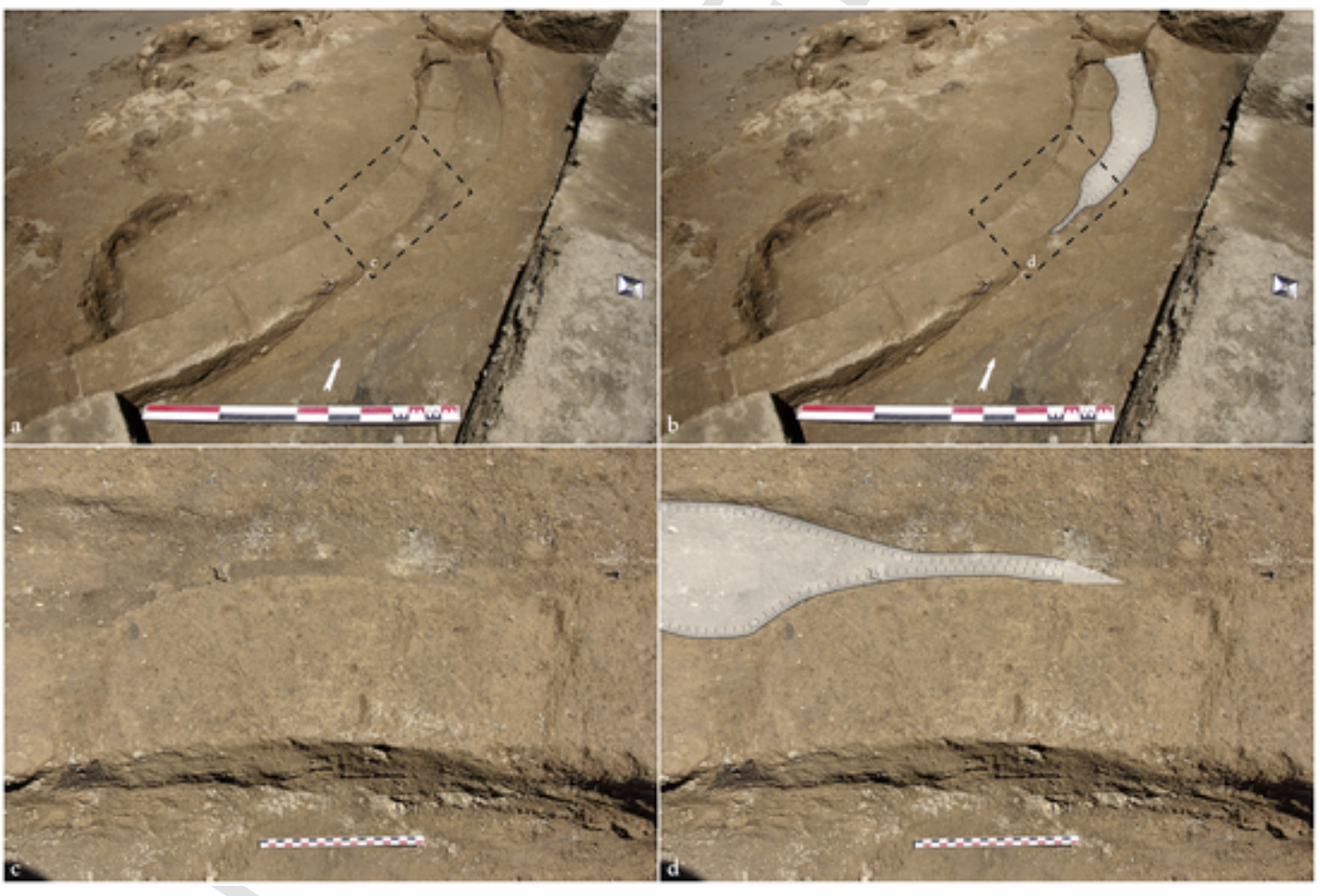

Fig. 19. Structure 18, square $\mathrm{H} 8$, with the foundation trench in the eastern part of the building. a) General view of the building with the trench in the eastern part, view from the south; b) Detail of the wall of STR 18 and its trench, view from the west (E. Baudouin).

phases. This interval is represented, in stratigraphic terms, by Phase $2 \mathrm{~A}$ and by the pack of sterile layers sandwiched between Phases 2A and 2B. This data seems to confirm that patterns of abandonment and very rapid reoccupations, already observed at the nearby settlements of Hac1 Elamxanli Tepe and Göy Tepe (Nishiaki et al., 2018), could have also characterized the modalities of the occupation at Kiçik Tepe. Finally, as regards the chronological relations with the available sequences of the nearby settlements, it is possible to state that Phase 3 was contemporary with Levels 1 and 2 at Hacı Elamxanlı Tepe (Nishiaki et al., 2015b) and therefore can be considered among the most ancient Neolithic occupations of the Middle Kura River Valley; and Phase 2A overlaps with the dates of the earliest occupation levels of Phase I at Mentesh Tepe (Lyonnet et al., 2016: 127).

\section{Botanical remains}

The archaeobotanical analyses were carried out on soil samples collected from various types of contexts, for example: ash layers, hearths 
Table 2

Measurements of STR 2 and 21 for restitution of the elevations (E. Baudouin).

\begin{tabular}{|c|c|c|}
\hline & $\begin{array}{l}\text { Structure } \\
2\end{array}$ & $\begin{array}{l}\text { Structure } \\
21\end{array}$ \\
\hline External diameter (in $\mathrm{m}$ ) & 4.7 & 3.3 \\
\hline Overall surface area (in $\mathrm{m}^{2}$ ) & 17.4 & 8.7 \\
\hline Internal diameter (in m) & 4.3 & 2.9 \\
\hline Usable surface area (in $\mathrm{m}^{2}$ ) & 14.5 & 6.6 \\
\hline Height of the preserved mud-brick wall (in m) & 1.4 & 1.6 \\
\hline Height of the preserved collapse layer (in m) & 0.6 & 0.5 \\
\hline Overall volume of the building (in $\mathrm{m}^{3}$ ) & 24.3 & 13.9 \\
\hline Usable volume of the building (in $\mathrm{m}^{3}$ ) & 20.3 & 10.6 \\
\hline Volume of the preserved mud-brick wall (in $\mathrm{m}^{3}$ ) & 4 & 3.4 \\
\hline Volume of the collapse layer inside the building (in $\mathrm{m}^{3}$ ) & 8.7 & 4.4 \\
\hline Presumed overall volume of the collapse layer (in $\mathrm{m}^{3}$ ) & 11.6 & 5.8 \\
\hline Presumed thickness of the roof (in m) & 0.3 & 0.3 \\
\hline Presumed volume of the roof (in $\mathrm{m}^{3}$ ) & 6.6 & 3.6 \\
\hline $\begin{array}{l}\text { Presumed volume of the collapse (mud-bricks and roof) } \\
\left(\text { in } \mathrm{m}^{3} \text { ) }\right.\end{array}$ & 13.1 & 6.7 \\
\hline $\begin{array}{l}\text { Presumed volume of the collapsed mud-brick wall (in } \\
\mathrm{m}^{3} \text { ) }\end{array}$ & 5.8 & 2.9 \\
\hline Presumed height of the missing elevation (in m) & 2.1 & 1.5 \\
\hline Presumed height of the overall elevation (in m) & 3.5 & 3.1 \\
\hline
\end{tabular}

or occupational layers. Water flotation was used for all samples in order to retrieve light fractions using a $0.5 \mathrm{~mm}$ mesh sieve. The macroremains were mainly charred and were analysed under a binocular microscope and identified with atlases (Cappers et al., 2012; Nesbitt and Goddard, 2006).

The preliminary results of 24 samples taken from the Neolithic Phases 3 and 2 (Table 4) indicate that cereals are the most frequent crops $(77 \%$ of the remains). Several types of cereals have been identified (Fig. 22): barley (Hordeum vulgare) mainly with $54 \%$ of the identified cereals, followed by hulled wheat (26\%), including emmer (Triticum turgidum subsp. dicoccon) and einkorn (Triticum monococcum), naked wheat (Triticum aestivum/durum, 13\%), and unidentified wheats (7\%). The only pulses to have been identified are lentils (Lens culinaris) though in very low numbers. Among the wild species, nutshells of Prunoideae type were found as well as arable weeds such as Aegilops sp., Heliotropium sp. or Trigonella sp. for example (Willcox, 2012).

Data from Kiçik Tepe testifies to the importance of cereals, their morphology is completely domesticated, with a sharp predominance of barley over wheat. A similar picture was also observed at the neighbouring sites of Mentesh Tepe (Decaix et al., 2016), Göy Tepe and Hac1 Elamxanlı Tepe (Akashi et al., 2018; Kadowaki et al., 2015), but also in the Mil and Ararat Plains (Hovsepyan and Willcox, 2008; Lyonnet et al., 2012; Neef et al., 2017), and in the Araxes valley (Decaix, 2016).

When comparing Phases 3 and 2, there is a notable increase in the proportion of naked wheat during the more recent Phase 2 . This same diachronic trend was also observed when comparing data from Hac1 Elamxanlı and Göy Tepe. While hulled wheat is predominant at Hacı Elamxanl, which is the earliest settlement of the region, free-threshing wheat is predominant at the later period site of Göy Tepe (Akashi et al., 2018). The same situation has also been identified at Kültepe I where emmer is the most represented wheat in the early phase of occupation (end of 7th millennium-beginning of the 6th millennium BC), whereas in the later phases of occupation the incidence of naked wheat increases and becomes predominant while hulled wheats are recorded in very low proportions (Decaix, 2016). The hulled/naked wheat ratio at Neolithic settlements of the South Caucasus has been interpreted as the result of regionalised farming practices and subsistence strategies with a preference for naked species in the Araxes valley and for hulled species in the Kura valley (Nishiaki et al., 2019). However, data from Kiçik Tepe confirms that the changing ratio of hulled/naked wheat is the result of a diachronic shift that took place at a regional level. The preference for hulled species is observed during the early stages of the $\mathrm{Ne}$ olithic in both the Kura and Araxes valley, while the preference for naked wheats is recorded starting from the second quarter of the 6th millennium BC, that is in the later stages of the Neolithic in the region.

Returning to Kiçik Tepe, an analysis of contexts from Phase 3 also showed significant results concerning the spatial distribution of the vegetal species in adjacent buildings. A comparison of the results from STR 2 and STR 21 shows that in the latter, wild plants are more important than in the STR 2 (Fig. 23), and that among the wild plants, Artemisia seeds, in many cases, still inside its panicles, is particularly significant. This data is consistent with other evidence showing that these two buildings contained a variety of materials and that it is probable that different, and possibly complementary types of activities took place here. There are several explanations for the use of Artemisia in STR 21, it may have been used as an insecticide or a fungicide or possibly as a medicinal herb, a use that is still prevalent in various regions today (Rivera et al., 2011). It is worth noting that Artemisia is also an important part of the assemblage at other nearby settlements in the Kura river Valley, such as Hacı Elamxanlı and Göy Tepe (Akashi et al., 2018). As the presence of this plant is statistically significant in these three sites, it is possible to suggest that it was part of a local tradition of exploitation of wild plants possibly in relation to medicinal use for humans or animals.

To conclude, the preliminary results from Kiçik Tepe are consistent with those from other Neolithic sites located in the Kura Valley and, generally, in the Southern Caucasus. The community at Kiçik Tepe practiced a cereal-focused agriculture from its earliest occupational phases. As to the agricultural strategies carried out at Kiçik Tepe, worth mentioning is the discovery of several types of cereals in silos USC 19 (STR 2) as weeds and chaffs; this may indicate that cereals were either cultivated in the same fields, or in different fields but processed and
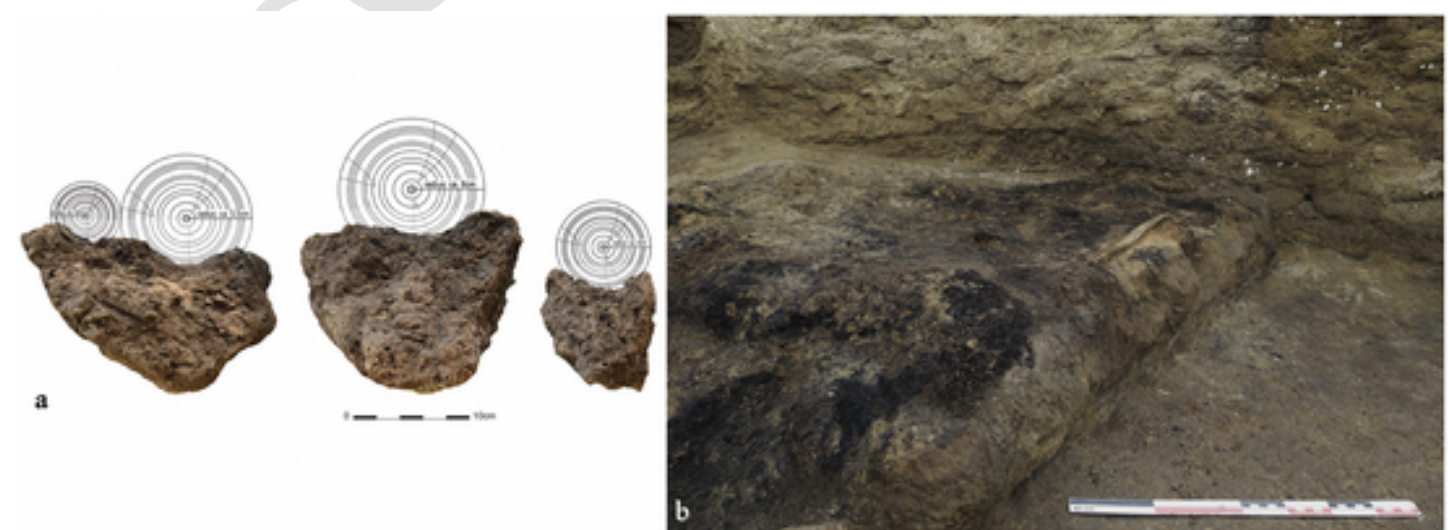

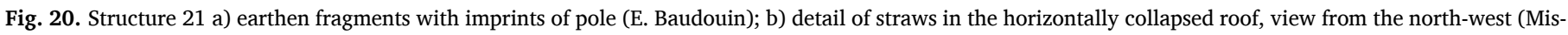
sion Boyuk Kesik, MEAE). 
Table 3

Radiocarbon dates from Kiçik Tepe.

\begin{tabular}{|c|c|c|c|c|c|c|c|}
\hline Sample N. & Structure & Phase & Species & Lab. Code & $\delta 13 \mathrm{C}(\%)$ & Measured BP date* & Calibrated radiocarbon dates (cal. $\mathrm{BC} / \mathrm{AD} ; 2 \sigma)^{* * *}$ \\
\hline KT RC 01 & STR 8 & 2B & Hordeum vulgare & LTL17698A & $-17.9 \pm 0.5$ & $7301 \pm 45$ & $6238-6062(95.4 \%)$ \\
\hline KT RC 14 & STR 19 & $2 \mathrm{~B}$ & Hordeum vulgare & LTL18627A & $-25.6 \pm 0.1$ & $6952 \pm 45$ & $5839-5649(95.4 \%)$ \\
\hline KT RC 15 & STR 8 & $2 \mathrm{~B}$ & Hordeum vulgare & TKA-19585 & $-22.5 \pm 0.3$ & $6939 \pm 31$ & $5891-5739(95.4 \%)$ \\
\hline KT RC 16 & STR 8 & $2 \mathrm{~B}$ & Hordeum vulgare & TKA-19584 & $-22.9 \pm 0.3$ & $6874 \pm 32$ & $\begin{array}{l}5841-5705(93.7 \%) \\
5691-5677(1.7 \%)\end{array}$ \\
\hline KT RC 03 & STR1 & 3 & Charcoal (unid.) & LTL18433A & $-28.7 \pm 0.2$ & $7270 \pm 45$ & $6227-6050(95.4 \%)$ \\
\hline KT RC 05 & STR1 & 3 & Charcoal (unid.) & LTL18434A & $-26.2 \pm 0.3$ & $7203 \pm 45$ & $\begin{array}{l}6209-6134(18.2 \%) \\
6124-5997(77.2 \%)\end{array}$ \\
\hline KT RC 08 & STR 2 & 3 & Hordeum vulgare & LTL17878A & $-20.8 \pm 0.2$ & $7165 \pm 45$ & $\begin{array}{l}6204-6190(1.4 \%) \\
6183-6168(1.4 \%) \\
6162-6140(2.1 \%) \\
6110-5975(86.2 \%) \\
5948-5919(4.4 \%)\end{array}$ \\
\hline KT RC 09 & STR 2 & 3 & Hordeum vulgare & TKA-19587 & $-22.5 \pm 0.3$ & $6995 \pm 32$ & $\begin{array}{l}5983-5940(20.9 \%) \\
5931-5792(74.5 \%)\end{array}$ \\
\hline KT RC 11 & STR 2 & 3 & Hordeum vulgare & TKA-21761 & $-19.6 \pm 0.6$ & $6980 \pm 27$ & $\begin{array}{l}5977-5948(9.9 \%) \\
5921-5779(85.5 \%)\end{array}$ \\
\hline KT RC 12 & STR 2 & 3 & Hordeum vulgare & TKA-19586 & $-24.4 \pm 0.4$ & $6946 \pm 31$ & 5897-5739 (95.4\%) \\
\hline KT RC 13 & STR 21 & 3 & Charcoal, Angiospermae & TKA-21759 & $-21.2 \pm 0.6$ & $6946 \pm 27$ & $5891-5745$ (95.4\%) \\
\hline KT RC 17 & STR 2 & 3 & Hordeum vulgare & LTL17700A & $-27.8 \pm 0.1$ & $6940 \pm 45$ & $\begin{array}{l}5970-5953(2.6 \%) \\
5911-5728(92.8 \%)\end{array}$ \\
\hline KT RC 18 & STR 2 & 3 & Hordeum vulgare & TKA-21760 & $-22.5 \pm 0.7$ & $6924 \pm 28$ & $5876-5735(95.4 \%)$ \\
\hline KT RC 19 & STR 2 & 3 & Hordeum vulgare & TKA-21762 & $-25.1 \pm 0.4$ & $6924 \pm 26$ & $5876-5735(95.4 \%)$ \\
\hline KT RC 20 & STR 2 & 3 & Hordeum vulgare & TKA-19588 & $-20.4 \pm 0.3$ & $6913 \pm 31$ & 5876-5727 (95.4\%) \\
\hline KT RC 21 & STR 21 & 3 & Hordeum vulgare & TKA-21763 & $-22.4 \pm 0.6$ & $6913 \pm 27$ & $\begin{array}{l}5871-5863(1.4 \%) \\
5847-5728(94.0 \%)\end{array}$ \\
\hline KT RC 22 & STR 21 & 3 & Charcoal, Angiospermae & LTL19738A & $-29.9 \pm 0.2$ & $6904 \pm 50$ & $\begin{array}{l}5898-5702(93.9 \%) \\
5693-5674(1.5 \%)\end{array}$ \\
\hline
\end{tabular}

stored together. Further studies on new samples and on the weeds may allow us to identify the intensity, durability and seasonality of crop cultivation and give greater insight into the Neolithic agricultural practices at Kiçik Tepe.

\section{Faunal remains}

This preliminary zooarchaeological analysis includes a sample of 884 faunal remains recovered during the 2018 and 2019 excavation seasons at Kiçik Tepe. A third of this sample comes from Phase 2 and the rest from Phase 3 . The animal bones analysed so far includes only samples from inside the structures. Samples from pits and layers from the building's exterior are yet to be analysed. Although the surface of the bones is generally well preserved, the remains are heavily fragmented. This explains the poor rate of anatomical and taxonomical identifications. The identification rate is higher in Phase 3 than in Phase 2 (39.4\% of the number of remains and $60.2 \%$ of the weight of remains versus $26.6 \%$ and $39.4 \%$ respectively). This difference is statistically significant (in number of remains $\chi 2=14.1$, $\mathrm{df}=1, p<0.05$; in weight of remains $\chi^{2}=62.1, \mathrm{df}=1, \mathrm{p}<0.05$ ). Faunal remains from Phase 3 were mostly found in occupation layers of well-preserved structures. This could explain the higher levels of preservation. In spite of this, the number of remains gnawed by carnivores is higher in Phase 3 than in Phase 2 (6.4\% and $1.4 \%$ respectively). Five bone fragments from Phase 3 are marked by rodent teeth. Overall, the high fragmentation rate in the two levels is due to both consumption practices, as suggested also by the presence of cut marks, and post-depositional processes.

Large mammal remains are noticeably rare at Kiçik Tepe. Only two finds tentatively identified as domesticated cattle were found in Phase 3. Considering both identified and unidentified large-sized (i.e. bovids, large cervids and equids) and medium-sized (i.e. caprids, suids, gazelle and small cervids) animals, large-sized mammals represent $3.2 \%$ and $5 \%$ of the number of faunal remains in Phase 2 and Phase 3 respectively. R. Meadow (1978) demonstrated that large bones are more likely to be discarded outside buildings than smaller ones. At Kiçik Tepe however, large bones are not more numerous in the upper fillings of the structures than in the lower occupation layers. The most frequent mammalian taxa in the faunal assemblage are the Caprinae and the Suidae (Table 5). The ratio between Suidae and Caprinae remains is 1:2.2 in Level 3 and drops to 1:5 in Level 2. In these matters the two levels are significantly different $(\chi 2=5.7, \mathrm{df}=1, \mathrm{p}<0.05)$. The Caprinae category comprises both sheep and goat remains. A small number of bones were indistinguishable (Ovis or Capra). So far only sheep were identified in Phase 3 while an equivalent number of sheep and goat remains was identified in Phase 2. The size of the Caprinae is compatible with the domesticated species. They have virtually all been identified as domesticated sheep and goat, although it is not possible to exclude that the assemblage contains a few wild sheep and goat remains that were not identified as yet. The Suidae category encompasses wild boar and domesticated pigs. Most specimens belong to juvenile and sub-adults individuals younger than two years old. It is therefore difficult to differentiate the wild boar remains from the domesticated pig. Among the few distinctive remains, however, four fragments were identified as domesticated pig, based on their size (Fig. 24) and none as wild boar. Therefore, all the Suidae remains in the assemblage could belong to the domesticated pig, although the presence of a few wild boar should not be excluded.

It seems that hunting played a very limited role in the subsistence strategy of the inhabitants of Kiçik Tepe in both Phases 3 and 2. As regards the presence of wild mammals, one gazelle bone was identified. Other gazelle bones may have been overlooked among the most fragmented remains. The only evidence of red deer is a piece of antler. This in itself is not evidence of deer hunting at Kiçik Tepe since antler can be collected as shed antler or traded as raw material. Some hare and fox remains were also identified.

The exploitation of animal resources is characterized at Kiçik Tepe, as well at the nearby settlements of Hacı Elamxanlı Tepe (Nishiaki et al., 2013, 2015a) and Mentesh Tepe (Lyonnet et al., 2016) by a strong emphasis on sheep and goats herding (Fig. 25). In this respect, these three settlements differ from other settlements of the SSC displaying more balanced herding strategies (Benecke, 2017; Berthon, 2014; Lyonnet et al., 2016). The faunal assemblage from Kiçik Tepe is also characterized by the almost absence of cattle remains contrary to the 


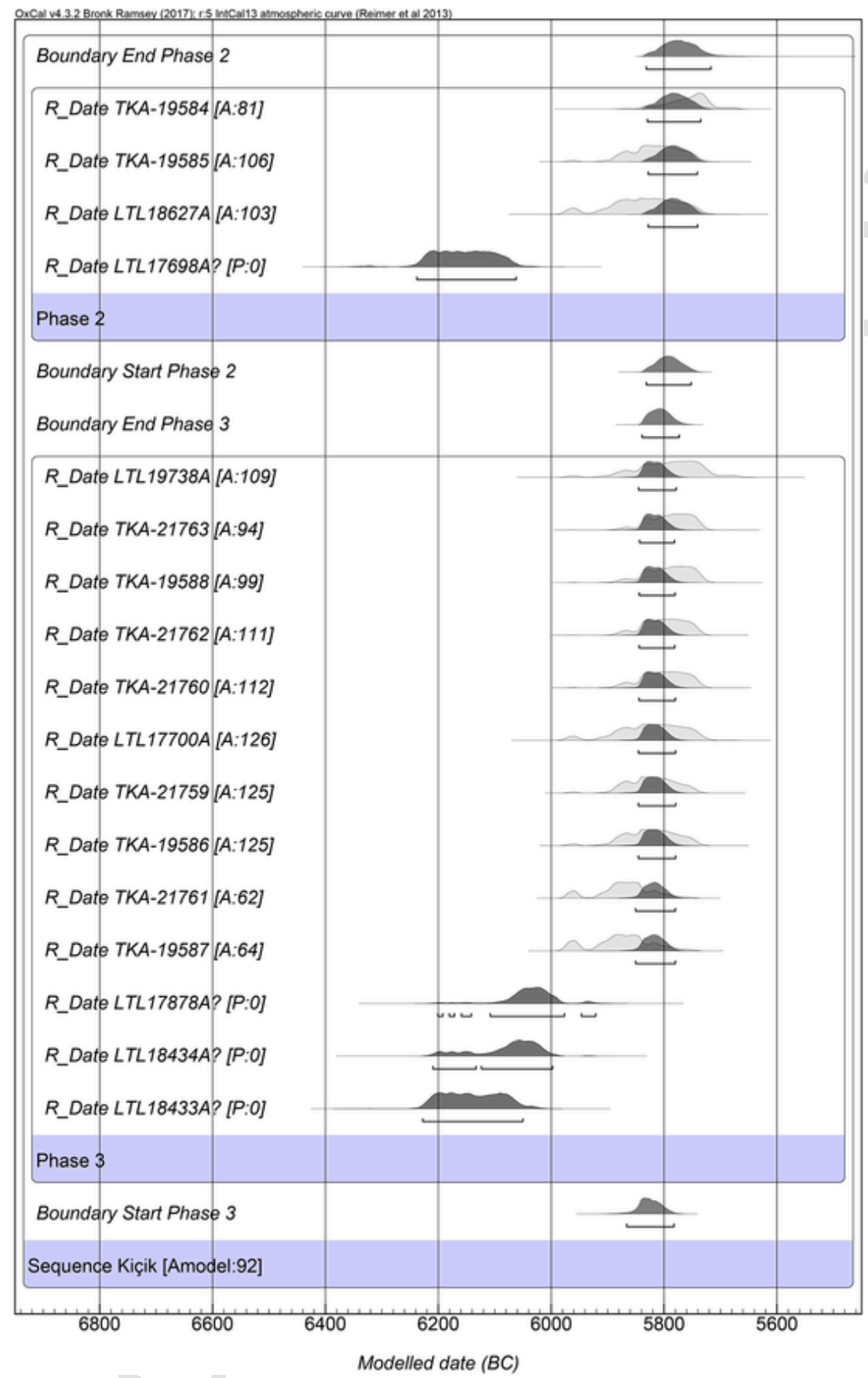

Fig. 21. Bayesian model of calibrated chronology of Phases 3 and 2.

slightly later assemblage from nearby Mentesh Tepe (Lyonnet et al., 2016). Finally, it is important to note that pigs are present at both the Early Neolithic settlements of Kiçik Tepe and Hacı Elamxanlı Tepe. Pigs might have even played a significant role in the diet of the Kiçik Tepe inhabitants. This evidence is particularly significant as it shows that pigs were part of Neolithic subsistence strategies throughout the 6th millennium BCE in the Kura valley while they are absent in the Araxes valley (Benecke, 2017; Berthon, 2014; Lyonnet et al., 2012; Marro et al., 2019).

\section{The chipped stone industry}

\subsection{Introduction and data quantification}

The lithic collection from the Neolithic occupation at Kiçik Tepe is still relatively limited in comparison to other contemporary settlements of the region. So-far it consists of 840 artefacts, half of them wasteproducts (Table 6). The results of the study are therefore mainly qualitative in nature and we must wait for additional material for more thorough quantitative analyses. Materials from Phases 3 and 2 are presented together as no significant technological difference appears between the two phases. 
Table 4

Seeds and fruits from Phases 3 and 2 (MNI of each taxa identified).

\begin{tabular}{|c|c|c|c|}
\hline Phase & 3 & 2 & TOTAL \\
\hline Number of samples & 12 & 12 & 24 \\
\hline \multicolumn{4}{|l|}{ Cereals } \\
\hline Hordeum vulgare, caryopsis & 913 & 286 & 1199 \\
\hline Hordeum vulgare, rachis segments & 267 & 23 & 290 \\
\hline Triticum turgidum subsp. dicoccon, caryopsis & 61 & 37 & 98 \\
\hline Triticum monococcum type, grains & 32 & 11 & 43 \\
\hline Hulled wheat, rachis segments & 157 & 52 & 209 \\
\hline Hulled wheat, glumes & 330 & 51 & 381 \\
\hline Triticum aestivum/durum, caryopsis & 201 & 80 & 281 \\
\hline Triticum aestivum/durum, rachis segments & 44 & 43 & 87 \\
\hline Triticum sp., caryopsis & 172 & 26 & 198 \\
\hline Cerealia, caryopsis & 2338 & 978 & 3316 \\
\hline Cerealia, rachis segments & 86 & 43 & 129 \\
\hline Cerealia, glumes & 0 & 1 & 1 \\
\hline \multicolumn{4}{|l|}{ Pulses } \\
\hline Lens culinaris, seeds & 11 & 1 & 12 \\
\hline Cultivated Fabaceae, seeds & 2 & 1 & 3 \\
\hline \multicolumn{4}{|l|}{ Technical/oleaginous plant } \\
\hline cf Linum usitatissimum, seeds & 0 & 2 & 2 \\
\hline \multicolumn{4}{|l|}{ Fruits } \\
\hline Prunoideae, fragments nutshell & 0 & 1 & 1 \\
\hline \multicolumn{4}{|l|}{ Wilds } \\
\hline Adonis sp., seeds & 7 & 6 & 13 \\
\hline Aegilops sp., caryopsis & 0 & 1 & 1 \\
\hline Aegilops sp., rachis segments & 0 & 2 & 2 \\
\hline cf Ajuga/Teucrium, seeds & 4 & 0 & 4 \\
\hline cf Alyssum/Lepidium, seeds & 242 & 0 & 242 \\
\hline cf Androsace maxima, seeds & 1 & 0 & 1 \\
\hline cf Artemisia sp., seeds & 315 & 0 & 315 \\
\hline cf Artemisia sp., inflorescence & 457 & 0 & 457 \\
\hline Astragalus sp., seeds & 5 & 0 & 5 \\
\hline Brassicaceae, seeds & 0 & 1 & 1 \\
\hline Bromus sp., caryopsis & 33 & 0 & 33 \\
\hline Buglossoides arvensis/sibthorpianum, seeds & 57 & 46 & 103 \\
\hline Caryophyllaceae, seeds & 0 & 24 & 24 \\
\hline cf Capparis sp., seeds & 1 & 0 & 1 \\
\hline Chenopodium album, seeds & 1 & 6 & 7 \\
\hline Chenopodiaceae, seeds & 77 & 226 & 303 \\
\hline cf Coronilla sp., seeds & 1 & 0 & 1 \\
\hline Cyperaceae, seeds & 24 & 12 & 36 \\
\hline Cyperaceae/Polygonaceae, seeds & 1 & 0 & 1 \\
\hline Euphorbia sp., seeds & 2 & 9 & 11 \\
\hline Small Fabaceae, seeds & 5 & 0 & 5 \\
\hline Heliotropium sp., seeds & 54 & 34 & 88 \\
\hline Hordeum sp., wild caryopsis & 3 & 0 & 3 \\
\hline Lithospermum officinale, seeds & 4 & 1 & 4 \\
\hline cf Malva sp., seeds & 3 & 0 & 3 \\
\hline Medicago astroites, seeds & 1 & 0 & 1 \\
\hline cf Medicago sp., seeds & 1 & 0 & 1 \\
\hline Poaceae, caryopsis & 97 & 17 & 114 \\
\hline cf Setaria sp., caryopsis & 1 & 0 & 1 \\
\hline cf Stipa sp., caryopsis & 1 & 0 & 1 \\
\hline Trigonella sp., seeds & 5 & 1 & 6 \\
\hline Thymelaea sp., seeds & 2 & 0 & 2 \\
\hline \multicolumn{4}{|l|}{ Other } \\
\hline Undeterminated seeds & 386 & 89 & 475 \\
\hline Monocotyledon stem fragments & 0 & 1 & 1 \\
\hline Undeterminated stem fragments & 12 & 0 & 12 \\
\hline Amorphous remains & 1775 & 11 & 1786 \\
\hline Coprolites & 82 & 0 & 82 \\
\hline Undeterminable elements & 10 & 0 & 10 \\
\hline TOTAL & 8284 & 2123 & 10,406 \\
\hline
\end{tabular}

\subsection{Raw materials}

Flint and obsidian were the only two raw materials exploited for knapping with flint predominant (66.6\%) over obsidian (Table 6). However, it should be emphasized that this general picture may actually be biased by the discovery of two concentrations of flint in Phase 3 (Fig. 8). The fact that both concentrations record a high percentage of waste suggests that they were the result of the cleaning of a knapping area. In other contexts, the quantity of obsidians is always higher than flint. If we extract waste from the total, the percentage of obsidian accounts for $67 \%$ of the artefacts. The different colors of the obsidian retrieved at Kiçik Tepe suggests that diverse outcrops were being exploited; the geochemical analyses confirm this hypothesis (see infra). Flint is of mudstone texture, with slight differences in grain size (fine or middle fine raw material) and the colors are green and purple-beige.

\subsection{Sources of obsidian}

The analysis of the 34 obsidian artefacts discussed here was conducted at the Center Ernest-Babelon of the IRAMAT (UMR 5060 CNRS / Univ. Orléans) using Laser Ablation - Inductively Coupled Plasma Mass Spectrometry (LA-ICP-MS) a method which enables an almost non-destructive analysis, invisible to the naked eye, of the obsidian artefacts (Gratuze, 1999; Chataigner and Gratuze, 2014b; Palumbi et al., 2014). The instrumentation consists of an Element XR doublefocusing mass spectrometer from Thermofisher Instruments associated with a Resonetics RESOlution M50e ablation device (Excimer ArF laser working at $193 \mathrm{~nm}$ ).

The results of the analyses have allowed us to identify five principal compositional groups (Table 7; Table 8; Fig. 26). Refering to recent published studies concerning the sources of obsidian for the South Caucasus and North-Eastern Turkey (Chataigner and Gratuze, 2014a; Chataigner and Gratuze, 2014b; Chataigner et al., 2014b; Biagi et al., 2017), these groups correspond to the obsidian sources of the volcanos of Gegham (1 specimen), Arteni (Arteni 3, 1 specimen), Sarıkamış (N1, N3 and S1, 9 specimens), Chikiani (Chikiani 2 and 3, 17 specimens) and Tsaghkunyats (Damlik and Ttvakar, 6 specimens). Taking into account the barium and zirconium concentrations and the ratios of concentrations between barium, strontium, zirconium, yttrium and niobium (Fig. 27; Fig. 28; Fig. 29), the group of tools from Sarıkamış has been subdivided into four sub-groups (N 1B, N 3A and N 3B, and S 1A), the group of Chikiani into two sub-groups (Chikiani 2 and 3 ) and the group of Tsaghkunyats 1 into two sub-groups (Damlik and Tvakar). With the exception of the artefacts attributed to the sub-groups Sarıkamış N 3A and $\mathrm{S} 1 \mathrm{~A}$, for which we have no geological reference of identical composition, the attributions were made by comparing the measured compositions of the tools to those obtained by the same method of analysis on geological obsidian collected during geological surveys in the various volcanic zones in Turkey, Armenia and Georgia (Chataigner and Gratuze, 2014b; Chataigner et al., 2014b; Biagi et al., 2017). Concerning the artefact KT 1732 18, attributed to the sub-group Sarıkamıs S $1 \mathrm{~A}$, an indirect correspondence with a source of obsidian in the region of Sarıkamıss was established. From a geochemical point of view, the artefact KT 173218 has an intermediate composition belonging to the domain defined by the sources as originating in the area around Sarıkamış and Yağlıca Dağ (Chataigner et al., 2014b). If we consider the contents of barium, strontium, zirconium and rare earths, the composition of this piece is more similar to the composition of the outcrops of south Sarıkamıs for its contents of barium and strontium, to the composition of the outcrops of north Sarıkamıs for its contents of zirconium and rare earths and to the composition of Yağlıca Dağ for its contents of barium, strontium and zirconium. This artefact is not, however, a unique example; eight other obsidian pieces found in Azerbaijan (six at Mentesh Tepe and one at Ismayilbey) and one in Armenia (Getahovit) have an identical composition (unpublished data and Chataigner et al., 

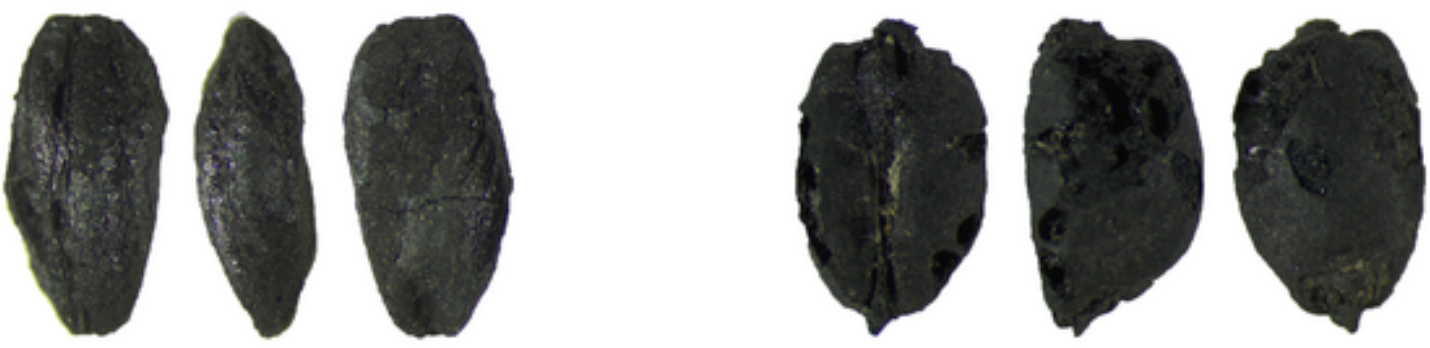

a.

b.
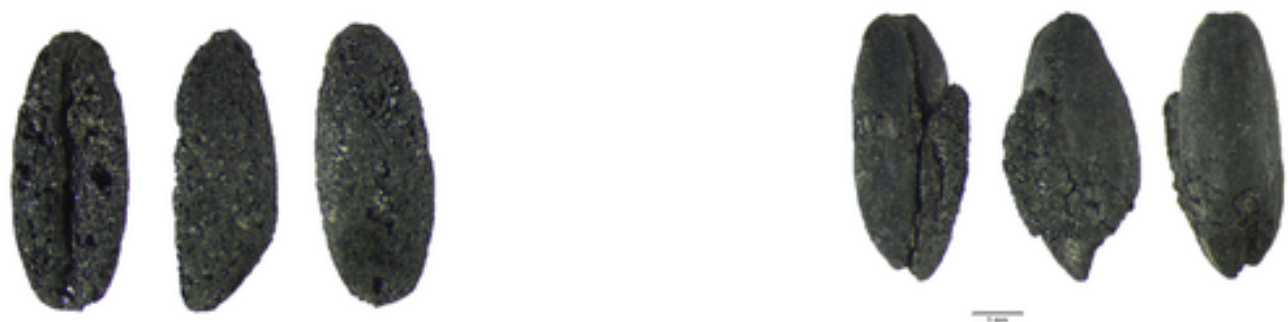

C.

d.

Fig. 22. Cereals identified at Kiçik Tepe: a. Hordeum vulgare, b. Triticum aestivum/durum, c. Triticum turgidum subsp. dicoccon, D. triticum monococcum type.

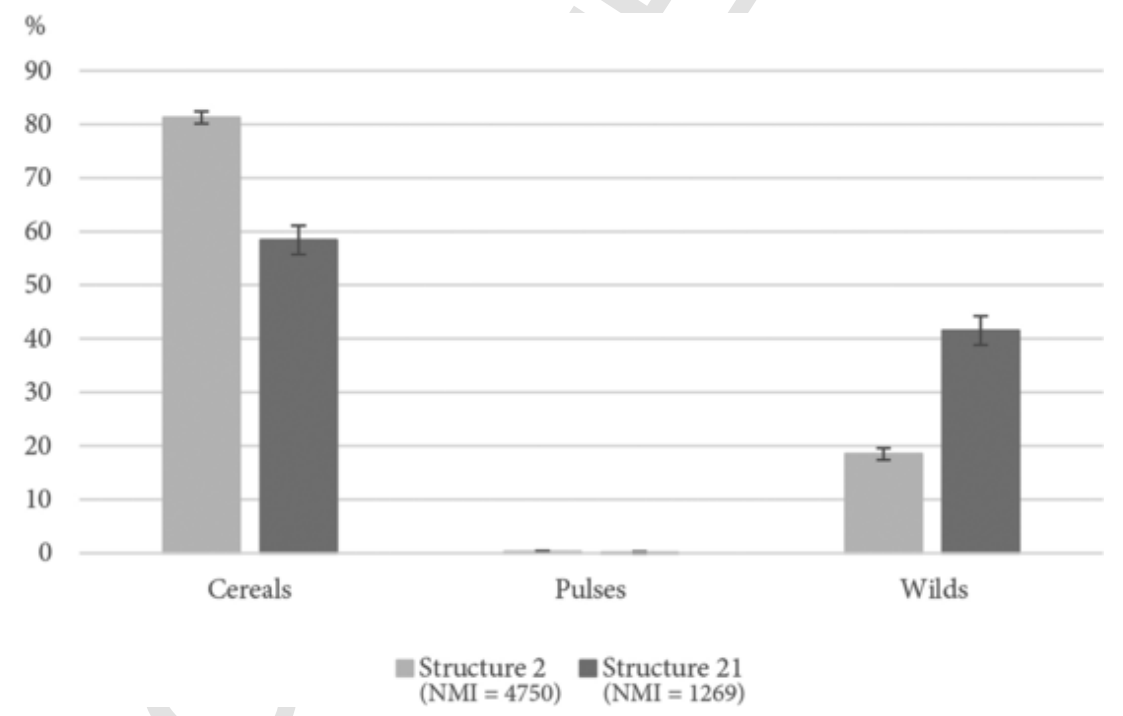

Fig. 23. Proportions of the main categories of plants identified in STR 2 and 21 (A. Decaix).

2020). Similarly, for the artefact KT 1884 18, attributed to the subgroup N 3B, three artefacts from Mentesh Tepe have a similar composition. The distinction between the zones of north Sarıkamıs and south Sarıkamıs is in fact more related to the geochemistry of the obsidian tools than to their geographic locations, and more particularly to their contents in barium and zirconium. The obsidian tools from north Sarıkamış are characterized by a high content of zirconium and a low content of barium, whereas inversely those of south Sarıkamış present a low content of zirconium and a high content of barium. The artefact KT 173218 has an intermediate composition between these to areas, and until there is a more detailed survey of the volcanic zone of Sarıkamıs,, it will be attributed to this broad zone.

The results of obsidian sourcing reveal a polysource model of acquisition (Fig. 30; Fig. 31; Table 9) documenting the exploitation of five sources: Chikiani (Georgia), Sarıkamış (Eastern Turkey), Tsaghkunyats,
Gegham and Arteni (Armenia). It has been widely discussed (Renfrew et al., 1968; Ibáñez et al., 2016) that the distance to the site is not the main criteria for explaining the circulation of raw materials and data from Kiçik Tepe confirm this view. The obsidian of Chikiani located north-west of Kicik tepe is the main source for the site, $170 \mathrm{~km}$ away as the crow flies. The Armenian sources are located between 110 and $190 \mathrm{~km}$ away. The most surprising result is exploitation from the furthest outcrops, in the region of Sarıkamış, which are c. $270 \mathrm{~km}$ away. It is however worth noting that obsidian sourced as Sarıkamış is also encountered in secondary deposits in the Akhurian valley (c. $200 \mathrm{~km}$ away). These results indicate that individuals or groups were very mobile during the Neolithic and highlights the scope of their networks of exchange and interaction. 
Table 5

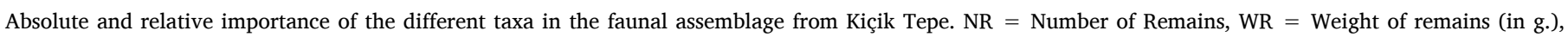
NISP $=$ Number of Identified Specimens, WISP = Weight of Identified Specimens (in g.).

\begin{tabular}{|c|c|c|c|c|c|c|c|c|c|}
\hline & & \multicolumn{2}{|c|}{ Level 2} & \multicolumn{2}{|c|}{ Level 3} & \multicolumn{2}{|l|}{ Level 2} & \multicolumn{2}{|l|}{ Level 3} \\
\hline & & NR & WR & NR & WR & \%NISP & \%WISP & \%NISP & \%WISP \\
\hline Hare & Lepus europaeus & 0 & 0 & 3 & 11.9 & & & 1.3 & 0.9 \\
\hline Fox & Vulpes vulpes & 0 & 0 & 16 & 18.3 & & & 6.9 & 1.5 \\
\hline Pig/Wild boar & Suidae & 12 & 73.6 & 57 & 436 & 15.4 & 19.5 & 24.5 & 34.8 \\
\hline incl. Domestic pig (Sus domesticus) & & 1 & 12.3 & 3 & 74.4 & & & & \\
\hline Red deer & Cervus elaphus & 0 & 0 & 1 & 16.5 & & & 0.4 & 1.3 \\
\hline Cattle & Bos cf. taurus & 0 & 0 & 2 & 18 & & & 0.9 & 1.4 \\
\hline Gazelle & Gazella sp. & 0 & 0 & 1 & 8.5 & & & 0.4 & 0.7 \\
\hline Sheep or goat & Caprinae & 61 & 292.2 & 126 & 661.9 & 78.2 & 77.5 & 54.1 & 52.8 \\
\hline incl. Goat (Capra hircus) & & 5 & 46.2 & 0 & 0 & & & & \\
\hline incl. Sheep (Ovis aries) & & 5 & 33.6 & 19 & 131.1 & & & & \\
\hline Tortoise & Testudinidae & 5 & 11.2 & 11 & 67.8 & 6.4 & 3.0 & 4.7 & 5.4 \\
\hline Birds & Aves & 0 & 0 & 15 & 15.2 & & & 6.4 & 1.2 \\
\hline Fish & Pisces & 0 & 0 & 1 & 0.2 & & & 0.4 & $<0.1$ \\
\hline Total identified & & 78 & 377 & 233 & 1254.3 & 100 & 100 & 100 & 100 \\
\hline Unidentified mammal & Mammalia & 35 & 32.4 & 43 & 46.3 & & & & \\
\hline unidentified large-sized mammal & & 8 & 39.4 & 24 & 193.4 & & & & \\
\hline unidentified medium-sized mammal & & 172 & 403.6 & 286 & 586.2 & & & & \\
\hline unidentified small-sized mammal & & 0 & 0 & 5 & 4.2 & & & & \\
\hline Total unidenfied & & 215 & 475.4 & 358 & 830.1 & & & & \\
\hline & & & & & & $\% \mathrm{NR}$ & $\% \mathrm{WR}$ & $\% \mathrm{NR}$ & $\% \mathrm{WR}$ \\
\hline Total identified & & 78 & 377 & 233 & 1254.3 & 26.6 & 44.2 & 39.4 & 60.2 \\
\hline Total unidentified & & 215 & 475.4 & 358 & 830.1 & 73.4 & 55.8 & 60.6 & 39.8 \\
\hline TOTAL & & 293 & 852.4 & 591 & 2084.4 & 100 & 100 & 100 & 100 \\
\hline
\end{tabular}

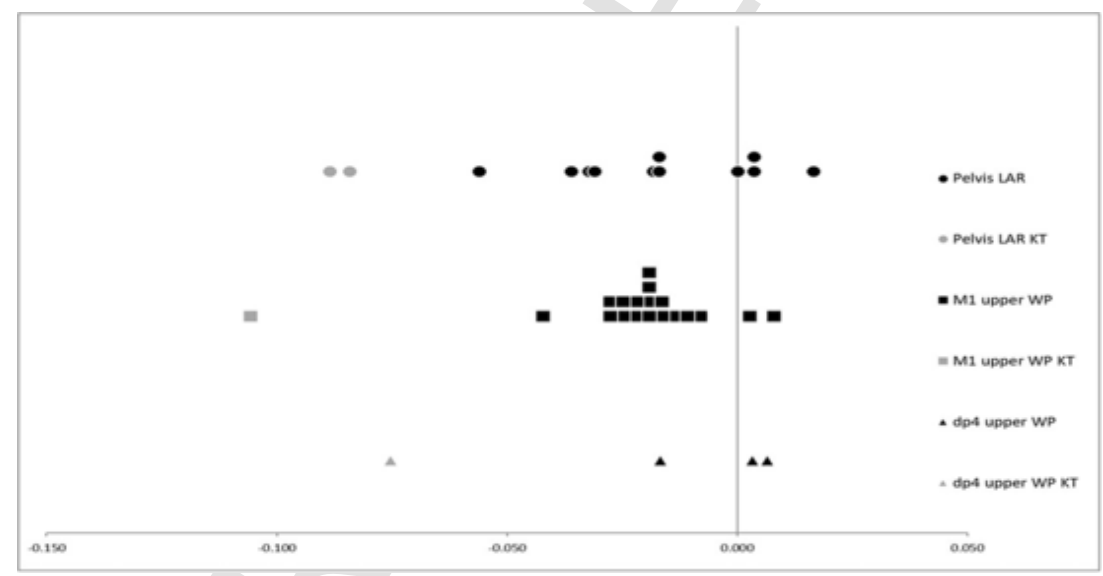

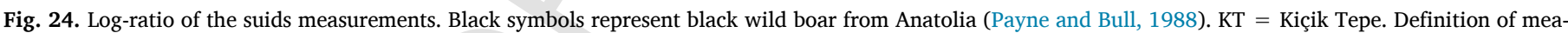

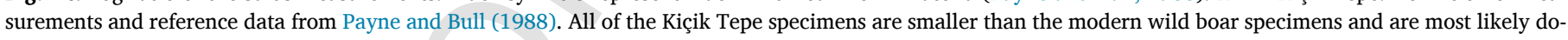
mesticated pigs (R. Berthon).

\subsection{Knapping technologies}

Flint was knapped to obtain flakes or elongated flakes using direct percussion. The exploitation of the cores is unipolar. We identified natural surfaces and cortex on some of the blanks. The most complete documentation on reduction sequences comes from two concentrations (USC 6 and 7) found in level 3 (Fig. 8). They were situated in two hollows found at the exterior of STR 3, and result from the exploitation of at least six blocks of flint of mudstone texture, one of which is green flint and the other a purple-beige flint (Fig. 32). Both concentrations are mainly composed of waste. An obsidian flake was also found. The concentration of green flint comprises a large core with a natural platform (from a tabular block) that produced elongated flakes. We refitted a small flake on the core. Three cortical flakes with a natural butt coming from another tabular block were also refitted. These elements indicate that these blocks were reduced on the spot in the living spaces. The other concentration includes waste, flakes and elongated flakes and one of the latter is a formal tool (a backed piece). The core and the products do not exceed $7.5 \mathrm{~cm}$ in length.

Obsidian was knapped to obtain blades by pressure flaking (Fig. 33). Conical cores with plane platforms had been exploited to produce flakes using direct percussion. A large flake corresponding to a secondary débitage of a blade core show on its dorsal surface the negatives of five bladelets extracted using pressure flaking with a crutch in standing position. The absence of opening platforms, cortical and shaping flakes, crested blades might show that the raw materials were mainly brought to the site as preforms or cores and/or blades or simply show that these sequences of the chaîne opératoire took place outside the excavated area. This hypothesis will be verified once the excavations are extended. Core tablets $(n=5)$ indicate that the reduction sequences would have required careful preparation and shaping of the cores made at the site. One of the tablets shows the scars of five blades on the débitage surface. Blades are the result of a semi-circular or circular exploitation. The codes of production are consistent with a very standardized unipolar exploitation of the core (code of $212^{\prime}$ are prevalent, fol- 


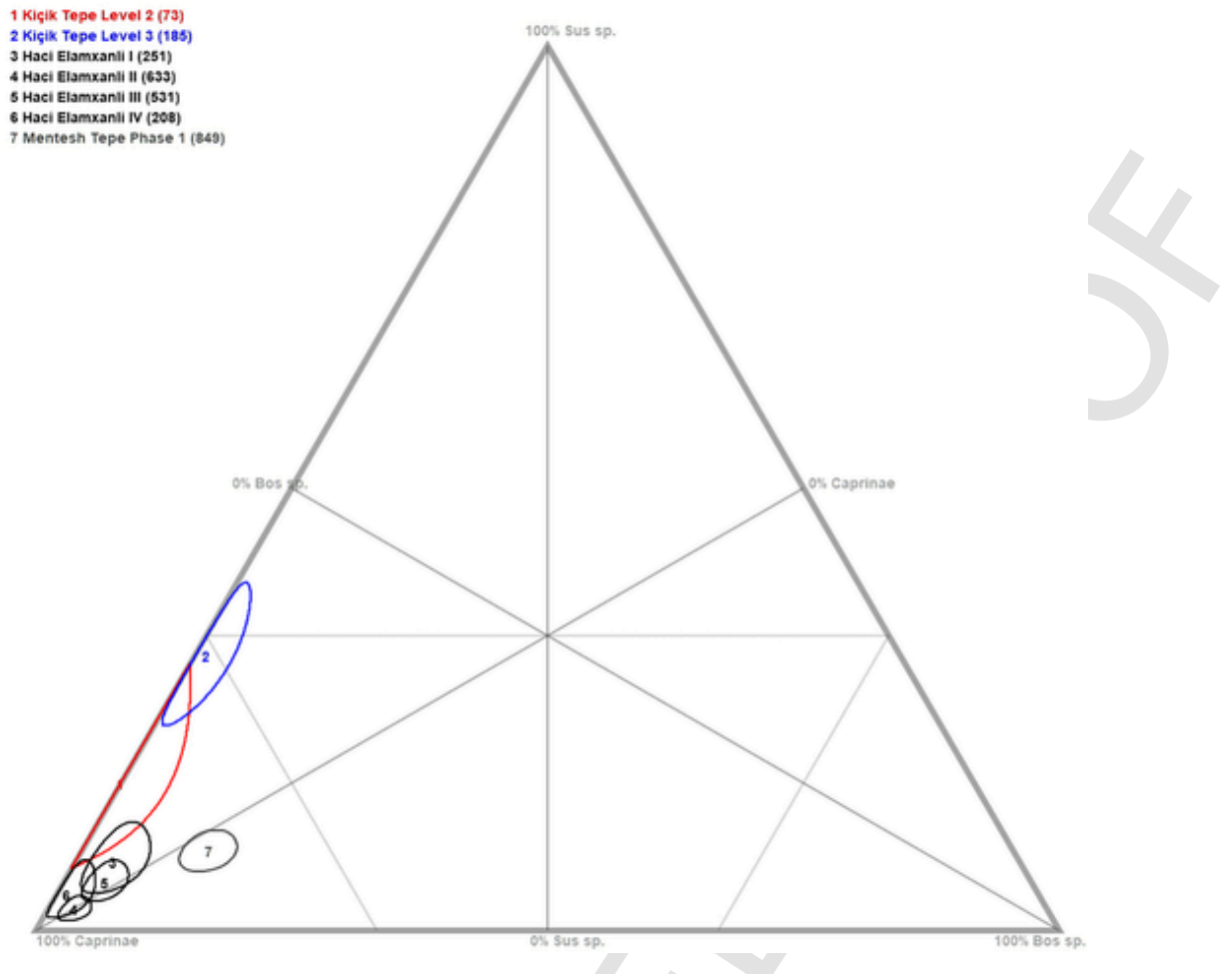

Fig. 25. Triangle graph representing the amount of Caprinae, cattle and Suidae remains in the assemblages from Kiçik Tepe, Hacı Elamxanlı Tepe (Nishiaki et al., 2013, 2015a) and Mentesh Tepe (Lyonnet et al., 2016). Figures in brackets are the number of remains. The ellipse represents the $95 \%$ confidence interval. Graph produced with the Triangle 2.0 software (Weaver et al., 2011) (R. Berthon).

Table 6

Technological breakdown of the lithic assemblage from the Neolithic occupation at Kiçik Tepe.

\begin{tabular}{llll}
\hline & Obsidian & Flint & Undetermined \\
\hline Waste & 112 & 333 & 4 \\
Flakes & 42 & 114 & 1 \\
Blade(let)s & 181 & 7 & 0 \\
Cores & 2 & 2 & 0 \\
Core tablets & 5 & 0 & 0 \\
Burin spalls & 8 & 0 & 0 \\
Undetermined & 23 & 6 & 0 \\
Total & 373 & 462 & 5 \\
\hline
\end{tabular}

Table 7

Distribution of the analysed artefacts in obsidian according to their sources of provenance.

\begin{tabular}{|c|c|c|c|c|c|c|c|c|c|c|}
\hline Total & Gegham & Arteni & Sarıkaı & mış & & & Chik & iani & Tsakhku & nyats 1 \\
\hline \multirow[t]{3}{*}{34} & 1 & 1 & 9 & & & & 17 & & 6 & \\
\hline & $2,9 \%$ & $2,9 \%$ & $29,4 \%$ & & & & 47,1 & & $17,6 \%$ & \\
\hline & Gegham & A 3 & N 1B & N 3B & N 3A & S $1 \mathrm{~A}$ & C 2 & C 3 & Damlik & Ttvakar \\
\hline 34 & 1 & 1 & 5 & 1 & 2 & 1 & 14 & 3 & 4 & 2 \\
\hline
\end{tabular}

lowed by code 321 and 123, Binder and Gassin, 1987) allowed by pressure flaking. As a large part of the collection's width corresponds to pressure flaking using a crutch in a standing position, several blades between 24 and $28.5 \mathrm{~mm}$ wide may have been detached from the core with the help of a lever (Pelegrin, 2012). For blade production, the larger the cores and the products, the higher the level of skills needed for production.

By combining the results of obsidian sourcing and technology, we can conclude that pressure flaked blades are the most common regardless of the origin of the raw material (Table 10). The pressure with a crutch in a standing position is highly dominant but blanks whose width exceeds $24 \mathrm{~mm}$ may indicate that pressure with the help of a lever was used (as with obsidian from Chikiani 2, Sarıkamış north, Tsaghkunyats 1 and Gegham). An elongated flake from Chikiani could be the result of a flaking accident while knapping large blades; in this case, it would be evidence of this kind of production at the site. Two conical cores and a flake coming from the same type of core, from Sarıkamıs North, and the flake extracted from a blade pressure core (supra) was knapped from the same raw material. Blade(let) cores (tablets) made from Chikiani 2 and Tsaghkunyats obsidian were rejuvinated. This shows that at least three raw materials were knapped on the spot: Chikiani 2, Tsaghkunyats and Sarıkamış north.

If we now pay attention to the typology, flint and obsidian are clearly distinct; $18.5 \%$ of the total assemblage is retouched but when considering the ratio of blank/retouched obsidian pieces (cores and waste are excluded), the number increases to $44.8 \%$, while the retouched pieces of flint equate to $12.4 \%$. The typological groups represented for each raw material are also distinct (Table 11). For obsidian, the typology is diverse: one trapeze (on segmented bladelet) ${ }^{2}$; burins (corresponding to burin spalls, Table 6); pieces with lateral or irregular retouch; wedge; truncations; scrapers and notches; and, reworked flakes. The trapeze and the burins are meaningful for the definition of the assemblage (see the comparisons below) and the other types are more common. Flint, typological groups are fewer: backed pieces and sickles (hafted obliquely) are the most frequent, followed by pieces with lateral retouch and a truncation, a stone hammer in flint being probably exceptional. The presence of sickles on flint and not on obsidian might be a question of identification of the traces of use: a characteristic gloss on flint is visible with the naked eye whereas the use-wear is less visible on obsidian.

2 The lithic assemblage was recovered through manual picking in the field and through the sorting of heavy fractions of the flotation. No other trapeze was found in the flotated samples. 
Table 8

Compositional data obtained by LA-ICP-MS for the 34 obsidian artefacts from Kiçik Tepe. Data are expressed in wt $\%$ of oxides for the main major and minor elements $\left(\mathrm{Na}_{2} \mathrm{O}\right.$ to $\left.\mathrm{Fe}_{2} \mathrm{O}_{3}\right)$ and in parts per million for trace elements ( $\mathrm{Li}$ to $\mathrm{U}$ ), $1 \mathrm{ppm}=0.0001 \%$.

\begin{tabular}{|c|c|c|c|c|c|c|c|c|c|c|c|c|c|c|c|c|c|c|c|}
\hline & Element & $\mathrm{Na}_{2} \mathrm{O}$ & $\mathrm{MgO}$ & $\mathrm{Al}_{2} \mathrm{O}_{3}$ & $\mathrm{SiO}_{2}$ & $\mathrm{~K}_{2} \mathrm{O}$ & $\mathrm{CaO}$ & $\mathrm{Fe}_{2} \mathrm{O}_{3}$ & $\mathrm{Li}$ & B & Sc & $\mathrm{Ti}$ & Mn & $\mathrm{Zn}$ & $\mathrm{Rb}$ & $\mathrm{Sr}$ & $\mathrm{Y}$ & $\mathrm{Zr}$ & $\mathrm{Nb}$ \\
\hline Arteni 3 & KT 173560 & 4.02 & 0.055 & 13.8 & 76.5 & 4.40 & 0.51 & 0.41 & 50.9 & 45.3 & 4.50 & 450 & 562 & 29.7 & 134 & 20.2 & 22.7 & 69.2 & 28.1 \\
\hline Gegham & KT 1731 07C & 4.10 & 0.045 & 13.9 & 76.4 & 4.25 & 0.58 & 0.54 & 68.0 & 49.5 & 4.54 & 353 & 621 & 28.6 & 206 & 9.65 & 20.9 & 58.9 & 45.3 \\
\hline Sarıkamış N 1B & KT 173219 & 4.63 & 0.022 & 13.5 & 76.1 & 4.31 & 0.21 & 1.00 & 50.3 & 31.0 & 5.64 & 453 & 478 & 58.5 & 140 & 2.20 & 43.0 & 199 & 25.0 \\
\hline Sarıkamış N 1B & KT 17521 & 4.44 & 0.031 & 13.4 & 76.3 & 4.21 & 0.30 & 1.07 & 46.9 & 31.0 & 5.39 & 418 & 590 & 61.8 & 143 & 2.14 & 43.3 & 179 & 25.1 \\
\hline Sarıkamış N 1B & KT 175424 & 4.51 & 0.028 & 13.7 & 75.9 & 4.26 & 0.26 & 1.10 & 36.6 & 30.0 & 5.79 & 469 & 534 & 66.5 & 137 & 2.41 & 43.6 & 214 & 25.7 \\
\hline Sarıkamış N 1B & KT 175424 BIS & 4.59 & 0.037 & 13.4 & 75.9 & 4.29 & 0.32 & 1.20 & 42.7 & 29.6 & 5.58 & 455 & 630 & 64.6 & 138 & 2.20 & 43.4 & 209 & 25.1 \\
\hline Sarıkamış N 1B & KT 18102 & 4.61 & 0.033 & 13.5 & 75.7 & 4.43 & 0.31 & 1.14 & 48.0 & 25.8 & 9.61 & 474 & 606 & 66.0 & 138 & 2.15 & 40.6 & 210 & 24.4 \\
\hline Sarıkamış N 1B & KT 19 G9 36 & 4.59 & 0.032 & 13.6 & 75.7 & 4.29 & 0.30 & 1.16 & 47.9 & 29.9 & 5.59 & 460 & 581 & 66.0 & 138 & 2.15 & 42.7 & 208 & 24.7 \\
\hline Sarıkamış N 3A & KT 18100 & 4.61 & 0.054 & 13.8 & 75.5 & 4.37 & 0.37 & 1.02 & 48.1 & 26.0 & 9.47 & 552 & 550 & 50.1 & 136 & 8.08 & 38.6 & 173 & 25.5 \\
\hline Sarıkamış N 3A & KT 18103 & 4.61 & 0.057 & 13.8 & 75.4 & 4.42 & 0.39 & 0.97 & 45.8 & 26.2 & 9.50 & 553 & 630 & 59.0 & 140 & 7.82 & 39.3 & 177 & 25.2 \\
\hline Sarıkamış N 3B & KT 188418 & 4.42 & 0.045 & 14.0 & 76.0 & 4.23 & 0.35 & 0.75 & 53.3 & 35.1 & 5.82 & 452 & 656 & 57.9 & 165 & 7.29 & 44.1 & 125 & 29.0 \\
\hline Sarıkamış S 1A & KT 173218 & 4.75 & 0.10 & 15.0 & 73.6 & 4.18 & 0.64 & 1.46 & 45.2 & 25.3 & 5.29 & 594 & 606 & 63.3 & 125 & 34.7 & 35.6 & 179 & 189 \\
\hline Chikiani 2 & KT 17732407 B & 3.86 & 0.10 & 14.3 & 75.5 & 4.49 & 0.71 & 0.77 & 37.7 & 27.9 & 4.08 & 536 & 466 & 39.2 & 127 & 72.3 & 12.7 & 76.3 & 17.1 \\
\hline Chikiani 2 & KT 190907 B & 3.83 & 0.11 & 14.3 & 75.4 & 4.52 & 0.74 & 0.73 & 36.8 & 25.9 & 3.74 & 563 & 441 & 37.6 & 128 & 75.3 & 12.6 & 80.5 & 17.0 \\
\hline Chikiani 2 & KT 1926 & 3.83 & 0.11 & 14.4 & 75.3 & 4.54 & 0.74 & 0.77 & 37.2 & 26.2 & 3.84 & 574 & 450 & 39.4 & 127 & 77.1 & 12.6 & 81.2 & 16.8 \\
\hline Chikiani 2 & KT 190907 A & 3.84 & 0.11 & 14.3 & 75.4 & 4.50 & 0.74 & 0.80 & 38.2 & 25.7 & 3.95 & 561 & 462 & 39.4 & 126 & 77.0 & 12.6 & 81.4 & 17.3 \\
\hline Chikiani 2 & KT 173107 A & 3.86 & 0.11 & 14.2 & 75.4 & 4.53 & 0.72 & 0.79 & 36.9 & 26.5 & 3.82 & 575 & 463 & 38.7 & 129 & 75.2 & 12.9 & 81.6 & 17.1 \\
\hline Chikiani 2 & KT 17732407 A & 3.81 & 0.11 & 14.3 & 75.4 & 4.48 & 0.73 & 0.81 & 37.4 & 26.7 & 3.94 & 591 & 434 & 37.7 & 126 & 77.0 & 12.4 & 82.3 & 16.6 \\
\hline Chikiani 2 & KT 192 A 7 A & 3.80 & 0.11 & 14.1 & 75.7 & 4.46 & 0.73 & 0.80 & 37.8 & 24.9 & 4.02 & 596 & 437 & 38.5 & 128 & 78.3 & 12.4 & 85.2 & 17.1 \\
\hline Chikiani 2 & KT 173216 & 3.76 & 0.11 & 14.4 & 75.5 & 4.40 & 0.74 & 0.76 & 35.9 & 27.0 & 4.29 & 602 & 437 & 36.8 & 121 & 79,2 & 12.2 & 85.5 & 16.7 \\
\hline Chikiani 2 & KT 192 A 7 E & 3.84 & 0.11 & 14.2 & 75.2 & 4.45 & 0.80 & 1.06 & 39.4 & 27.0 & 4.34 & 600 & 469 & 45.3 & 127 & 78,8 & 12.8 & 86.1 & 17.4 \\
\hline Chikiani 2 & KT 19 2A 7 D & 3.80 & 0.12 & 14.2 & 75.6 & 4.46 & 0.75 & 0.85 & 35.3 & 25.8 & 3.64 & 625 & 433 & 46.2 & 124 & 83,1 & 12.5 & 88.1 & 16.6 \\
\hline Chikiani 2 & KT $173107 \mathrm{D}$ & 3.88 & 0.12 & 14.2 & 75.5 & 4.40 & 0.76 & 0.81 & 33.7 & 25.0 & 3.54 & 619 & 439 & 38.8 & 123 & 86,3 & 12.5 & 89.0 & 16.8 \\
\hline Chikiani 2 & KT 19 2A 7 B & 3.78 & 0.11 & 14.1 & 75.6 & 4.47 & 0.75 & 0.83 & 37.0 & 25.2 & 4.16 & 626 & 434 & 39.2 & 125 & 82,8 & 12.5 & 91.7 & 16.6 \\
\hline Chikiani 2 & KT 177138 & 3.82 & 0.12 & 14.5 & 75.1 & 4.48 & 0.80 & 0.85 & 36.3 & 24.2 & 4.20 & 631 & 437 & 38.7 & 125 & 87,6 & 12.8 & 91.7 & 16.6 \\
\hline Chikiani 2 & KT 1734 & 3.82 & 0.12 & 14.3 & 75.3 & 4.48 & 0.76 & 0.85 & 35.4 & 25.8 & 4.11 & 647 & 427 & 37.2 & 124 & 84,4 & 12.4 & 93.7 & 16.4 \\
\hline Chikiani 3 & KT 1723 A & 3.73 & 0.14 & 14.4 & 75.2 & 4.34 & 0.82 & 1.03 & 35.0 & 23.8 & 4.62 & 703 & 409 & 38.6 & 118 & 95,7 & 12.2 & 108 & 15.0 \\
\hline Chikiani 3 & KT 173107 B & 3.77 & 0.16 & 14.2 & 75.4 & 4.26 & 0.89 & 0.98 & 28.8 & 22.8 & 3.57 & 740 & 395 & 36.2 & 110 & 118 & 11.7 & 112 & 15.2 \\
\hline Chikiani 3 & KT 19 2A 7C & 3.82 & 0.22 & 14.3 & 74.6 & 4.37 & 1.03 & 1.19 & 31.8 & 23.0 & 4.50 & 960 & 373 & 40.3 & 107 & 144 & 11.6 & 136 & 14.3 \\
\hline Tsaghkunyats 1 Damlik & KT 1723 B & 3.90 & 0.11 & 14.1 & 75.8 & 4.16 & 0.92 & 0.71 & 37.3 & 25.3 & 4.39 & 552 & 408 & 29.5 & 110 & 135 & 9.1 & 82.3 & 17.8 \\
\hline Tsakhkunyats 1 Damlik & KT 17522 & 4.07 & 0.11 & 13.9 & 75.8 & 4.04 & 0.96 & 0.80 & 34.1 & 23.3 & 4.00 & 562 & 355 & 29.6 & 106 & 152 & 9.2 & 78.5 & 18.1 \\
\hline Tsakhkunyats 1 Damlik & KT 1909 07C & 3.96 & 0.12 & 14.6 & 75.1 & 4.17 & 0.94 & 0.80 & 36.0 & 23.6 & 3.53 & 563 & 410 & 28.9 & 109 & 141 & 9.1 & 82.0 & 18.4 \\
\hline Tsakhkunyats 1 Damlik & KT 1924 & 3.92 & 0,11 & 14.4 & 75.2 & 4.23 & 0.94 & 0.85 & 36.5 & 23.3 & 3.66 & 544 & 410 & 28.0 & 110 & 137 & 9.5 & 81.8 & 17.9 \\
\hline Tsakhkunyats 1 Ttvakar & KT 173217 & 4.02 & 0.12 & 14.5 & 74.9 & 4.30 & 0.84 & 1.01 & 26.0 & 27.6 & 3.51 & 579 & 419 & 26.9 & 93.7 & 155 & 7.5 & 89.3 & 20.1 \\
\hline Tsakhkunyats 1 Ttvakar & KT 17 23C & 4.07 & 0.12 & 14.5 & 75.1 & 4.16 & 0.88 & 0.81 & 38.4 & 27.8 & 3.89 & 578 & 440 & 26.0 & 91.9 & 163 & 7.77 & 91.6 & 20.1 \\
\hline
\end{tabular}

\begin{tabular}{|c|c|c|c|c|c|c|c|c|c|c|c|c|c|c|c|c|c|c|c|c|}
\hline Element & Cs & $\mathrm{Ba}$ & $\mathrm{La}$ & $\mathrm{Ce}$ & $\operatorname{Pr}$ & $\mathrm{Nd}$ & $\mathrm{Sm}$ & Eu & $\mathrm{Gd}$ & $\mathrm{Tb}$ & Dy & Ho & $\mathrm{Er}$ & $\mathrm{Tm}$ & $\mathrm{Yb}$ & $\mathrm{Lu}$ & $\mathrm{Hf}$ & $\mathrm{Ta}$ & Th & $\mathrm{U}$ \\
\hline KT 173560 & 3.37 & 196 & 17.5 & 33.6 & 3.36 & 11.6 & 3.03 & 0.35 & 2.61 & 0.54 & 3.68 & 0.74 & 2.20 & 0.34 & 2.59 & 0.36 & 2.78 & 1.77 & 14.4 & 6.48 \\
\hline KT 1731 07C & 7.26 & 10.4 & 16.4 & 30.8 & 3.17 & 11.6 & 269 & 0.19 & 2.50 & 0.50 & 3.35 & 0.66 & 1.91 & 0.30 & 2.31 & 0.34 & 2.74 & 3.65 & 26.8 & 14.0 \\
\hline KT 173219 & 4.15 & 31.9 & 37.8 & 70.0 & 7.30 & 27.1 & 6.11 & 0.19 & 5.80 & 1.04 & 6.84 & 1.43 & 4.25 & 0.68 & 4.96 & 0.68 & 6.17 & 1.38 & 18.3 & 6.30 \\
\hline KT 17521 & 4.19 & 32.1 & 34.6 & 65.0 & 7.00 & 25.9 & 5.96 & 0.26 & 5.72 & 1.08 & 6.98 & 1.50 & 4.36 & 0.66 & 4.83 & 0.72 & 5.87 & 1.45 & 18.4 & 6.32 \\
\hline KT 175424 & 4.07 & 31.8 & 40.3 & 75.2 & 7.72 & 29.2 & 6.41 & 0.26 & 5.98 & 1.13 & 7.24 & 1.56 & 4.40 & 0.70 & 5.15 & 0.74 & 6.67 & 1.47 & 18.8 & 6.34 \\
\hline KT 175424 BIS & 4.04 & 30.5 & 39.8 & 74.1 & 7.66 & 27.8 & 6.30 & 0.34 & 5.78 & 1.07 & 7.11 & 1.46 & 4.43 & 0.67 & 5.09 & 0.73 & 6.38 & 1.42 & 18.0 & 6.19 \\
\hline KT 18102 & 4.04 & 31.8 & 39.8 & 75.4 & 7.70 & 28.2 & 6.09 & 0.30 & 5.68 & 1.06 & 6.88 & 1.45 & 4.17 & 0.64 & 4.86 & 0.68 & 6.23 & 1.39 & 17.7 & 6.12 \\
\hline KT 19 G9 36 & 4.10 & 31.4 & 39.0 & 72.3 & 7.48 & 27.5 & 6.37 & 0.31 & 5.76 & 1.11 & 6.93 & 1.51 & 4.29 & 0.69 & 4.93 & 0.73 & 6.42 & 1.41 & 18.0 & 6.09 \\
\hline KT 18100 & 4.20 & 115 & 38.0 & 74.7 & 7.30 & 26.4 & 5.78 & 0.38 & 5.28 & 1.01 & 6.51 & 1.35 & 3.92 & 0.61 & 4.51 & 0.65 & 5.50 & 1.44 & 17.3 & 6.24 \\
\hline KT 18103 & 4.17 & 111 & 38.8 & 72.8 & 7.41 & 27.7 & 5.99 & 0.39 & 5.68 & 0.99 & 6.64 & 1.41 & 3.98 & 0.63 & 4.51 & 0.66 & 5.68 & 1.49 & 17.9 & 6.23 \\
\hline KT 188418 & 5.17 & 107 & 26.1 & 50.8 & 5.47 & 21.0 & 5.57 & 0.28 & 5.38 & 1.06 & 7.03 & 1.45 & 4.32 & 0.65 & 5.04 & 0.68 & 4.89 & 1.72 & 19.6 & 7.36 \\
\hline KT 173218 & 3.72 & 509 & 39.3 & 70.0 & 7.32 & 28.0 & 5.86 & 0.76 & 5.14 & 0.91 & 5.86 & 1.24 & 3.78 & 0.56 & 4.12 & 0.60 & 5.19 & 1.14 & 16.3 & 5.72 \\
\hline KT 17732407 B & 4.36 & 627 & 22.9 & 41.9 & 4.11 & 13.8 & 2.91 & 0.54 & 2.17 & 0.35 & 2.09 & 0.43 & 1.21 & 0.19 & 1.39 & 0.20 & 2.74 & 1.16 & 14.2 & 5.16 \\
\hline KT 190907 B & 4.29 & 664 & 24.4 & 43.9 & 4.19 & 14.3 & 2.88 & 0.53 & 2.17 & 0.35 & 2.11 & 0.42 & 1.16 & 0.17 & 1.44 & 0.19 & 2.72 & 1.14 & 14.4 & 5.02 \\
\hline KT 1926 & 4.14 & 664 & 24.6 & 44.4 & 4.29 & 14.8 & 2.75 & 0.56 & 2.14 & 0.35 & 2.10 & 0.43 & 1.22 & 0.18 & 1.41 & 0.19 & 2.76 & 1.11 & 14.3 & 5.2 \\
\hline KT $190907 \mathrm{~A}$ & 4.24 & 661 & 25.1 & 44.3 & 4.37 & 14.4 & 2.84 & 0.58 & 2.23 & 0.37 & 2.16 & 0.42 & 1.24 & 0.19 & 1.37 & 0.19 & 2.83 & 1.15 & 14.7 & 5.17 \\
\hline KT 173107 A & 4.22 & 659 & 25.2 & 44.1 & 4.26 & 14.8 & 2.83 & 0.54 & 2.15 & 0.36 & 2.10 & 0.43 & 1.21 & 0.18 & 1.35 & 0.18 & 2.80 & 1.14 & 14.6 & 5.03 \\
\hline KT 17732407 A & 4.17 & 684 & 25.4 & 44.9 & 4.30 & 14.5 & 2.71 & 0.57 & 2.13 & 0.35 & 2.19 & 0.43 & 1.18 & 0.17 & 1.30 & 0.19 & 2.89 & 1.13 & 14.3 & 4.96 \\
\hline KT 192 A 7 A & 4.25 & 674 & 26.0 & 46.0 & 4.40 & 15.0 & 2.75 & 0.56 & 2.13 & 0.35 & 2.12 & 0.41 & 1.17 & 0.19 & 1.39 & 0.20 & 2.79 & 1.11 & 14.4 & 4.96 \\
\hline KT 173216 & 4.09 & 699 & 26.1 & 46.1 & 4.40 & 15.2 & 2.82 & 0.58 & 2.20 & 0.34 & 2.07 & 0.42 & 1.15 & 0.17 & 1.36 & 0.19 & 2.87 & 1.09 & 14.2 & 4.89 \\
\hline KT 192 A 7 E & 4.40 & 683 & 26.5 & 47.1 & 4.49 & 15.2 & 2.86 & 0.60 & 2.34 & 0.37 & 2.14 & 0.43 & 1.15 & 0.19 & 1.37 & 0.19 & 2.87 & 1.16 & 14.8 & 5.12 \\
\hline KT 19 2A 7 D & 4.07 & 710 & 27.1 & 48.6 & 4.57 & 15.4 & 2.88 & 0.57 & 2.22 & 0.34 & 2.13 & 0.41 & 1.22 & 0.18 & 1.41 & 0.19 & 2.95 & 1.10 & 14.6 & 4.98 \\
\hline KT 173107 D & 3.98 & 728 & 27.4 & 48.6 & 4.52 & 15.8 & 2.84 & 0.59 & 2.17 & 0.37 & 2.16 & 0.41 & 1.19 & 0.18 & 1.38 & 0.19 & 2.84 & 1.10 & 14.8 & 4.82 \\
\hline KT 19 2A 7 B & 4.24 & 720 & 28.5 & 49.0 & 4.68 & 15.9 & 2.89 & 0.59 & 2.34 & 0.37 & 2.08 & 0.44 & 1.20 & 0.18 & 1.39 & 0.19 & 2.96 & 1.13 & 15.0 & 4.95 \\
\hline KT 177138 & 4.17 & 760 & 28.5 & 49.0 & 4.74 & 16.0 & 3.02 & 0.61 & 2.31 & 0.38 & 2.25 & 0.43 & 1.23 & 0.20 & 1.39 & 0.20 & 3.00 & 1.15 & 15.4 & 5.06 \\
\hline KT 1734 & 4.02 & 772 & 28.9 & 49.5 & 4.68 & 15.9 & 2.94 & 0.57 & 2.17 & 0.36 & 2.18 & 0.42 & 1.20 & 0.18 & 1.25 & 0.19 & 3.08 & 1.08 & 15.0 & 4.83 \\
\hline KT 1723 A & 3.73 & 860 & 33.0 & 55.4 & 5.21 & 17.6 & 3.02 & 0.62 & 2.32 & 0.36 & 2.05 & 0.41 & 1.18 & 0.17 & 1.35 & 0.20 & 3.22 & 1.00 & 15.3 & 4.52 \\
\hline KT 173107 B & 3.58 & 902 & 33.6 & 55.8 & 5.21 & 17.8 & 3.04 & 0.62 & 2.25 & 0.34 & 1.99 & 0.41 & 1.08 & 0.18 & 1.37 & 0.20 & 3.15 & 0.97 & 14.8 & 4.39 \\
\hline KT 19 2A 7C & 3.23 & 1137 & 38.9 & 64.8 & 6.01 & 19.7 & 3.22 & 0.73 & 2.30 & 0.36 & 2.03 & 0.39 & 1.14 & 0.17 & 1.35 & 0.21 & 3.58 & 0.89 & 15.3 & 4.13 \\
\hline
\end{tabular}


Table 8 (continued)

\begin{tabular}{|c|c|c|c|c|c|c|c|c|c|c|c|c|c|c|c|c|c|c|c|c|}
\hline Element & Cs & $\mathrm{Ba}$ & $\mathrm{La}$ & $\mathrm{Ce}$ & $\operatorname{Pr}$ & $\mathrm{Nd}$ & $\mathrm{Sm}$ & $\mathrm{Eu}$ & Gd & $\mathrm{Tb}$ & Dy & Ho & $\mathrm{Er}$ & $\mathrm{Tm}$ & $\mathrm{Yb}$ & $\mathrm{Lu}$ & $\mathrm{Hf}$ & $\mathrm{Ta}$ & Th & $\mathrm{U}$ \\
\hline KT 1723 B & 3.44 & 596 & 34.4 & 52.7 & 4.64 & 14.8 & 2.31 & 0.41 & 1.71 & 0.26 & 1.51 & 0.32 & 0.84 & 0.13 & 1.10 & 0.15 & 2.56 & 1.27 & 21.6 & 7.64 \\
\hline KT 17522 & 3.45 & 601 & 34.4 & 52.9 & 4.61 & 14.7 & 2.33 & 0.40 & 1.64 & 0.27 & 1.52 & 0.31 & 0.86 & 0.13 & 1.01 & 0.15 & 2.50 & 1.22 & 21.1 & 7.73 \\
\hline KT 1909 07C & 3.44 & 622 & 34.8 & 53.5 & 4.67 & 14.9 & 2.31 & 0.43 & 1.73 & 0.27 & 1.53 & 0.33 & 0.93 & 0.14 & 1.10 & 0.16 & 2.57 & 1.27 & 21.8 & 7.86 \\
\hline KT 1924 & 3.44 & 616 & 35.3 & 53.2 & 4.69 & 14.5 & 2.34 & 0.42 & 1.65 & 0.26 & 1.63 & 0.32 & 0.93 & 0.14 & 1.09 & 0.16 & 2.59 & 1.29 & 22.0 & 8.02 \\
\hline KT 173217 & 2.63 & 656 & 39.0 & 56,5 & 4,74 & 14.5 & 2.05 & 0.29 & 1.45 & 0.20 & 1.21 & 0.24 & 0.70 & 0.12 & 0.87 & 0.14 & 2.67 & 1.32 & 28.4 & 9.74 \\
\hline KT 17 23C & 2.69 & 659 & 39.1 & 56.5 & 4.74 & 14.6 & 2.12 & 0.37 & 1.45 & 0.22 & 1.26 & 0.24 & 0.72 & 0.11 & 0.88 & 0.13 & 2.63 & 1.32 & 28.8 & 9.66 \\
\hline
\end{tabular}

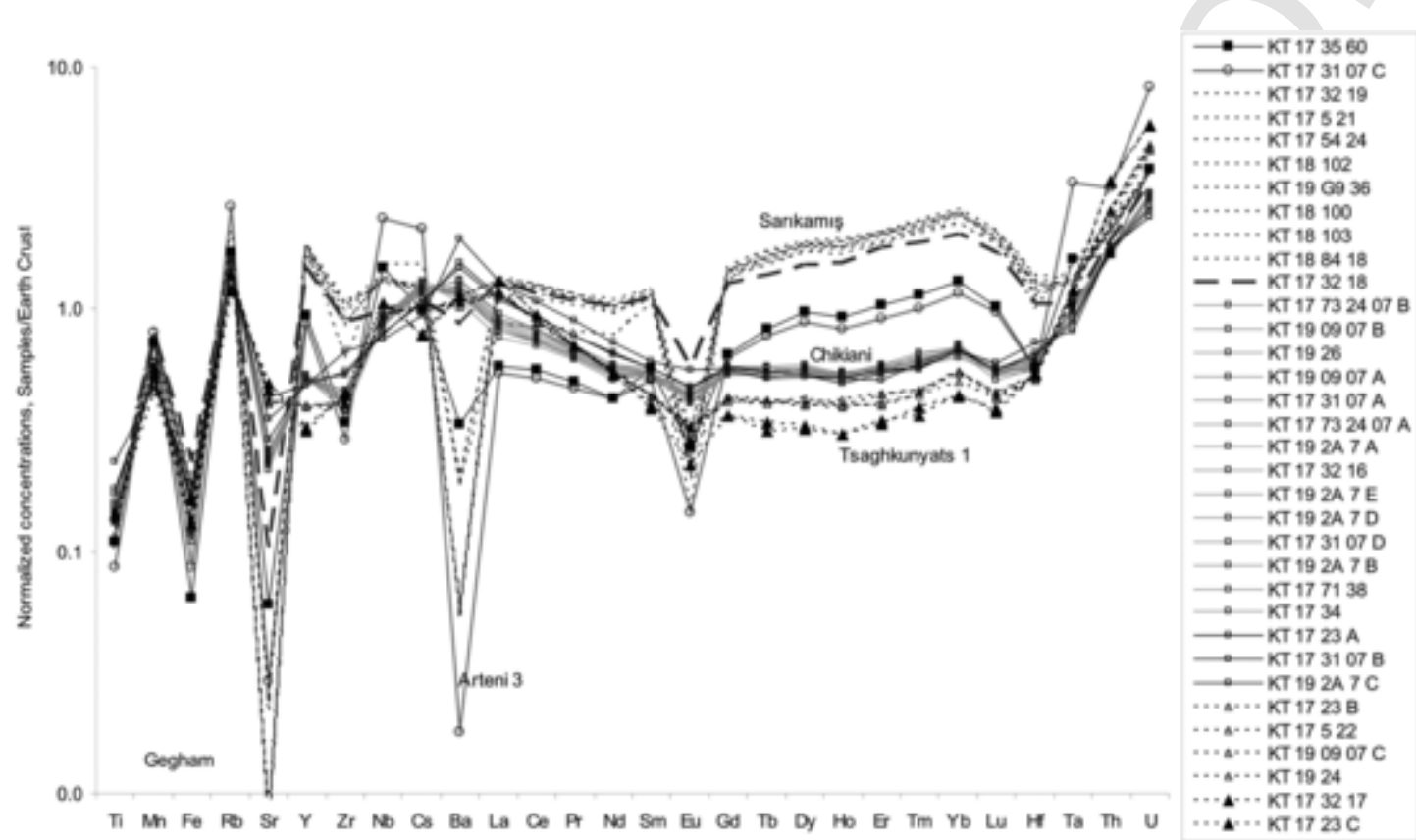

Fig. 26. Spectra of Earth's crust-normalized REE (Rare Earth Elements) values (Wedepohl, 1995) for the analysed obsidian artefacts from Kiçik Tepe (B. Gratuze).

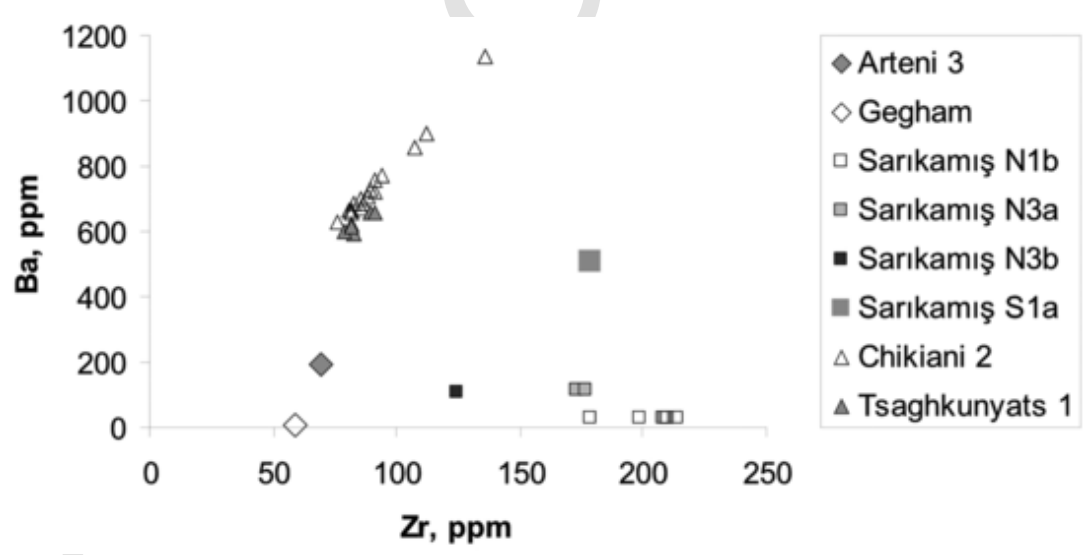

Fig. 27. Binary diagram of $\mathrm{Ba}-\mathrm{Zr}$ contents for the artefacts from Kiçik Tepe (B. Gratuze).

\subsection{Lithics in contexts}

The lithic artefacts in Kicik are overall scarce and were mostly found in backfill deposits rather than in situ suggesting that living spaces were frequently cleaned. So far, no traces of in situ workshop or hoards ('caches') have been identified. However, material directly associated with three living floors was found in STR 21 where 27 lithic elements were retrieved. On the first floor (US 152) three waste, four indeterminate fragments, two flakes and two blades were found. Among these latter, six typological tools were identified: a wedge; two pieces with lateral retouch; a reworked flake; a truncated piece with lateral retouch; and, an element with irregular retouch. On the two other floors three debris, a burin spall, two flakes and eight blades were retrieved. This material may indicate that retooling (presence of a burin spall), storage and possibly use of different blanks and tools were among the activities performed within this structure.

\subsection{Comparisons with other assemblages}

In the frame of the abundant corpus of literature on the Neolithic of the Southern Caucasus comparisons with the neighbouring sites of Hac1 Elamxanlı Tepe; Mentesh Tepe; and, Göytepe can be made. The assemblages from Kiçik Tepe and Hacı Elamxanlı Tepe (Nishiaki et al., 2013; Nishiaki and Guliyev, 2019; Kadowaki et al., 2014) share in particular the importance of the pressure flaking for the production of obsidian blade(let)s, and typological similarities such as the presence of trapezes, and burins on obsidian and the presence of sickle elements made of flint showing an oblique gloss. At Göytepe, the team collected 


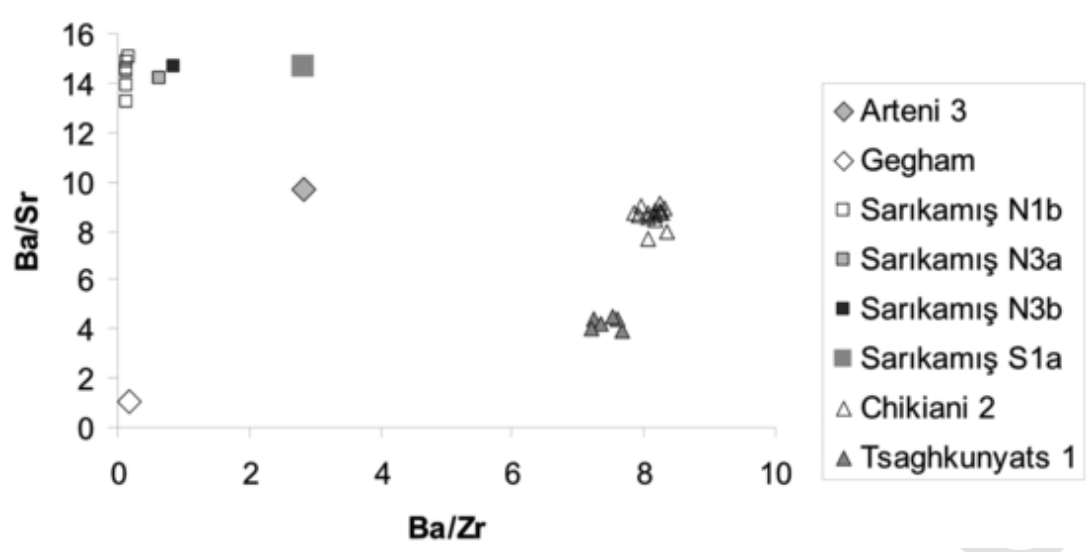

Fig. 28. Binary diagram of Ba/Zr-Ba/Sr ratios for the artefacts from Kiçik Tepe (B. Gratuze).

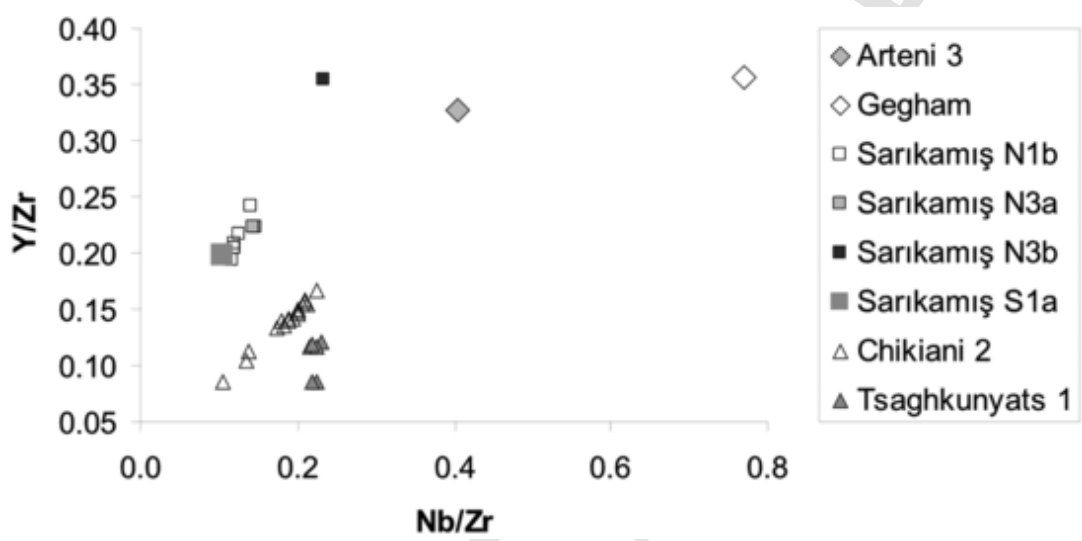

Fig. 29. Binary diagram of $\mathrm{Nb} / \mathrm{Zr}-\mathrm{Y} / \mathrm{Zr}$ ratios for the artefacts from Kiçik Tepe (B. Gratuze).

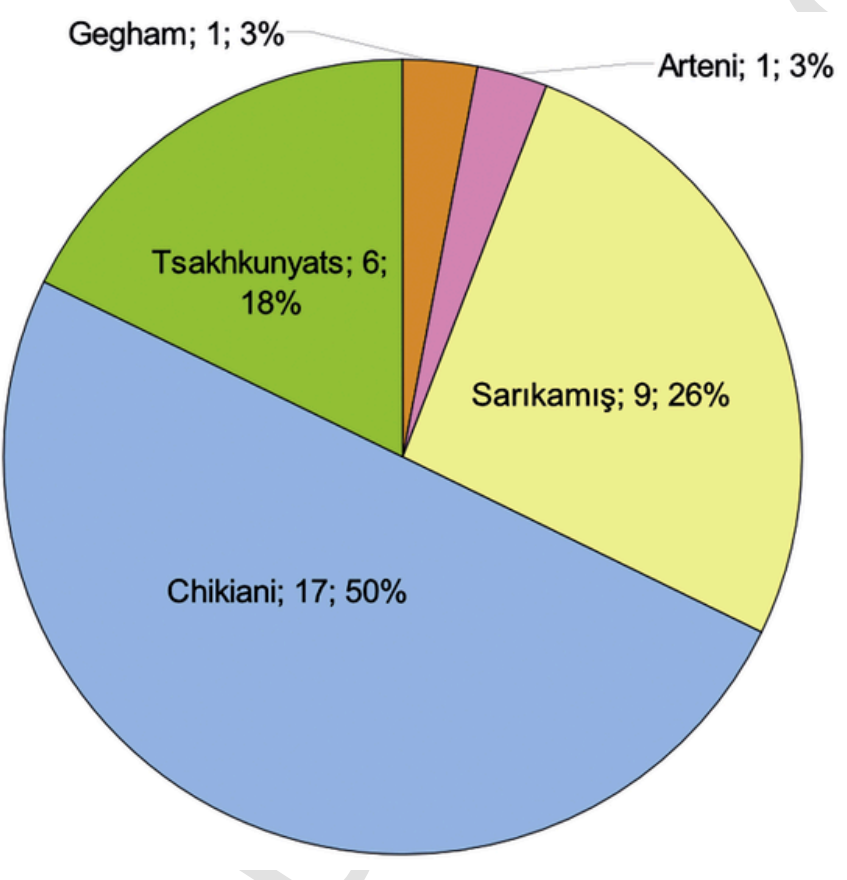

Fig. 30. Proportion of the different sources in Kiçik Tepe (B. Gratuze).

several complete composite sickles with lithic elements hafted obliquely. Similarities and differences also appear with the assemblage from Mentesh Tepe. At this site (Lyonnet et al., 2016; Guilbeau et al., 2017; Astruc et al., forthcoming), obsidian comprises $85 \%$ of the assemblage whereas chalcedony (with distinctive sickle elements with oblique gloss) represents the $12.3 \%$ of the raw material. Pressure flaking technique is consistently used for obsidian artefacts and direct percussion for chalcedony. We collected trapezes and burins at Mentesh Tepe. Here, pressure flaking with the help of a crutch is dominant but several larger blanks suggest a lever was used (as seen at Kiçik Tepe).

Crucially, although they lived in close proximity, and during a relatively restricted chronological time span, the inhabitants of the four sites have distinct strategies for the acquisition of raw material, although this may result from the fact that not all of the settlements were contemporary. For instance, we already referred to the presence of chalcedony in Mentesh Tepe where flint is nearly absent while at Kiçik Tepe chalcedony is completely absent and flint is abundant. The results of obsidian sourcing analyses in these sites also show differences in terms of provisioning patterns (though data from Hacı Elamxanlı Tepe is not yet published). Analyses from Kicik Tepe has just begun with 34 specimens (while 901 were analysed at Göy Tepe and 165 at Mentesh Tepe) and former studies showed that the greater the number of analyses the greater the complexity of patterns of exploitations (Campbell and Healey, 2018). However, in all the sites being studied, the exploitation of multiple sources is observed. These sources are located in eastern Turkey, Georgia and Armenia, but not all of the Armenian sources are present. Moreover, the procurement is very specific for each site. In Kicik Tepe, five sources are present (vs. 8 sources in Mentesh and 14 in Göytepe) and two main characteristics can be observed. Firstly, the fact that obsidian from Chikiani is the most frequent (17 specimens, 47\%), whilst Chikiani is a secondary source at other sites ( $8 \%$ in Mentesh, $8 \%$ in Göytepe). Secondly, Sarıkamış plays a major role as the second source acquired in Kicik Tepe and this matches the evidence from the nearby sites where Eastern Anatolian sources are present in the Neolithic assemblage at Mentesh tepe (54\% Sarıkamış) as well as at Göytepe (18.7\% Sarıkamış, 20\% Kars, 0.8 Ikizdere, 0.4\% Pasinler). The 


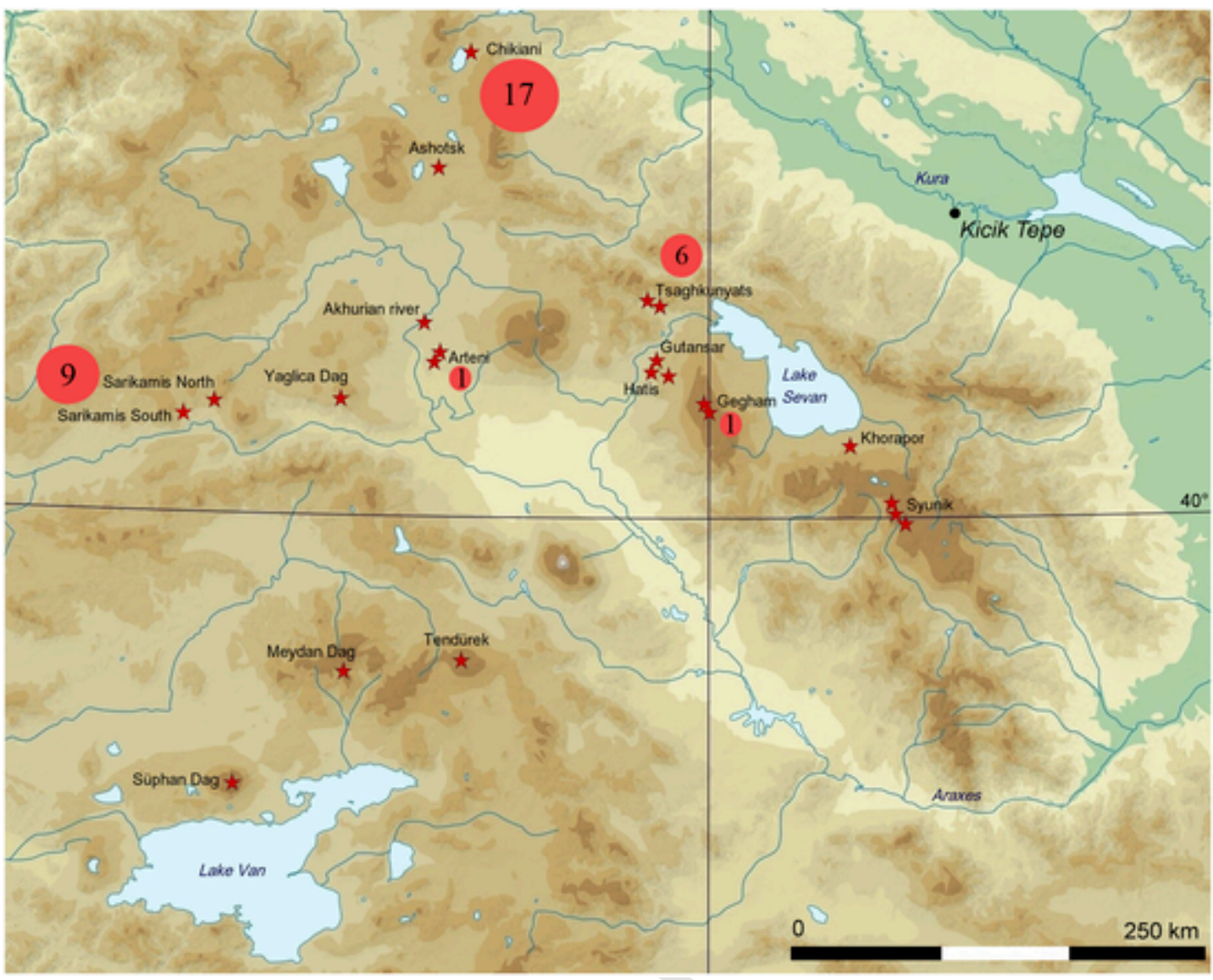

Fig. 31. Map showing the localisation of the obsidian sources exploited at Kicik Tepe (L. Astruc, B. Gratuze).

Table 9

Distances from Kicik Tepe to the sources as the crow flies.

\begin{tabular}{llllll}
\hline & Chikiani & Sarıkamış & Tsaghkunyats & Arteni & Gegham \\
\hline $\mathrm{N}$ & 17 & 9 & 6 & 1 & 1 \\
$\mathrm{Km}$ & 170 & 270 & 120 & 190 & 110 \\
\hline
\end{tabular}

results from Kicik Tepe are very interesting as they show the acquisition of Chikiani obsidian to the north-west at a middle distance along the Kura valley, and of Sarıkamıs obsidian to the west at a very long distance and could highlight the preference for a west-oriented obsidian sourcing network. As a whole, the obsidian industry from these sites features a series of common techno-typological traits. These common traits may indicate that knappers with specific skills and know-how shared and transmitted their practical knowledge in the frame of the same social entity, the so-called Shomu - Shulaveri Culture.

\section{The macrolithic tools}

\subsection{Introduction and data quantification}

The macrolithic tools dating to the Neolithic only include 15 tools excavated during the 2017 and 2018 fieldwork seasons. Tools that are typical of the regional context have been found together with more exceptional examples, possibly highlighting that there were extraregional cultural interactions which contributed to the emergence of the Shomu-Shulaveri Culture.

\subsection{Raw materials}

Most of the selected rocks are volcanic, locally available in secondary position in the terraces of the rivers that cross the foothills of the volcanic plateau to reach the Kura valley from west to east. These rocks, which would have been collected as cobbles, were exploited in different ways depending on their mechanical properties. Abrasive rocks, such as pumice, have been used as abraders or vesicular basalts as grinding tools. Compact and hard rocks, such as dense basalts or porphyric andesites, were used as hammerstones due to their resistance to shock. These observations are in complete conformity with the strategies of raw material supply, selection and use known regionally within Neolithic occupations (Hamon, 2012). More atypical rocks have been selected for three types of objects: two polished adzes in green volcanic rocks, one macehead in soft limestone and one grooved polisher on a quarzitic sandstone slab. Though rare, these rocks are also of local origin.

\subsection{Grinding tools}

Only two grinding tools come from the Neolithic levels. A quern was discovered against the wall of STR 20 (Phase 2B), in a storage area (Fig. 34).

It was a shaped-out cobble of porphyric andesite $(51 \times 21 \times 13 \mathrm{~cm})$, and secondary heating had partly altered its surface. Its sides were modeled by a series of flakings, sometimes recovered by fine pecking. Its active surface is a $4 \mathrm{~cm}$ deep basin; it is delimited by a wide edge on its proximal and distal ends. This type of ovoid and concave quern has direct comparisons at the site of Shulaveris Gora (Hamon, 2008: 94). An end of handstone in basalt found in STR 20 is narrow and quite thick, it has a plano-convex surface characterized by a levelled microre- 


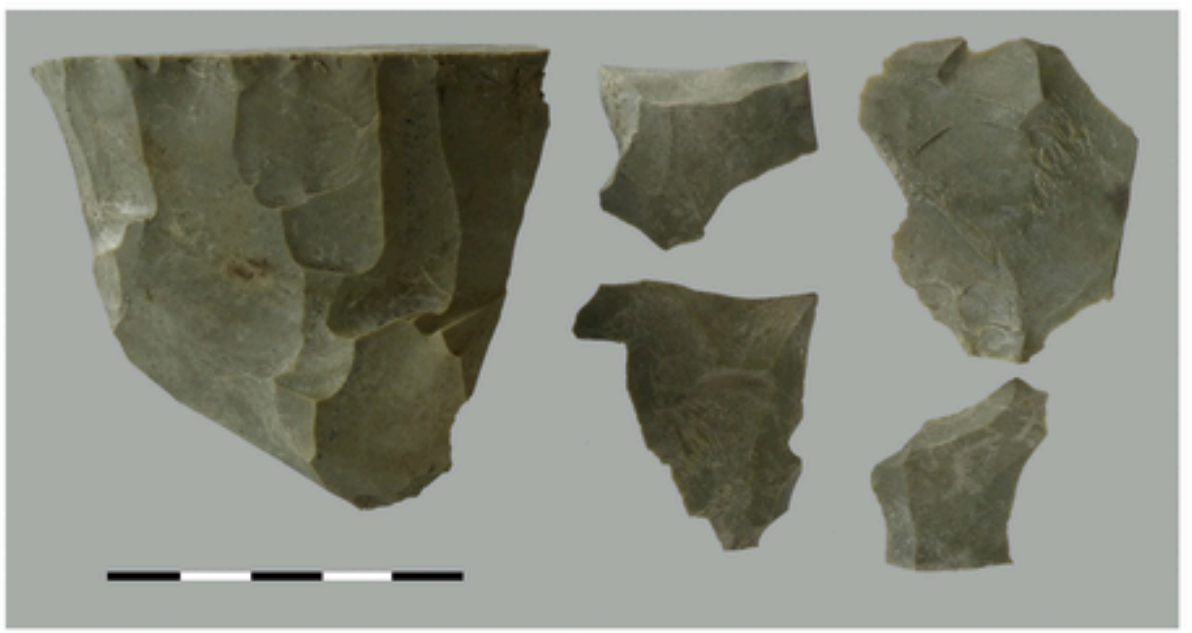

a

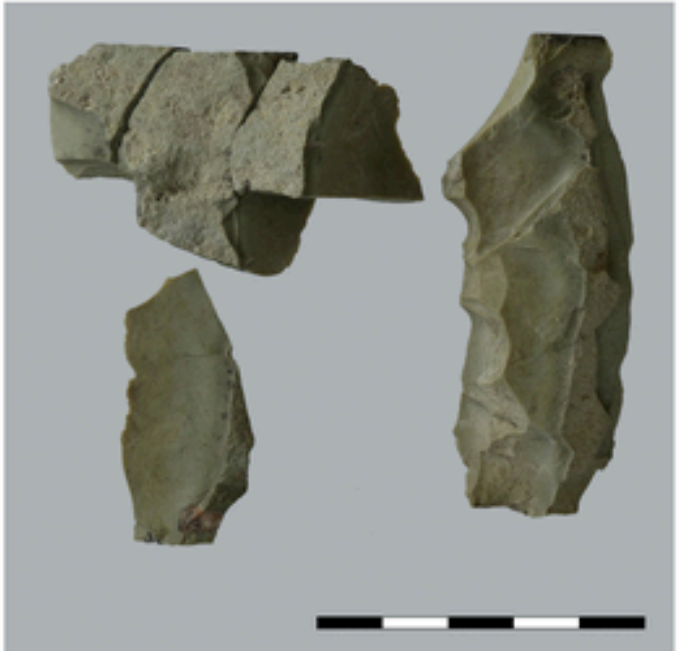

b

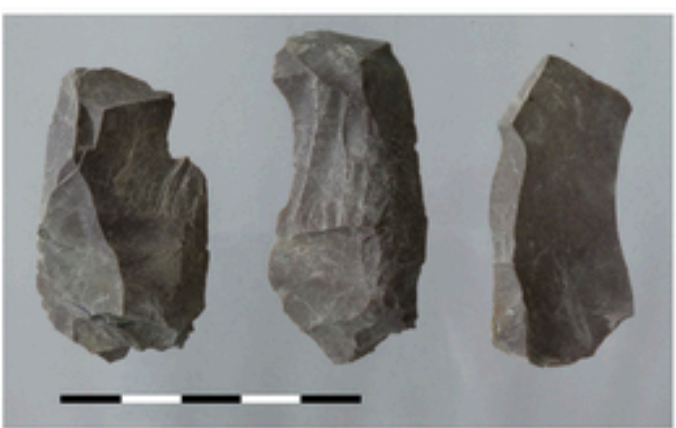

C

Fig. 32. Flint core and products from the concentrations. A. core and blanks from the same raw material (green flint). b. blanks from a second block with the refitting of three cortical flakes (green flint). c. Three flakes (purple flint) (L. Astruc). (For interpretation of the references to colour in this figure legend, the reader is referred to the web version of this article.)

lief, and fluid and covering smoothing, which is characteristic of cereal grinding.

\subsection{Hammerstones and retouchers}

Three hammerstones were found in both the Neolithic phases of occupation. One of them is made of dense basalt and has evidence of coarse impacts of percussion on its two large ends. A discoid hammerstone displays a 1 to $2 \mathrm{~cm}$ wide stripe which is finely pecked and abraded on its side. These zones were preformed by bifacial debitage. Another discoid hammerstone in dense basalt presents similar characteristics. On the center of each of its faces, a circular central zone shows small impacts of percussion covered by residues of red coloring. This kind of tool is commonly widespread in the Shomu-Shulaveri sites of the Kura valley (Hamon, 2008: 99). A cobble of small dimensions has on its distal part a very limited circular zone of fine percussion and abrasion. It may be a retoucher used for lithic debitage, though the ephemerality of the traces does not allow any further functional interpretation.

\subsection{Abrader-pestle and smoother}

An abrader-pestle in pumice is hammered and abraded on four of its faces, while its concave surfaces are marked by a concentration of coarse impacts of percussion on its ends. This kind of tool is documented, but rare, in the Kura basin (Hamon, 2008: Fig. 3e). The fragment of a smoother on an oblong cobble has a flat bevelled zone on its end; its position and morphology closely resembles tools used for ceramic manufacturing.

\subsection{Grooved polishers}

Two exceptional grooved polishers were found one on the top of the other just north of STR 11 dating to Phase 3 (Fig. 10; Fig. 35) .

The first one is a quadrangular slab in fine quartzitic sandstone on which a transversal groove with "u" section was carved (Fig. 36a).

Its back as well as its sides have been smoothed by manipulation, associated with random microimpacts and short microstriations. The bottom of the groove has a covering and very shiny smoothing, associated to a strong levelling of the sandstone grains and to longitudinal microstriations cut by fine oblique ones. The second polisher was made from 

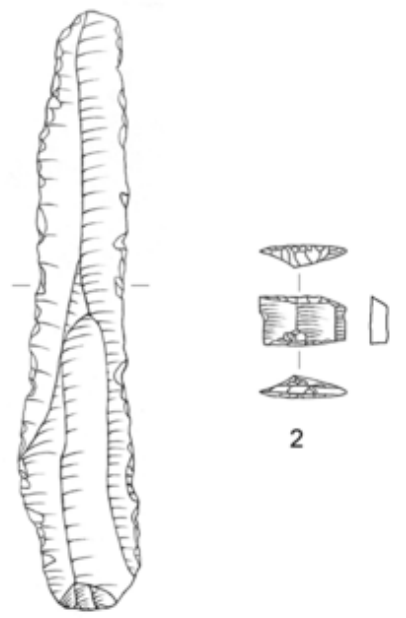

2
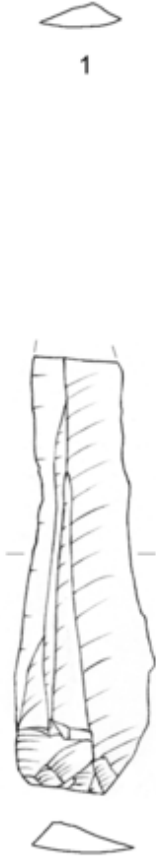

4
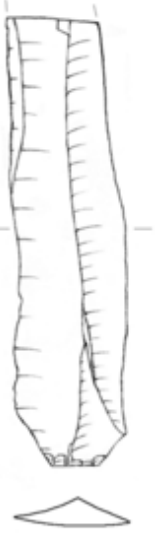

5
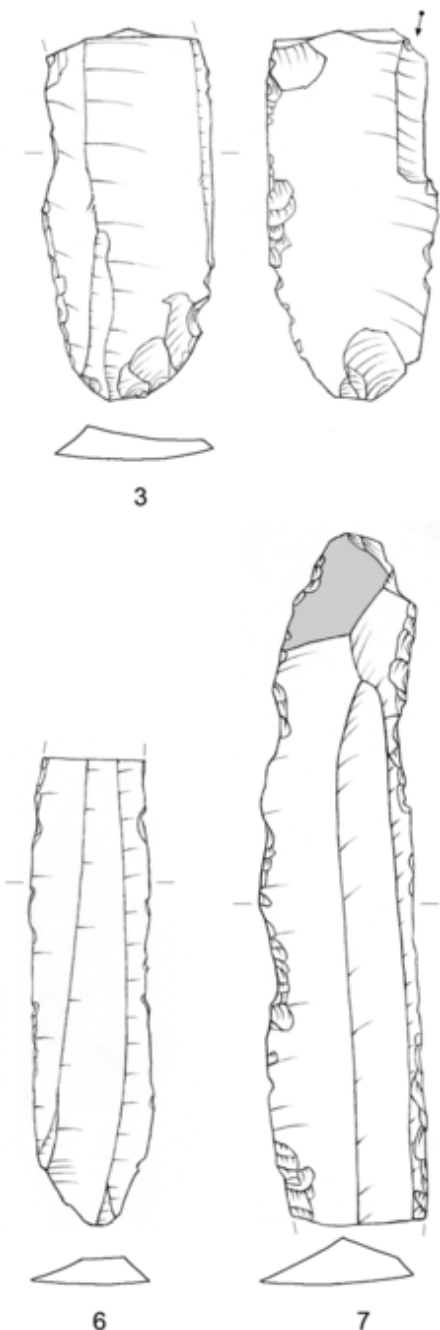

6

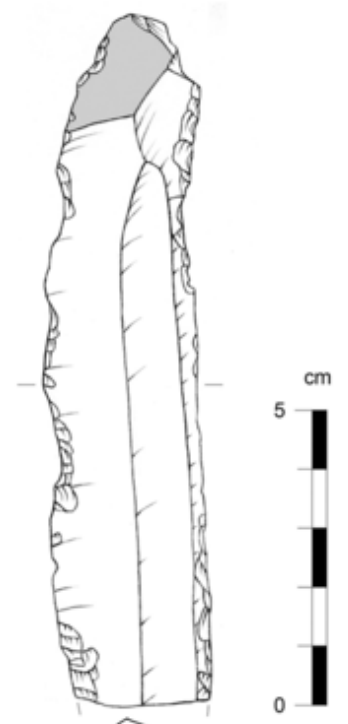

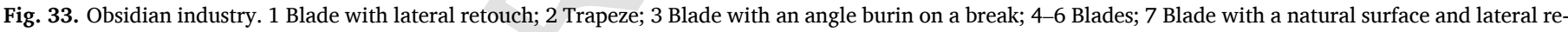
touch. (1, 5, 7 from Chikiani 2; 3, 6 from Sarıkamış North; 4 from Tsaghkunyats 1) (L. Astruc).

Table 10

Technological breakdown of the obsidian artefacts analysed by LA-ICP-MS.

\begin{tabular}{llllll}
\hline & Flake core & Flake & Tablet & Blade $<24 \mathrm{~mm}$ & Blade $>24 \mathrm{~mm}$ \\
\hline Arteni & & & & 1 & \\
Chikiani 2 & & 2 & 1 & 10 & 1 \\
Chikiani 3 & & & & 3 & \\
Gegham & & & & & 1 \\
Sarkkamış & 2 & 1 & & 5 & 1 \\
Tsaghkunyats 1 & & & 1 & 4 & 1 \\
Total & 2 & 3 & 2 & 23 & 4 \\
\hline
\end{tabular}

an ovoid basalt cobble and has a longitudinal and curvilinear groove. Its external surface was regularized by fine and random pecking, and also smoothing due to manipulation. The "u" section groove has a flat bottom. It was pre-formed by a very fine pecking, still visible on the highest part of the groove (Fig. 36b). The shine is associated with black residues deposited at the bottom of the groove; it has a micropitted and shiny micropolish. The upper parts of the two polishers were altered by heating. Microscopic traces observed on the bottom part of the grooves
Table 11

Typological breakdown of the lithic tools.

\begin{tabular}{lll}
\hline & Obsidian & Flint \\
\hline Trapeze & 1 & 0 \\
Burin & 16 & 0 \\
Scraper & 2 & 0 \\
Notch & 2 & 0 \\
Wedge & 24 & 0 \\
Lateral retouch & 35 & 2 \\
Irregular retouch & 10 & 0 \\
Backed piece & 0 & 4 \\
Truncation & 9 & 1 \\
Truncation/sickle & 0 & 1 \\
Sickle & 0 & 6 \\
Reworked flake & 1 & 0 \\
Hammer & 0 & 1 \\
Total & 100 & 15 \\
\hline
\end{tabular}




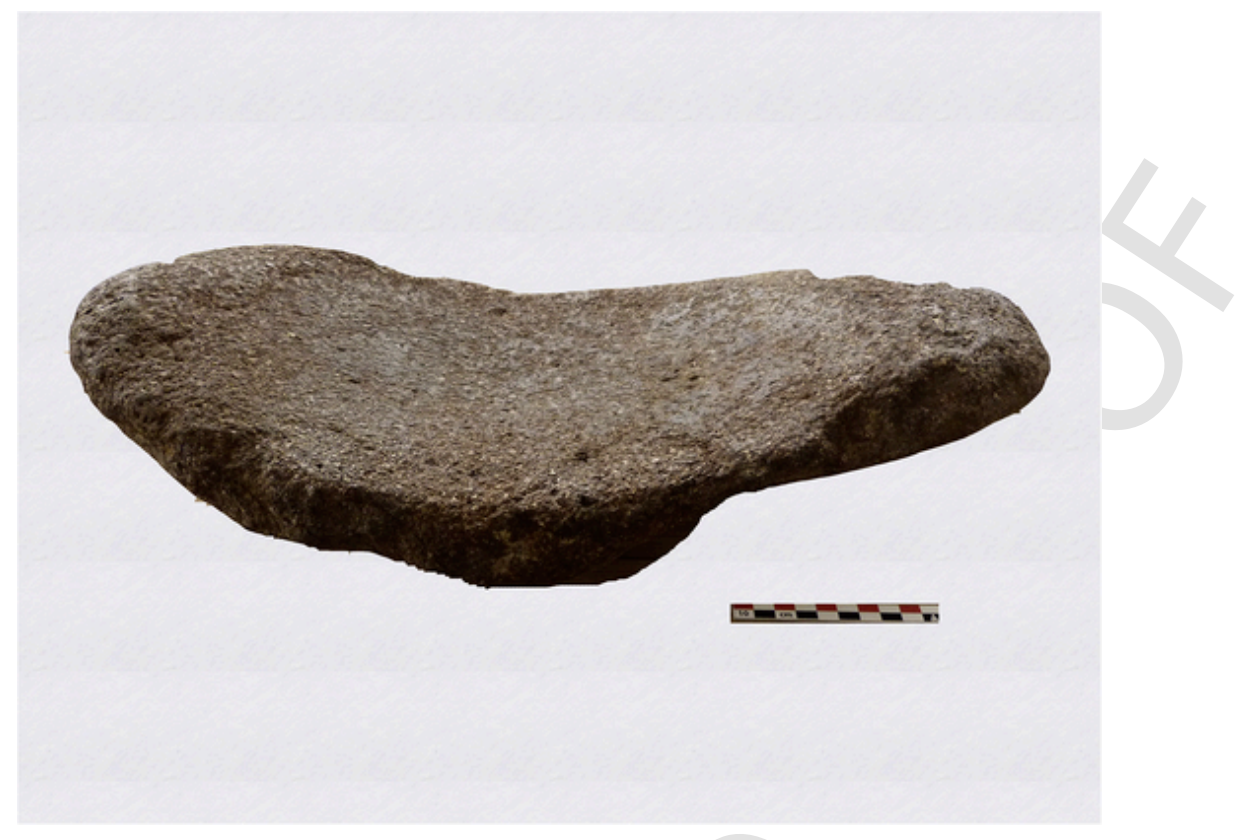

Fig. 34. Concave quern in porphyric andesite with proximal and distal edges (C. Hamon).

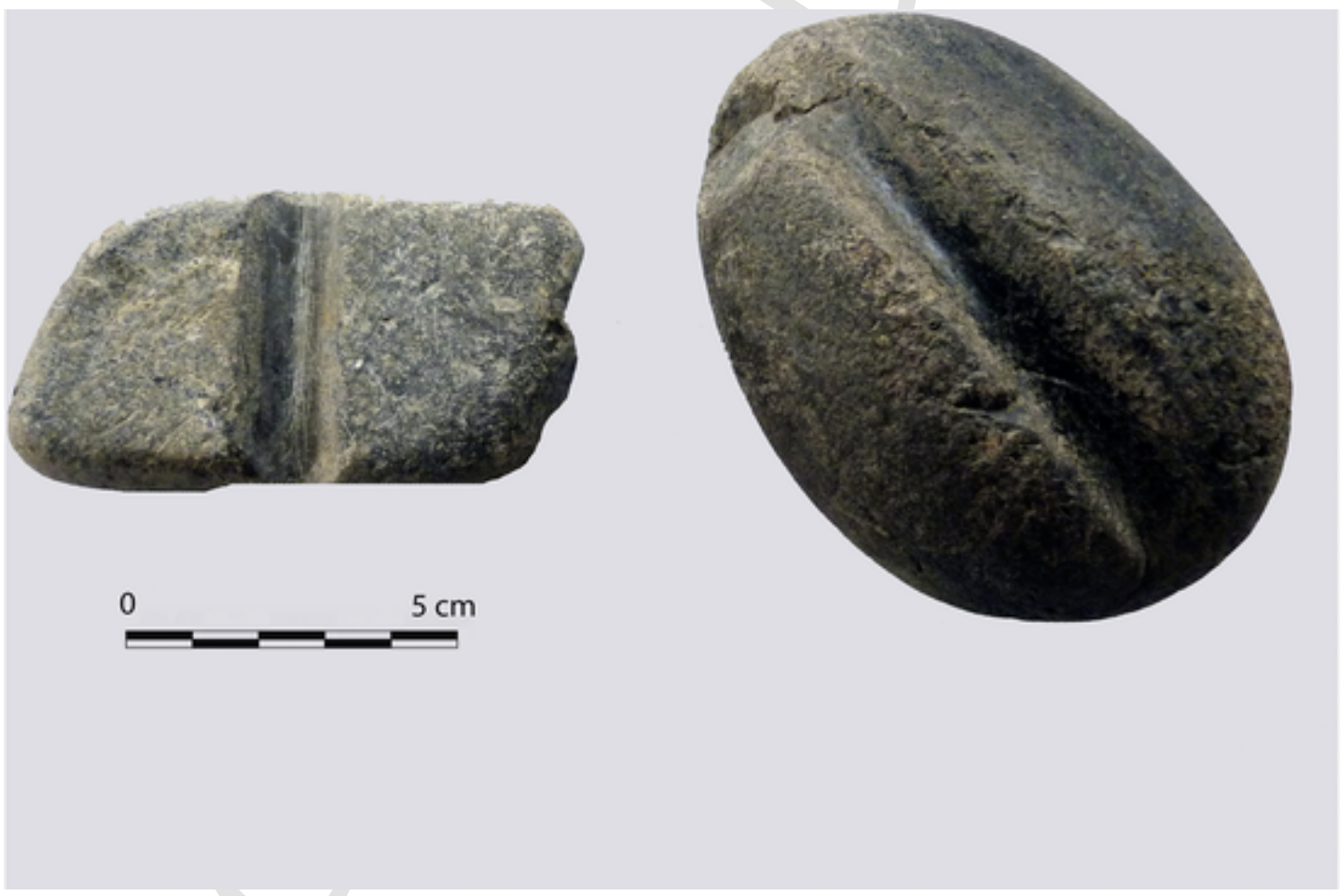

Fig. 35. Grooved polishers from STR 1 (Phase 3) (C. Hamon).

of these two objects suggest an action of longitudinal polishing of a cylindrical object in hard, probably mineral, matter with water adjunction. There are very few comparisons to these tools in the Kura valley. Transverse grooved polishers comparable to the one in Kiçik Tepe were found at the neighbouring site of Hacı Elamxanlı (Nishiaki et al., 2015b), as well as at other sites of the Kura valley, such as Imiris and Khramis Didi Gora (Kiguradze, 1986: Fig. 18 n², Fig. 11.m, Fig. 17.f). This type is also reminscent of some examples from the site of Aknashen in the Ararat valley (Badalyan et al., 2007: Fig. 7; Badalyan et al., 2010: Fig. 13). In contrast, no longitudinal grooved and curvilinear abraders are known in Southern Caucasus. This type is present from the PPNA in the Levant and western Mesopotamia as well as at Körtik Tepe in East- ern Anatolia (Özkaya and Coşkun, 2011), but absent from NorthEastern Mesopotamia and the Zagros (Arimura et al., 2010). The presence of this object in Kiçik Tepe is completely new for the South Caucasus and would indicate some close relationships with regions located to the south-west of the South Caucasus.

\subsection{Adzes}

Among the well-shaped objects found at Kiçik Tepe, three small polished adzes of less than $10 \mathrm{~cm}$ feature a trapezoidal shape and thin ovoid section. One of them, found in STR 1, was made out an andesite cobble: it shows a semi-covering polishing of pecked surfaces, and its 

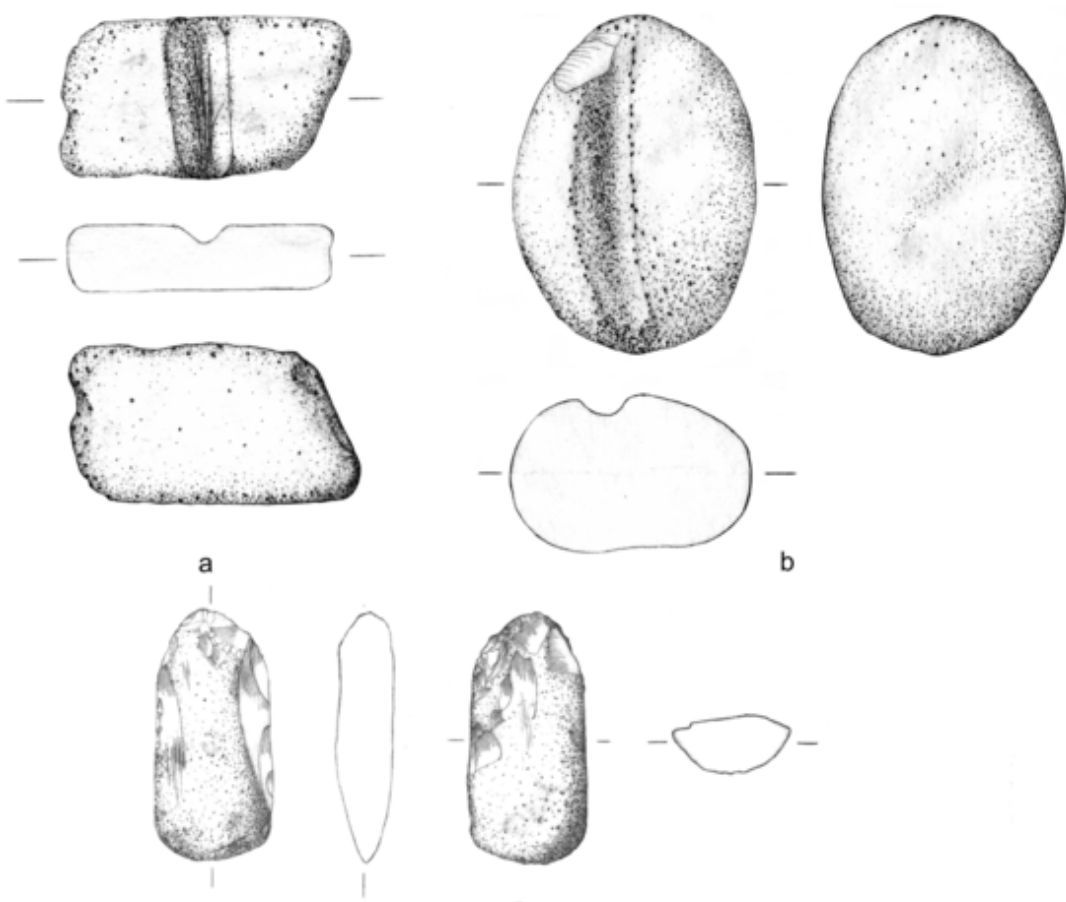

b
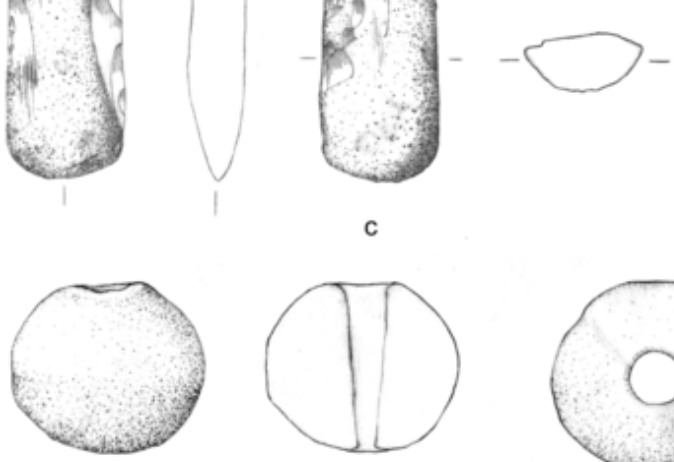

Fig. 36. Grooved abraders a. quadrangular and thin slab of hard sandstone with tranverse groove, b. ovoid cobble of sandstone with longitudinal groove, c. adze out of cobble with fine pecking, d. macehead in soft limestone (drawings by K. Schmitt and M. Poulmarc'h).

edge is broken. An adze from STR 8 was made of a flake of green microgranular volcanic rock and was in the process of being reshaped. Its ends are completely microflaked, while several lateral flakes attest of shaping stages before polishing (Fig. 36c). Finally, a fragment of volcanic cobble from STR 4, pecked on its lateral side, could be a fragment of adze roughout. Again, these adzes completely fit with the type of polished tools found in the Kura valley, in terms of size, typology and raw material (Hamon, 2008).

\subsection{Perforated macehead}

A spherical and perforated macehead in soft limestone (Fig. 36d) is flattened on its ends with a mesial hull. It was shaped by fine pecking, though this is barely visible under the altered surface. The technique of perforation remains difficult to determine, but it seems that the perforation was made in one single episode through the whole thickness of the object, from the widest of the two openings $(1.5 \mathrm{~cm}$ diameter) to the narrowest $(0.5 \mathrm{~cm}$ diameter). This type of macehead is relatively rare but regularly mentioned in the Shomu-Shulaveri Culture in the Kura valley: in Shulaveris Gora (Kiguradze, 1986: Fig. 18.1, 29), Aruchlo (Hansen, 2011: Figs. 38, 36, Imiris Gora and Khramis Didi Gora. They are made of sandstone, basalt and limestone (Hamon, 2008: 105). Their possible function, as utilitarian or symbolic tools, still remains enigmatic. This type of maceheads is known in other near-eastern regions: such simple maceheads in limestone are for example well known in the PPNC, Yarmukian and Pottery Neolithic sites in the Levant (Rosenberg, 2010).

\subsection{Considerations on the macrolithic tools}

Considering the extension of the excavated domestic area, the macrolithic assemblage appears very poor in quantitative terms in comparison to other assemblages of the region (Hamon, 2008). Two explanations can be provided on this observation. The first is that the low quantity of macrolithic assemblages could mirror the short lifetime of the houses, though this contradicts the observations made for other categories of materials. The second explanation is related to the recovery of stone implements as raw material and blanks for further reuse before or after the abandonment of each phase of occupation. This latter hypothesis has already been suggested for other contemporary sites of the Kura valley such as Gadachrili Gora (Hamon et al., 2016).

Despite the relative paucity of macrolithic tools in the Neolithic occupation, some specific characteristics can be identified for each phase. Phase 3 is characterized by at least three categories of tools that find parallels with the Araxes valley and beyond the regions of Southern Caucasus. The two grooved polishers and the macehead in limestone suggest influences from Eastern Anatolia, and possibly Western Mesopotamia and the Levant in the earliest Neolithic occupations of the Kura valley. The tools from the following Phase 2 present a more clearly domestic composition, such as the two grinding tools, the hammerstones and the adzes. During this phase, macrolitihc tools share regional features with tools typically found in the Shomu-Shulaveri cultural sphere. 


\section{Pottery}

\subsection{Quantifation of the ceramic finds}

After three years of excavations, the number of ceramic fragments retrieved from structures and layers excavated from Phases 3 and 2 is very limited and consists of 51 sherds accounting for a total weight of $1691 \mathrm{~g}$. (Table 12). In spite of the small size of the data set, the quantitative distribution of the ceramics throughout the sequence is unequal and shows a low progression from the earlier to the later phases (Table 12).

Phase 3, which is the earliest, is the one with the least number of ceramic finds. Quite interestingly, ceramics were only found in STR 21 and not, as it could have been expected, in STR 2 which was equipped with a series of fire installations. The ceramics from STR 21, however, were not found on the floor but in the backfills of the structure. One sherd, consisting of the rim of a small hole-mouth jar was found in the layer of ash and charcoal covering the floor (US 143), while six fragments of a large bowl were found among the burnt branches of the collapsed roof, thus suggesting that the pot could have been on the top of it at the moment of the destruction of the building. The quantity of ceramic finds increases in the following Phase $2 \mathrm{~A}$ that was excavated for an area equivalent to that of Phase 3 . The total number of ceramic sherds is 23 fragments corresponding to a minimum number of six vessels. It is worth noting that at least two of these vessels were in direct spatial connection with a fire-pit (Fy8), thus clearly highlighting the functional connection between fire-installations, ceramic containers and cooking activities. As concerns the following levels $2 \mathrm{~B}$ and 2C, even if the exposed surface is much larger than that of the previous occupations, the number of ceramic fragments does not increase proportionally. Conversely, it remains basically the same (21 units corresponding to a minimum number of seven vessels).

When interpreting this data according to the absolute chronological dates from the stratigraphic sequence at Kiçik Tepe, the following considerations can be made: regarding Phase 3 , which the absolute dates allow to place in the $5870-5775 \mathrm{cal}$ BC time-span, the very sporadic occurrence of ceramics mirrors analogous data from the nearby settlement of Hacı Elamxanl1 (21 fragments throughout the entire excavated sequence) and from the lowest levels at Shulaveris Gora in the Kura River valley (Kiguradze, 1986: 16-19). A similar picture was also observed in the earliest occupation horizons at Aknashen and Aratashen dating to the beginning of the 6th millennium BCE where there were few ceramic finds, which were mainly painted and presumably imported (Harutyunyan, 2014). Data from Phases 3 and 2A at Kiçik Tepe confirms this trend; the initially scarce evidence of the use and production of ceramic containers during the Early Neolithic in the South Caucasus gradually increases, with increasing numbers of sherds found as we move from Phase 3 to 2 . As concerns the following levels $2 \mathrm{~B} / \mathrm{C}$, dated to $5830-5720$ cal BC time-span, a larger scale use and production of the ceramics is seen throughout the region in this period, for example at the nearby settlement of Mentesh Tepe (Lyonnet et al., 2016) ${ }^{3}$, at several other settlements of the Kura River valley, such as Aruchlo (Bastert-Lamprichs, 2017) and in the Ararat plain (Harutyunyan, 2014). This is why the rarity of the ceramics from Levels $2 B / C$ at Kiçik Tepe might have a different explanation from that provided for the previous phase. As observed earlier, the low occurrence of ceramics from levels $2 \mathrm{~B} / \mathrm{C}$ mirrors the generalized scarcity of findings in these two levels which may result from the deliberate abandonment of the settlement. This depositional behaviour could have also applied to the ceramic vessels which may have been collected before the site's abandonment thus following the displacement of their owners.

\footnotetext{
3 The Neolithic ceramic sherds at Mentesh sum up to 1157 pieces; however, "Most of it comes from a large dump pit or from fills and only a few sherds have been found in situ" (Lyonnet, 2017b, 141).
}

Table 12

Quantification of the Neolithic ceramics at Kiçik Tepe per phase.

\begin{tabular}{lll}
\hline Phase & Nr. of Fragments & Weight in g. \\
\hline Phases 2B/C & 21 & 347 \\
Phase 2A & 23 & 1057 \\
Phase 3 & 7 & 287 \\
Total & 51 & 1691 \\
\hline
\end{tabular}

8.2. Morphological and technological remarks on the Neolithic ceramics of Kiçik Tepe

Most of the 54 ceramic fragments comprise body sherds of close shaped containers; however, five diagnostic pieces have been found in Phase 2 and two in the lower Phase 3 . The better-preserved pieces from Phase 3 are the rim and upper body part of a medium size holemouthed jar with simple lip (Fig. 37a) and a large fragment of a rather big open-shaped container with simple lip (Fig. 37b). Both pots are handmade and fired in an oxidising atmosphere; wall thickness is irregular so is the rim's height, pointing to low skill levels of these early potters.

The hole-mouthed jar is heavily tempered with fine and elongated organic material (Fig. 38:a-b); very few mineral inclusions are visible together with some silver-coloured mica. Along the profile three coils 2.5 to $4 \mathrm{~cm}$ high are visible; a similar technique characterises Hac1 Elamxanlı pottery (Nishiaki et al., 2013: 11). This jar was slightly burnished on the external side, while the original internal surface is largely missing. The largest preserved piece of this jar has two holes close to each lateral break. We believe that these are evidence of repairs, as they have been drilled post-firing and are located near two breaks.

This kind of simple, closed bag-shaped container with inclined walls is very common in the Neolithic of the Southern Caucasus, as it is subsequently present at Goy Tepe (Alakbarov, 2018: Fig. 7a-c; Fig. 8;); at Mentesh Tepe (Lyonnet, 2012: 97; Lyonnet et al., 2016: Fig. 9.3-4; 2017b: 142); at Aruchlo in larger dimensions (Bastert-Lamprichs, 2017: Fig. 1.5-8 and 4.1-4); with an applied horizontal band at Kül Tepe I (Nakhchivan) in the Neolithic level 2 (Marro et al., 2019: fig. 15.4); and in both the two ceramic horizons of the Mil Plain, namely at Kamiltepe (Aliyev and Helwing, 2009: Fig. 14; D'Anna, 2012: fig. 45-46, fig. 50), and as cooking pots at MPS 4 (Helwing and Aliyev, 2017: Fig. 38), MPS 5 (see D'Anna, 2012: fig. 57), and MPS 103 (D'Anna, 2017: Fig. 7). As to the bowl from Phase 3, the fabric is brown to light brown (7.5YR 6/4) and reddish yellow (5YR 6/6) in colour, it is heavily tempered with 2 to $3 \mathrm{~mm}$ large, oval organic matter, highly visible on the external surface (Fig. 38:c). This material seems to be the same used at Mentesh Tepe in the group 1 Neolithic pottery, identified as poaceae seeds (Lyonnet, 2017b: Fig. 2); however, in this piece they seem larger. Very sparse, subangular dark grey grits are also present, but they might have been a natural component of the clay. This piece is more uniformly burnished and the cross section is completely oxidised. At Hac1 Elamxanl, one large deep bowl has been found (Nishiaki et al., 2013: Fig. 21.3), and at Mentesh, too, at least one large bowl with slightly closing rim is attested (Lyonnet et al., 2016: Fig. 9.1); interestingly this pot shows profound abrasions in the inner side which might testify to its use in pounding. At later sites, the assemblage of open shapes becomes more varied (Alakbarov, 2018; Aliyev and Helwing, 2009; D'Anna, 2012). From Phase 2A (Fig. 39) there is a fragment of a singularly-shaped jar with part of its opening closed with clay turned from the rim into the opening at a sharp angle. This piece is pinkish buff in colour; its paste is relatively fine and was tempered with thin, elongated organic inclusions; the external surface is smoothed and, in some points, burnished or at least regularized when the clay was in the leather hard state. Fir- 


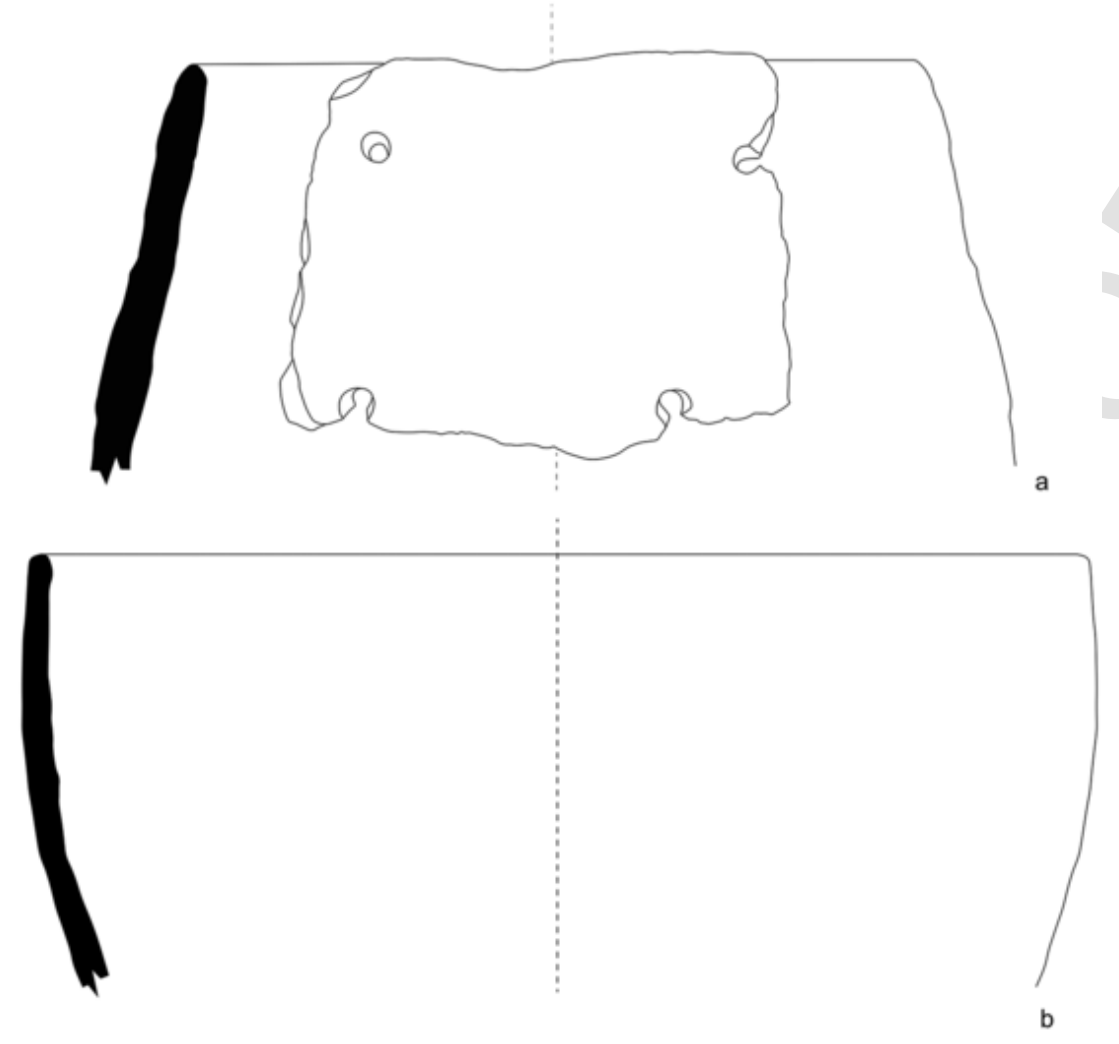

Fig. 37. Phase 3 pottery: a. fragment of a hole-mouthed jar with reparation holes; b. large bowl (drawings by K. Schmitt, archive Mission Boyuk Kesik; scale $5 \mathrm{~cm}$ ).

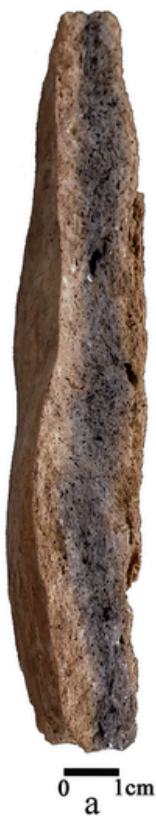

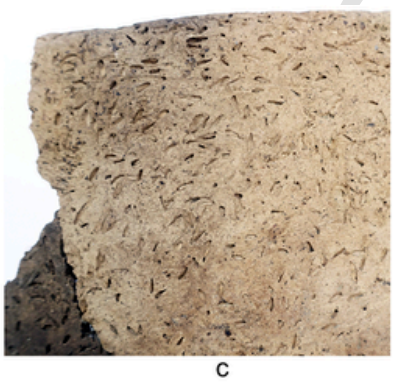

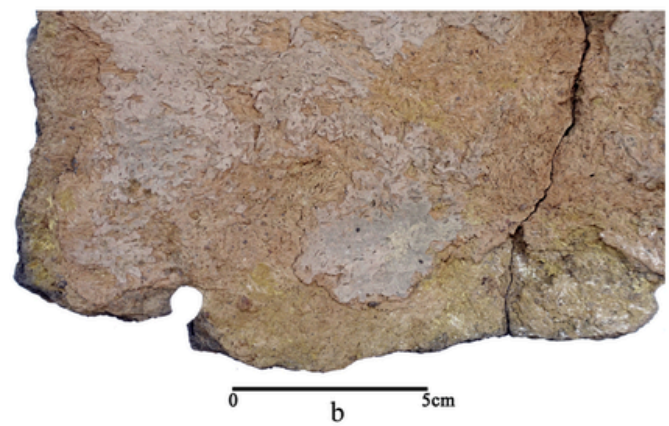

Fig. 38. Cross section of the Phase 3 hole-mouthed jar and close up of the internal surface (a-b); close up of the Phase 3 bowl showing imprints of poacee seeds (c, not to scale) (Mission Boyuk Kesik MEAE).

ing completely oxidised the piece. This shape can be compared to pieces from Neolithic Mentesh Tepe (Lyonnet, 2017b: Fig. 3a-c, 4a-b). ${ }^{4}$

It is important to stress that so-far mineral tempered and painted exemplars recalling the Halaf or Samarra painted ceramics, analogous to those found at Hacı Elamxanlı (Nishiaki et al., 2013) and also at Aratashen and Akhnashen in the Ararat plain (Harutyuniyan, 2014)

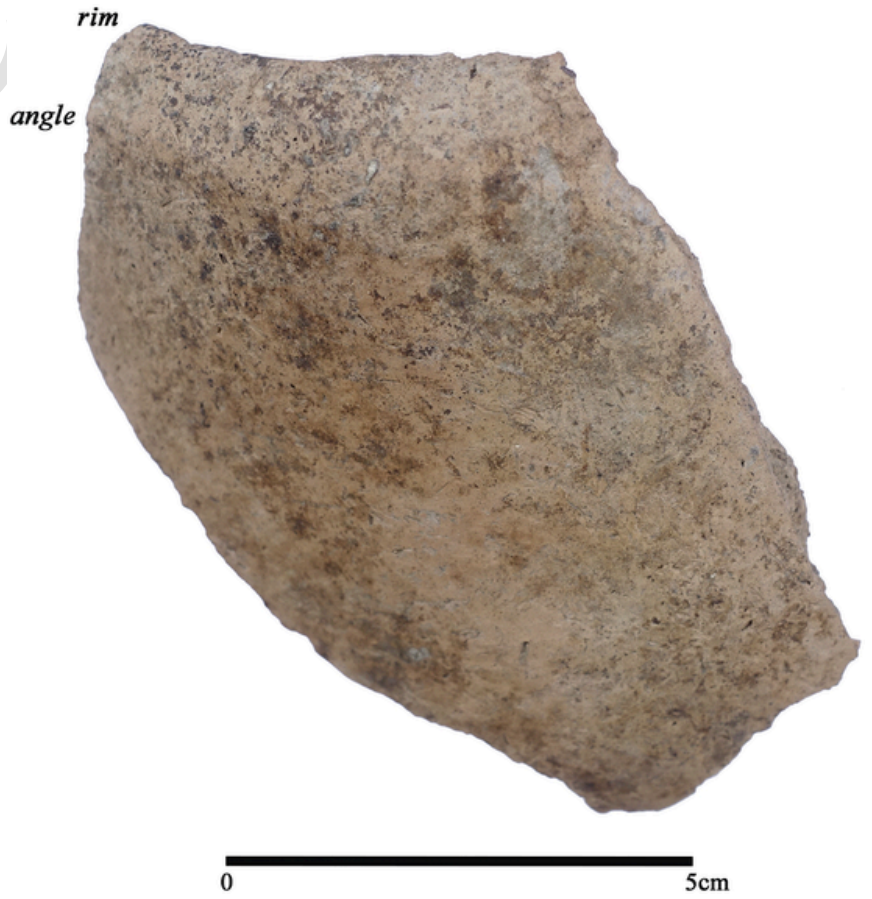

Fig. 39. Fragment of a small jar from Phase $2 \mathrm{~A}$ with rim folded in the opening (Mission Boyuk Kesik MEAE).

\footnotetext{
${ }^{4}$ A similar shape, but with a smoothed angle of the inward rim, has been found at all the investigated Neolithic sites of the Mil Plain (see for example D'Anna, 2017: Fig. 12a; Helwing, 2017: Fig. 39; Ricci, 2012: fig. 178).
} 
and finally at Kültepe I (Abibullaev, 1982) that were presumably imported from Upper Mesopotamia or Eastern Anatolia, were not found at Kiçik Tepe. Altogether, the few Neolithic pottery fragments from Kiçik Tepe form a rather homogenous assemblage of mainly or exclusively vegetal tempered ceramics; their colour varies from pinkish to light brown; firing occurred always in oxidising atmospheres, but it often results uneven with dark grey cores commonly observable. Only in two cases the vegetal tempering material was identified as coarse chaff. In contrast, in most sherds abundant fine, elongated vegetal matter is observed, while few pieces present small circular or oval-shaped voids, at times with a central veining that might be poaceae seeds as the ones attested in the Neolithic phase 1 ceramics of the nearby Mentesh Tepe. This peculiar tempering material was possibly also used at Hacı Elamxanlı Tepe, where "grains" are reported together with chaff in the vegetal-tempered ware (Nishiaki et al., 2013: 11). However, ceramic raw materials at Hacı Elamxanlı are much more varied, as most sherds are tempered with a variety of minerals, using a variety of surface finishes.

A few body sherds from Phase 2B-C have evidence of soot or carbonisation, pointing to the use of some ceramic pots to cook on the fire. At Hac1 Elamxanl1, fragments of both mineral and vegetal tempered containers show "often traces of secondary firing" (Nishiaki et al., 2013: 11), as if cooking in pots there was relatively more common than at Kiçik. Bringing together all these elements, the resulting picture is that of communities that started to make and use ceramic small and medium size containers occasionally, mainly used for foodstuffs, more likely to be liquid or semi-liquid than dry. The only bowls found both at Kiçik Tepe and at Hacı Elamxanlı are large deep containers that may have been used for communal food consumption, as well as in food preparation practices such as mixing, crushing or kneading. At Kiçik Tepe only vegetal matters were mixed with clay, but it seems that they were using different plants or plants' parts; surface finishing is mainly dry smoothing.

The technological differences with Hacı Elamxanlı Tepe seems to indicate that this early pottery Neolithic phase in the region is characterized by a rather high degree of experimentations at a very local scale. Hacı Elamxanlı Tepe is located at close distance to Kiçik Tepe, and the low numbers of sherds found there mirrors the paucity of ceramic containers on our site, not to mention the close chronology of the two occupations. However, the pot makers at the two sites experimented in very different ways, more creatively at Hacı Elamxanl,, while an explicit choice to use exclusively vegetal tempering was made at Kiçik Tepe as it is further corroborated by the evidence from Mentesh Tepe.

\section{Results and discussion}

The excavations at Kiçik Tepe have brought to light a sequence of occupation stretching between 5870 and $5720 \mathrm{cal}$ BCE at the maximum of 2 sigma level of confidence. Phase 3 at Kiçik Tepe contains some of the earliest evidence of Neolithic occupations in the Kura River valley. The exceptional preservation of the architectural remains allows us to put forward a reconstruction of buildings with flat roofs held up by wooden posts, as well as analyse the spatial distribution of activities carried out both indoors and outdoors. The abundance of in situ materials and architectural features highlights a certain degree of functional differentiation between the circular buildings where activities linked to daily subsistence took place and others with evidence of artefact production. The spatial segregation of these activities appears to be linked to a new concept of circular Neolithic "house". This represents, a new spatial and physical focus for the productive and reproductive activities in South Caucasian Neolithic households. This model was hypothesised for the Neolithic houses of the Near East where this concept of house had already developed at least two millennia earlier than in the South Caucasus (Hodder, 1990).

During the following phase (2B) the functional differentiation is even more clear with a sharp dimensional hierarchy between buildings.
Furthermore, the large area excavated of Phase 2B levels allowed us to identify circular clusters of buildings that we have defined as "protocompounds". These could represent an intermediate stage in the evolution of the architectural models observed among the Shomu-Shulaveri communities of the Kura River valley consisting of the incorporation of the "archaic" snowman free-standing module into a larger circular compound composed of more buildings. Stratigraphic data point to the fact that this intermediate stage should be placed in between the early freestanding bicellular snowman shaped modules and the later multicellular walled and closed compounds like the one documented at Kiçik Tepe in Phase 2C. The "proto-compound" at Kiçik Tepe demonstrate that the change from snowman to walled compound was not abrupt. Also the identification of similar "proto-compounds" at Gadachrili Gora (Hamon et al., 2016: 158, Figs. 5-6) confirms that the evolution of the architectural traditions could have been a generalised trajectory shared among the communities of the Kura River valley. It has been suggested that the transition from free-standing snowman shaped buildings to the closed walled compounds could mirror a series of important changes in the social organisation of the Shomu-Shulaveri communities (Baudouin, 2019). E. Baudouin further showed that an increase of circular units within the same compound could reflect a higher number of family units coming together to form residential groups and this would represent a shift from a more segmented to a more integrated political organisation of these communities. The clearer definition of the compounds with perimeter walls could reflect changing needs; perhaps the need to separate households or activity areas as well as the byproducts of these activities. These new needs could have been the outcome of a new and growing economic role, possibly more independent and competitive, that the single households acquired in the frame of the increasingly large village communities that emerged during the later stages of the Neolithic (Flannery, 1972; Flannery, 2002; Baudouin, 2019).

Returning to Kiçik Tepe, the combination of stratigraphic and 14C data highlights the brevity of the intervals between different phases of occupation and suggests that the above mentioned architectural evolution, though gradual, may have taken place over a very brief period corresponding to a maximum of a couple of decades. The patterns of accidental (Phase 3) or intentional abandonment (Phase 2B), quickly followed by new occupations observed at Kiçik Tepe and at other settlements of the Kura River valley, could point to some type of short-range mobility that was commonly practiced by the Neolithic communities of the region (Ricci et al., 2018). In this frame of reference, the general assumption that the origins of agriculture are associated with sedentism, is challenged by this data showing that mobility could have been a structural feature of these early farming communities. Finally, data from Kiçik Tepe also shows that during this abandonment and reoccupation, there were significant changes in the spatial layout of the residential structures, presumably occurring together with socio-economic transformations hinting at rapidly evolving types of societies. We still ignore the factors at the origin of these systematic residential shifts, however, we cannot exclude that this type of mobility could have reflected changing needs and requirements related to a shift in agricultural practices (Batiuk et al., 2019) or mobile herding strategies.

As at other Neolithic settlements in the South Caucasus, there is no evidence for local domestication at Kiçik Tepe, thus confirming the rapid and systematic adoption, as early as the beginning of the 6th millennium BCE, of subsistence strategies that relied on pre-domesticated species (Decaix, 2016; Akashi et al., 2018; Marro et al., 2019; Nishiaki et al., 2019). At Kiçik Tepe, cereals and caprines are the most commonly domesticated species in the substistence 'package' adopted widely by other communities in the region as well. Among these regional commonalities, Kiçik Tepe also confirms a diachronic trend from hulled wheat in the early stages to naked wheat in the later stages of the Neolithic. Simultaneously, the nearly total absence of cattle at Kiçik Tepe contrasts with the abundance of pig. As observed elsewhere (Marro et al., 2019; Nishiaki et al., 2019) this shows variability in the 
adoption of farming and herding practices, thus highlighting that within the "Neolithic economic system" the ways in which these communities exploited domesticated livestock (Thomas, 1999: 7-17) mirrored regional environmental characteristics or even site-specific preferences. On this note, the intensive use of wild plants, and namely of Artemisia, could hint at the persistence and transmission of previous Mesolithic knowledge and experience (Nishiaki et al., 2019) adding further elements of complexity to local Neolithic lifestyles.

Similarly, the material culture from Kiçik Tepe includes broadly shared regional elements as well as very localised traits framed into both long and short distance contacts and interactions. For instance, the production of obsidian blades by means of pressure flaking, as well as other typological elements suggest the knowledge of a knapping technology that was widely shared in the frame of the larger ShomuShulaveri Culture. These analogies highlight what appears to be a homogenous flow of information and practical know-how that circulated among the Neolithic knappers of the South Caucasus in the early 6th millennium BCE. At the same time, the raw material acquisition of the knappers from Kiçik Tepe differed from neighbouring communities. Although the substantial presence of flint in Phase 3 points to greater reliance on local resources in the early stages of the occupation; the unusual prevalence of obsidian from Chikhiani and Sarıkamış also highlights a sharp preference for a westward sourcing network reaching as far as North Eastern Anatolia. This, in turn, emphasises the scale of the networks of procurement of obsidian that could have mirrored the longdistance mobility of the groups and individuals living at Kiçik Tepe.

A complex dialectic between long-distance and more local regional interactions is also seen in the macrolithic tools. On the one hand, the grooved polishers found in Phase 3 point to long distance contacts and connections with techniques and practices originated in Syria, East Anatolia and the Zagros during the Pre-Pottery Neolitic A. On the other hand, the rest of the macrolithic tools produced with local raw materials show technical and morphological similarities with tools produced by the contemporary South Caucasian communities. This evidence confirms the interaction of Kiçik Tepe's with its broader SSC community.

The sporadic presence of ceramic artefacts at Kiçik Tepe is also fully in line with the data already observed at other Early Neolithic sites in the Kura River valley and Ararat plain, confirming that the adoption of this new technology and innovative material was not a straightforward process in the South Caucasus (Nishiaki et al., 2019). Meanwhile, the Kiçik Tepe potters' preference for vegetal tempered ceramics differs from the mineral-tempered clays used by the potters from the Ararat plain, pointing to the existence of local, possibly even site-specific, manufacturing traditions (see also Iserlis, 2017 [2020]). In the context of this general, though highly localised trend, Kiçik Tepe stands out due to the absence of imported painted ceramics. The latter, that were found at several contemporary settlements in the Kura river and Araxes valley as well as in the Ararat plain, indicate that there was some kind of contact with Upper Mesopotamia and Eastern Anatolia. However, it seems that these contacts did not foster a direct transfer of ceramic technologies; rather they possibly promoted some inputs of the concept of fired clay containers. From this point of view, the South Caucasian Neolithic communities did not "imitate" exogenous techniques but reelaborated them to their own needs, creativity and know how. The ceramic evidence from Kiçik Tepe further emphasises the "autochtonous" dynamics embedded in the adoption of this new technology and in the practices associated to "fired-clay" containers. Their scarcity suggests that the ceramic containers still played a marginal role in daily practices such as cooking and food consumption; these practices remained essentially "aceramic" and were still tied to pre-existing Mesolithic food-processing and cooking techniques (Nishiaki et al., 2015b).

\section{Conclusions}

Excavations and research at Kiçik Tepe contribute important data on cultural and socio-economic developments experienced by Early Neolithic communities in the Middle Kura River valley and thus help to explain the complexity of the dynamics at work during the early stages of Neolithisation in the South Caucasus. There is a growing body of evidence pointing to a wide spectrum of interactions between the South Caucasus and the Anatolian, North Mesopotamian and Iranian regions vehiculated by movements of different nature and scope from both sides. These interactions suggest that the already Neolithisised regions of the Near East could have played an important role in the transmission of a series of socio-economic and ideological "structures" (Hodder, 1990: 20-43) as well as technological knowledge and cultural practices, that were re-elaborated in the South Caucasus. On this basis, we propose that the Shomu-Shulaveri Culture should be seen as the material expression of this process of re-structuration of exogenous "Neolithic" inputs, that were profoundly re-elaborated in and by the South Caucasian ecological and human environnement.

Data from Kiçik Tepe show the active participation of a community of the Kura River valley in this process from its early stages in what appears to be a state of constant interaction with contemporary neighbouring communities. However, the material culture, subsistence strategies and raw material provisioning networks also tend to display a set of strongly local characteristics, thus calling into question previous assumptions as to the homogeneity of the Shomu-Shulaveri Culture (Lyonnet, 2017a; Marro et al., 2019) and highlighting that individual communities, like that at Kiçik Tepe, may have elaborated and adapted this new cultural repertoire and resource strategies in ways that were different from the neighbouring ones (Thomas, 1999: 13-17). Finally, the apparently contradictory tensions at Kiçik Tepe between sedentism and mobility, introduction of ceramic technologies and persitence of aceramic food-consuming practices, as well as adoption of a productive ecomomy and a reliance on wild resources, show that the Neolithisation in the Kura River valley, and possibly in the whole South Caucasus, did not consist of an abrupt and full adoption of an exogenous 'package'. Most probably this was a gradual, though radical, and very complex process of change (Thomas, 1999: 3-17) encompassing a broad variability of ecological, cultural and social dynamics embedded in daily dynamics of resilience and innovation between old and new ways of life experienced by the indigenous populations.

\section{CRediT authorship contribution statement}

Giulio Palumbi: Conceptualization, Validation, Investigation, Resources, Writing - original draft, Writing - review \& editing, Visualization, Supervision, Project administration, Funding acquisition. Farhad Guliyev: Investigation, Resources, Supervision, Funding acquisition, Writing - original draft. Laurence Astruc: Formal analysis, Investigation, Data curation, Writing - original draft, Writing - review \& editing, Visualization. Emmanuel Baudouin: Formal analysis, Investigation, Data curation, Writing - original draft, Writing - review \& editing, Visualization. Rémi Berthon: Formal analysis, Investigation, Data curation, Writing - original draft, Writing - review \& editing, Visualization. Maria Bianca D'Anna: Formal analysis, Investigation, Data curation, Writing - original draft, Writing - review \& editing, Visualization. Alexia Decaix: Formal analysis, Investigation, Data curation, Writing - original draft, Writing - review \& editing, Visualization. Bernard Gratuze: Formal analysis, Investigation, Writing - original draft, Writing - review \& editing, Visualization. Caroline Hamon: Formal analysis, Investigation, Writing - original draft, Writing - review \& editing, Visualization. Modwene Poulmarc'h: Investigation, Data curation, Writing - original draft, Writing - review \& editing, Visualization. Andrea Ricci: Formal analysis, Investigation, Writ- 
ing - original draft, Writing - review \& editing, Visualization. Valeh Alakbarov: Project administration.

\section{Declaration of Competing Interest}

None.

\section{Acknowledgments}

Excavations at Kiçik Tepe were undertaken in the frame of the activities of the archaeoogical expedition "Mission Boyuk Kesik" which is funded by the French Ministry of Foreign Affairs (MEAE). Scientific activities at Kiçik Tepe were also supported by the following CNRS Laboratories: CEPAM (UMR 7264), Archéorient (UMR 5133) and Trajectoires (UMR 8215). Special thanks go to Didier Binder (CNRS CEPAM) for the feedback on 14C dates and chronological modelling. We would also like to warmly thank Prof. Yoshihiro Nishiaki of the University of Tokyo for generously providing the first set of radiocarbon dates of Kiçik Tepe. In Azerbaidjan, we are grateful to the French Embassy in Baku for the support provided to the "Mission Boyuk Kesik" and we express our gratitude to Dr. Maissa Regimova, director of the Institute of Archaeology and Ethnography of the National Academy of Sciences of Azerbaijan for according the permission to carry out investigations at Kiçik Tepe. Many thanks go to E. Muradova, S. Salimbeyov and E. Babazade for their participation to the excavations and to Z. Jafarov and his team of workers for assistance in the field. We would also like to thank the two anonymous reviewers for their feedback and suggestions. Last but not least, our warmest thanks go to Bertille Lyonnet former director of the "Mission Boyuk Kesik" for generously sharing her knowledge and experience matured during over more than 10 years of investigations in the Caucasus, for her practical help and continuous advice and finally for having understood, before anyone else, during the first survey carried out at in 2016, the great potential of Kiçik Tepe. This is why we dedicate to Bertille Lyonnet these discoveries.

\section{References}

Abibullaev, O., 1982. Eneolit i Bronza na Territorii Nakhičevanskoj ASSR. Elm, Baku. Akashi, C., Tanno, K., Guliyev, F., Nishiaki, Y., 2018. Neolithisation processes of the South Caucasus: as viewed from macro-botanical analyses at Hacı Elamxanlı Tepe, West Azerbaidjan. Paléorient 44 (2), 75-89.

Akhundov, T., 2012. U Istokov Kavkazskoj Tsivilizatsii. Neolit Azerbajdzhana, Kniga Pervaja, Shomutepe. Institut Arkheologii i Etnografii, Baku.

Alakbarov, V., 2018. Formation and development of ceramic production in the South Caucasus at Neolithic period. Azərbaycan Arxeologiyası 21 (1), 177-198.

Aliyev, T., Helwing, B., 2009. Kamiltepe in der Milebene. Archäologische Untersuchungen 2009. Archäologische Mitteilungen aus Iran und Turan 41, 23-45.

Arimura, M., Badalyan, R., Gasparyan, B., Chataigner, C., 2010. Current Neolithic research in Armenia. Neo-lithics 1 (10), 77-99.

Badalyan, R., Harutyunyan, A., 2014. Aknashen - the late Neolithic settlement of the Ararat Valley: Main results and prospects for the research. In: Gasparyan, B., Arimura, M. (Eds.), Stone age of Armenia. A guide-book to the stone age archaeology in the Republic of Armenia. Center for Cultural Resource Studies Kanazawa University, Kanazawa, pp. 161-176.

Badalyan, R., Lombard, P., Avetisian, P., Chataigner, C., 2004. The Neolithic and chalcolithic phases in the Ararat plan (Armenia): The view from Aratashen. In: Sagona, A. (Ed.), A View from the Highlands: Archaeological Studies in Honour of Charles Burney. Peeters, Herent, pp. 399-420.

Badalyan, R., Lombard, P., Avetisyan, P., Chataigner, C., Chabot, J., Vila, E., Hovsepyan, R., Willcox, G., Pessin, H., 2007. New data on the late prehistory of the southern Caucasus. The excavations at Aratashen (Armenia): Preliminary report. In: Lyonnet, B. (Ed.), Les Cultures du Caucase (VIe-IIIe millénaires avant notre ère). Leurs Relations avec le Proche-Orient. CNRS Editions, Paris, pp. 37-61.

Badalyan, R., Harutyunyan, A., Chataigner, C., Le Mort, F., Chabot, J., Brochier, J.E. Balasescu, A., Radu, V., Hovsepyan, R., 2010. The settlement of Aknashen-Khatunarkh, a Neolithic site in the Ararat plain (Armenia): excavation results 2004-2009. TÜBA-AR 13, $185-218$.

Bastert-Lamprichs, K., 2017. Das neolithische Aruchlo: die Keramik der Kampagnen 2012-2014. In: Helwing, B., Aliyev, T., Lyonnet, B., Guliyev, F., Hansen, S., Mirtskhulava, G. (Eds.), The Kura Projetcs. New research on the later prehistory of the southern Caucasus, Archäologie in Iran und Turan, 16. Dietrich Reimer Verlag, Berlin, pp. 233-246.

Batiuk, S., Jayyab, K.A., Jalabadze, M., Graham, A., Rhodes, S., Losaberidze, L., 2019. The 2017-18 Gadachrili Gora regional archaeological project (grape): second preliminary report. Anatolica 45, 43-76.
Baudouin, E., 2019. Rethinking architectural techniques of southern Caucasus in the 6th millennium BC: a re-examination of former data and new insights. Paléorient 45 (1), $115-150$

Benecke, N., 2012. Archaezoological studies. In: Lyonnet, B., Guliyev, F., Helwing, B.,

Aliyev, T., Hansen, S., Mirtskhulava, G. (Eds.), Ancient Kura 2010-2011: The First Two Seasons of Joint Field Work in the Southern Caucasus. In: Archäologische Mitteilungen aus Iran und Turan, vol. 44. pp. 154-155.

Benecke, N., 2017. Exploitation of animal resources in Neolithic settlements of the Kura region (South Caucasia). In: Helwing, B., Aliyev, T., Lyonnet, B., Guliyev, F., Hansen, S., Mirtskhulava, G. (Eds.), The Kura Projetcs. New Research on the Later Prehistory of the Southern Caucasus, Archäologie in Iran und Turan, 16. Dietrich Reimer Verlag, Berlin, pp. 357-369.

Berthon, R., 2014. Past, current and future contribution of Zooarchaeology to the knowledge of the Neolithic and chalcolithic cultures in South Caucasus. Studies in Caucasian Archaeology 2, 4-30.

Biagi, P., Nisbet, R., Gratuze, B., 2017. Obsidian mines and their characterization: new aspects of the exploitation of the obsidian sources of Mt. Chikiani (Koyun Dağ) in the lesser Caucasus of Georgia. The Quarry 12, 2-24.

Binder, D., Gassin, B., 1987. Le débitage laminaire chasséen après chauffe : technologie et traces d'utilisation. In: Beyries, S. (Ed.), Industries lithiques. Aspects archéologiques. In: BAR International Series 411 (i), vol. 1. Archaeopress, Oxford, pp. 93-127.

Campbell, S., Healey, E., 2018. Diversity in obsidian use in the prehistoric and early historic Middle East. Quat. Int. 468, 141-154.

Cappers, R.T.J., Neef, R., Bekker, R.M., 2012. Digital Atlas of Economic Plants in Archaeology. Barkhuis and Gröningen University Library, Gröningen.

Chataigner, C., Gratuze, B., 2014a. New data on the exploitation of obsidian in the southern Caucasus (Armenia, Georgia) and eastern Turkey, part 2: obsidian procurement from the upper Paleolithic to the late bronze age. Archaeometry 56 (1), 48-69.

Chataigner, C., Gratuze, B., 2014b. New data on the exploitation of obsidian in the southern Caucasus (Armenia, Georgia) and eastern Turkey, part 1: source characterization. Archaeometry 56 (1), 25-47.

Chataigner, C., Badalyan, R., Arimura, M., 2014a. The Neolithic of the Caucasus. In: Oxford Handbook Online. Oxford. https://doi.org/10.1093/oxfordhb/9780199935413. 013.13.

Chataigner, C., Ișıklı, M., Gratuze, B., Cil, V., 2014b. Obsidian sources in the regions of Erzurum and Kars (north-East Turkey): new data. Archaeometry 56 (3), 351-374.

Chataigner, C., Gratuze, B., Tardy, N., Abbes, F., Kalantaryan, I., Hovsepyan, R., Chahoud, J., Perello, B., 2020. Diachronic variability in obsidian procurement patterns and the role of the cave sheepfold of Getahovit-2 (NE Armenia) during the chalcolithic period. Quat. Int. 550, 1-19. https://doi.org/10.1016/j.quaint.2020.02.010.

D'Anna, M.B., 2012. The pottery of Kamiltepe and site MPS 5. In: Lyonnet, B., Guliyev, F., Helwing, B., Aliyev, T., Hansen, S., Mirtskhulava, G. (Eds.), Ancient Kura 2010-2011: The First Two Seasons of Joint Field Work in the Southern Caucasus. In: Archäologische Mitteilungen aus Iran und Turan, vol. 44. pp. 38-46.

D'Anna, M.B., 2017. The 2013 sounding at site MPS 103: preliminary report. Some new insights into the Neolithic 'unpainted ceramic horizon' of the mil plain. In: Helwing, B., Aliyev, T., Lyonnet, B., Guliyev, F., Hansen, S., Mirtskhulava, G. (Eds.), The Kura Projetcs. New research on the later prehistory of the southern Caucasus, Archäologie in Iran und Turan, 16. Dietrich Reimer Verlag, Berlin, pp. 43-49.

Decaix, A., 2016. Origine et évolution des économies agricoles dans le sud du Caucase recherches archéobotaniques dans le bassin Kuro-Araxe. Université Paris 1 PanthéonSorbonne, Paris.

Decaix, A., Messager, E., Tengberg, M., Neef, R., Lyonnet, B., Guliyev, F., 2016. Vegetation and plant exploitation at Mentesh Tepe (Azerbaijan), 6th-3rd mill. BC. First results of the archaeobotanical study. Quat. Int. 395, 19-30.

Dzhavakhishvili, A., Dzhaparidze, O., 1975. Otchet Kvemo-Kartlijskoj arkheologicheskoj ekspeditsii (1965-1971 gg). Metsniereba, Tbilisi.

Flannery, K.V., 1972. The origins of the village as a settlement type in Mesoamerica and the near east: A comparative study. In: Ucko, P.J., Tringham, R., Dimbleby, G.W. (Eds.), Man, Settlement and Urbanism. Duckworth, London, pp. 23-53.

Flannery, K.V., 2002. The origins of the village revisited: from nuclear to extend households. Am. Antiq. 67 (3), 417-433.

Gratuze, B., 1999. Obsidian characterisation by laser ablation ICP-MS and its application to the prehistoric trade in the Mediterranean and the near east: the sources and distribution of obsidian within the Aegean and Anatolia. J. Archaeol. Sci. 26, 869-881. Guilbeau, D., Astruc, L., Samzun, A., 2017. Chipped stone industries from the mil plain (Kamiltepe) and the middle Kura Valley (Mentesh Tepe), Azerbaijan. In: Helwing, B., Aliyev, T., Lyonnet, B., Guliyev, F., Hansen, S., Mirtskhulava, G. (Eds.), The Kura Projetcs. New Research on the Later Prehistory of the Southern Caucasus, Archäologie in Iran und Turan, 16. Dietrich Reimer Verlag, Berlin, pp. 385-398.

Guliyev, F., Nishiaki, Y., 2014. Excavations at the Neolithic settlement of Göytepe, west Azerbajan 2010-2011. In: Bielinski, P., Gawlikowski, M., Kolinsk, R., Lawecka, D., Soltysiak, A., Wygnanska, Z. (Eds.), Proceedings of the $8^{\text {th }}$ International Congress on the Archaeology of the Ancient near East. 30 April-4 May 2012, University of Warsaw. In: Excavation and Progress Reports Posters, vol. 2. Harrassowitz Verlag, Wiesbaden, pp. 3-16.

Hamilton, D., Krus, A., 2018. The myths and realities of Bayesian chronological modeling revealed. Am. Antiq. 83 (2), 187-203.

Hamon, C., 2008. From Neolithic to chalcolithic in the southern Caucasus: economy and macrolithic implements from Shulaveri-Shomu sites of Kvemo-Kartli (Georgia). Paléorient 34 (2), 85-135.

Hamon, C., 2012. Macrolithic tools from Neolithic and chalcolithic sites in southern Caucasus: Menteshtepe and mil steppe (Azerbaidjan). In: Lyonnet, B., Guliyev, F., Helwing, B., Aliyev, T., Hansen, S., Mirtskhulava, G. (Eds.), Ancient Kura 2010-2011: The First Two Seasons of Joint Field Work in the Southern Caucasus. In: Archäologische Mitteilungen aus Iran und Turan, vol. 44. pp. 165-172. 
Hamon, C., Jalabadze, M., Agapishvili, T., Baudouin, E., Koridze, I., Messager, E., 2016. Gadachrili Gora: a new Neolithic excavation within the Shulaveri group (Chramis Valley, Georgia). Quat. Int. 395, 154-169.

Hansen, S., 2011. Der Beginn der Landwirtschaft im Südkaukasus. Die Ausgrabungen in Aruchlo in Georgien. Eurasien-Abteilung des Deutschen Archäologischen Instituts and Otar-Lordkipanidze-Zentrum fur Archaologische Forschung, Berlin and Tbilisi.

Hansen, S., Ullrich, M., 2017. Report on the 2012-2014 excavation Campaing in Aruchlo. In: Helwing, B., Aliyev, T., Lyonnet, B., Guliyev, F., Hansen, S., Mirtskhulava, G. (Eds.), The Kura Projects. New Research on the Later Prehistory of the Southern Caucasus. Dietrich Reimer Verlag, Berlin, pp. 201-222.

Harutyunyan, A., 2014. On Neolithic pottery from the settlement of Aknashen in the Ararat Valley. In: Gasparyan, B., Arimura, M. (Eds.), Stone Age of Armenia. Center for Cultural Resource Studies, Kanazawa University, Kanazawa, pp. 191-204.

Helwing, B., Aliyev, T., 2017. Excavations in the mil plain sites, 2012-2014. In: Helwing, B., Aliyev, T., Lyonnet, B., Guliyev, F., Hansen, S., Mirtskhulava, G. (Eds.), The Kura Projetcs. New Research on the Later Prehistory of the Southern Caucasus, Archäologie in Iran und Turan, 16. Dietrich Reimer Verlag, Berlin, pp. 11-42.

Hodder, I., 1990. The Domestication of Europe. Blackwell Publishers, Oxford.

Houben, H., Guillaud, H., Dayre, M., 2006. Traité de construction en terre. Éd. Parenthèses, Marseille.

Hovsepyan, R., Willcox, G., 2008. The earliest finds of cultivated plants in Armenia: evidence from charred remains and crop processing residues in pisé from the Neolithic settlements of Aratashen and Aknashen. Veg. Hist. Archaeobotany 17, 63-71.

Ibáñez, J.J., Campos, D., Khalidi, L., Méndez, V., Teira, L., 2016. Developing a complex network model of obsidian exchange in the Neolithic near east: linear regressions, ethnographic models and archaeological data. Paléorient 42 (2), 9-32.

Ioseliani, V., 2017. Architecture debris from the burnt layers. In: Helwing, B., Aliyev, T., Lyonnet, B., Guliyev, F., Hansen, S., Mirtskhulava, G. (Eds.), The Kura Projetcs. New Research on the Later Prehistory of the Southern Caucasus, Archäologie in Iran und Turan, 16. Dietrich Reimer Verlag, Berlin, pp. 281-286.

Iserlis, M., 2017 [2020]. Local dynamics and the emergence of pottery traditions in the Neolithic southern Caucasus. Archäologische Mitteilungen aus Iran und Turan 49, 1-48. Joannin, S., Ali, A., Ollivier, V., Roiron, P., Peyron, O., Chevaux, S., Nahapetyan, S., Tozalakyan, P., Karakhanyan, A., Chataigner, C., 2014. Vegetation, fire and climate history of the lesser Caucasus: a new Holocene record from Zarishat fen (Armenia). J. Quat. Sci. 29, 70-82.

Kadowaki, S., Guliyev, F., Nishiaki, Y., 2014. Chipped stone technology of the earliest agricultural village in the southern Caucasus: Hacı Elamxanlı Tepe. In: Kaelin, O., Mathys, H.P. (Eds.), Proceedings of the 9th ICAANE, vol. 3. Harrassowitz Verlag, Wiesbaden, pp. 709-723.

Kadowaki, S., Maher, L., Portillo, M., Albert, R.M., Akashi, C., Guliyev, F., Nishiaki, Y., 2015. Geoarchaeological and palaeobotanical evidence for prehistoric cereal storage in the southern Caucasus: the Neolithic settlement of Göytepe (mid $8^{\text {th }}$ millenium BP). J. Archaeol. Sci. 53, 408-425.

Kadowaki, S., Ohnishi, K., Arai, S., Guliyev, F., Nishiaki, Y., 2017. Mitochondrial DNA analysis of ancient domestic goats in the southern Caucasus: a preliminary result from Neolithic settlements at Göytepe and Hacı Elamxanlı Tepe. Int. J. Osteoarchaeol. 27, 245-260.

Kiguradze, T., 1986. Neolithische Siedlungen von Kwemo-Kartli, Georgien. C.H. Beck, Munchen.

Kvavadze, E., Connor, S., 2005. Zelkova carpinifolia (Pallas) K. Koch in Holocene sediments of Georgia - an indicator of climatic optima. Review of Palaeobotany and Palynology 133, 69-89. https://doi.org/10.1016/j.revpalbo.2004.09.002.

Leroyer, C., Joannin, S., Aoustin, D., Ali, A., Peyron, O., Ollivier, V., Tozalakyan, P., Karakhanyan, A., Jude, F., 2016. Mid Holocene vegetation reconstruction from Vanevan peat (south-eastern shore of Lake Sevan, Armenia). Quat. Int. 395, 5-18.

Lyonnet, B., 2017a. Mentesh Tepe, concluding remarks. In: Helwing, B., Aliyev, T., Lyonnet, B., Guliyev, F., Hansen, S., Mirtskhulava, G. (Eds.), The Kura Projetcs. New Research on the Later Prehistory of the Southern Caucasus, Archäologie in Iran und Turan, 16. Dietrich Reimer Verlag, Berlin, pp. 193-194.

Lyonnet, B., 2017b. Mentesh Tepe 2012-2014. The Pottery. In: Helwing, B., Aliyev, T., Lyonnet, B., Guliyev, F., Hansen, S., Mirtskhulava, G. (Eds.), The Kura Projetcs. New Research on the Later Prehistory of the Southern Caucasus, Archäologie in Iran und Turan, 16. Dietrich Reimer Verlag, Berlin, pp. 141-150.

Lyonnet, B., 2018. Rethinking the 'Sioni cultural complex' in the South Caucasus (chalcolithic period). New data from Mentesh Tepe (Azerbaijan). In: Batmaz, A. Bedianashvili, G., Michalewicz, A., Robinson, A. (Eds.), Context and Connection: Essays on the Archaeology of the Ancient Near East in Honour of Antonio Sagona. Peeters, Leuven, pp. 547-567.

Lyonnet, B., Guliyev, F., Helwing, B., Aliyev, T., Hansen, S., Mirtskhulava, G., 2012. Ancient Kura 2010-2011: the first two seasons of joint field work in the Southern Caucasus. Archäologische Mitteilungen aus Iran und Turan 44, 1-190.

Lyonnet, B., Guliyev, F., Bouquet, L., Bruley-Chabot, G., Samzun, A., Pecqueur, L., Jovenet, E., Baudouin, E., Fontugne, M., Raymond, P., Degorre, E., Astruc, L., Guilbeau, D., Dosseur, G., Benecke, N., Hamon, C., Poulmarc'h, M., Courcier, A., 2016. Mentesh Tepe, an early settlement of the Shomu-Shulaveri culture in Azerbaijan. Quat. Int. 395, $170-183$.

Lyonnet, B., Guliyev, F., Baudouin, E., Bouquet, L., Bruley-Chabot, G., Samzun, A., Fontugne, M., Degorre, E., Husson, X., Raymond, P., 2017. Mentesh Tepe (Azerbaijan), a preliminary report on the 2012-2014 excavations. In: Helwing, B., Aliyev, T., Lyonnet, B., Guliyev, F., Hansen, S., Mirtskhulava, G. (Eds.), The Kura Projetcs. New Research on the Later Prehistory of the Southern Caucasus, Archäologie in Iran und Turan, 16. Dietrich Reimer Verlag, Berlin, pp. 125-140.

Margueron, J.C., 1987. Notes complémentaires sur la question de l'étage. In: Huot, J.L. (Ed.), Préhistoire de la Mésopotamie : la Mésopotamie préhistorique et l'exploration récente du Djebel Hamrin. CNRS Éditions, Paris, pp. 447-460.
Marro, C., Bakhshaliyev, V., Berthon, R., 2019. New light on the late prehistory of the South Caucasus: data from the recent excavation campaigns at Kültepe I in Nakhchivan, Azerbaijan (2012-2018). Paléorient 45 (1), 81-113.

Meadow, R., 1978. Effects of context on the interpretation of faunal remains: A case study. In: Meadow, R.H., Zeder, M.A. (Eds.), Approaches to Faunal Analysis in the Middle East, Peabody Museum Bulletin 2. Harvard University, Cambridge, pp. 15-21.

Messager, E., Belmecheri, S., von Grafenstein, U., Nomade, S., Ollivier, V., Voinchet, P., Puaud, S., Courtin-Nomade, A., Guillou, H., Mgeladze, A., Dumoulin, J.P., Mazuy, A., Lordkipanidze, D., 2013. Late quaternary record of the vegetation and catchment-related changes from Lake Paravani (Javakheti, South Caucasus). Quat. Sci. Rev. 77, 125-140. Messager, E., Nomade, S., Wilhelm, B., Joannin, S., Scao, V., Grafenstein, U.,

Martkoplishvili, I., Ollivier, V., Mgeladze, A., Dumoulin, J.P., Mazuy, A., Belmecheri, S., Lordkipanidze, D., 2017. New pollen evidence from Nariani (Georgia) for delayed postglacial forest expansion in the South Caucasus. Quat. Res. 87, 121-132.

Narimanov, I., 1987. Kul'tura drevnejshego zemledel'chesko-skotovodcheskogo naselenija Azerbaidzhana (epokha Eneolita VI-IV tys. do n. e.). Elm, Baku. Neef, R., Decaix, A., Tengberg, M., 2017. Agricultural practices and palaeoenvironment of the southern Caucasus during the Neolithic. A transect along the Kura River. In: Helwing, B., Aliyev, T., Lyonnet, B., Guliyev, F., Hansen, S., Mirtskhulava, G. (Eds.), The Kura Projetcs. New Research on the Later Prehistory of the Southern Caucasus, Archäologie in Iran und Turan, 16. Dietrich Reimer Verlag, Berlin, pp. 371-377. Nesbitt, M., Goddard, J., 2006. Near Eastern Grass Seeds. Institute of Archaeology, University College London, London.

Nishiaki, Y., Guliyev, F., 2019. Neolithic lithic industries of the southern Caucasus: Göytepe and Hacı Elamxanlı Tepe, west Azerbaijan (early $6^{\text {th }}$ millennium cal. BC). In: Astruc, L., McCartney, C., Briois, F., Kassianidou, V. (Eds.), Near Eastern Lithic technologies on the move. Interactions and Contexts in the Neolithic Traditions, $8^{\text {th }}$ International conference on PPN chipped stone and ground stone industries of the Near East, Nicosia, November 23-27th 2016, SIMA CL. Astrom editions, Nicosia, pp. 471-483. Nishiaki, Y., Guliyev, F., Kadowaki, S., Arimatsu, Y., Hayakawa, Y., Shimogama, K., Miki, T., Akashi, C., Arai, S., Salimbeyov, S., 2013. Hacı Elamxanlı Tepe: excavations of the earliest pottery Neolithic occupations on the middle Kura, Azerbaijan. Archäologische Mitteilungen aus Iran und Turan 45, 1-25.

Nishiaki, Y., Guliyev, F., Kadowaki, S., Alakbarov, V., Miki, T., Salimbeyov, S., Akashi, C., Arai, S., 2015a. Investigating cultural and socioeconomic change at the beginning of the Pottery Neolithic in the southern Caucasus: the 2013 excavations at Hacı Elamxanlı Tepe, Azerbaijan. BASOR 374, 1-28.

Nishiaki, Y., Guliyev, F., Kadowaki, S., 2015b. Chronological contexts of the earliest pottery Neolithic of the South Caucasus: radiocarbon dates from Göytepe and Hac1 Elamxanlı Tepe, Azerbaijan. American Journal of Archaeology 119, 279-294.

Nishiaki, Y., Guliyev, F., Kadowaki, S., Omori, T., 2018. Neolithic residential patterns in the Southern Caucasus: radiocarbon analysis of rebuilding cycles of mudbrick architecture at Göytepe. West Azerbaijan, Quaternary International 474, 119-130. Nishiaki, Y., Zeynalov, A., Mansrov, M., Akashi, C., Arai, S., Shimogama, K., Guliyev, F., 2019. The Mesolithic-Neolithic interface in the Southern Caucasus: 2016-2017 excavations at Damjili Cave, West Azerbaijan, Archaeological Research in Asia. 19. pp. $1-16$.

Nishiaki, Y., Guliyev, F., Baudouin, E., 2020. Mud-bricks in Neolithic architecture at Göytepe. In: Nishiaki, Y., Guliyev, F. (Eds.), Göytepe, Neolithic Excavations in the Middle Kura Valley, Azerbaijan, Archaeopress Archaeology. Oxford, pp. 97-108. Ollivier, V., Fontugne, M., Lyonnet, B., Chataigner, C., 2016. Base level changes, river avulsions and Holocene human mode of occupations in the Caspian Sea area (middle Kura valley, South Caucasus). Quaternary International 395, 79-94. https://doi.org/10. 1016/j.quaint.2015.03.017.

Ollivier, V., Fontugne, M., Hamon, C., Decaix, A., Hatté, C., Jalabadze, M., 2018. Neolithic water management and flooding in the lesser Caucasus (Georgia). Quat. Sci. Rev. 197, 267-287.

Özdoğan, M., 2011. Archaeological evidence on the westward expansion of farming communities from eastern Anatolia to the Aegean and the Balkans. Curr. Anthropol. 52 (4), 415-430.

Özkaya, V., Coşkun, A., 2011. Körtik Tepe. In: Özdoğan, M., Başgelen, N., Kuniholm, P. (Eds.), The Neolithic in Turkey 1. Archaeology and Art Publications, Istanbul, pp. 89-127.

Palumbi, G., 2007. A preliminary analysis on the prehistoric pottery from Aratashen (Armenia). In: Lyonnet, B. (Ed.), Les Cultures du Caucase (VIe-IIIe millénaires avant notre ère). Leurs Relations avec le Proche-Orient. CNRS Editions, Paris, pp. 63-76. Palumbi, G., Gratuze, B., Harutyunyan, A., Chataigner, C., 2014. Obsidian-tempered pottery in the southern Caucasus: a new approach to obsidian as a ceramic-temper. J. Archaeol. Sci. 44, 43-54.

Payne, S., Bull, G., 1988. Components of variation in measurements of pig bones and teeth, and the use of measurements to distinguish wild from domestic pig remains. ArchæoZoologia 2, 27-65.

Pelegrin, J., 2012. New experimental observations for the characterization of pressure blade production techniques. In: Desrosiers, P.M. (Ed.), The Emergence of Pressure Blade Making. From the Origin to Modern Experimentation. Springer, New York, pp. 465-500.

Reimer, P.J., Bard, E., Bayliss, A., Beck, J.W., Blackwell, P.G., Ramsey, C.B., Buck, C.E., Cheng, H., Edwards, R.L., Friedrich, M., Grootes, P.M., Guilderson, T.P., Haflidason, H., Hajdas, I., Hatte, C., Heaton, T.J., Hoffmann, D.L., Hogg, A.G., Hughen, K.A., Kaiser, K. F., Kromer, B., Manning, S.W., Niu, M., Reimer, R.W., Richards, D.A., Scott, E.M., Southon, J.R., Staff, R.A., Turney, C.S.M., van der Plicht, J., 2013. IntCal13 and Marine13 radiocarbon age calibration curves 0-50,000 years cal BP. Radiocarbon 55 (4), 1869-1887.

Renfrew, C., Dixon, J.E., Cann, J.R., 1968. Further analyses of near eastern obsidians. Proceedings of the Prehistoric Society 34, 319-331.

Ricci, A., 2012. Ancient Kura project. Archaeological landscape studies. The mil-Karabakh plain and the Kvemo Kartli survey projects: A preliminary account of the first two field 
seasons (2010-11). In: Helwing, B., Lyonnet, B., Hansen, S. (Eds.), The Kura Projects. New Research on the Later Prehistory of the Southern Caucasus. Dietrich Reimer Verlag, Berlin, pp. 127-145.

Ricci, A., D'Anna, M.B., Lawrence, D., Helwing, B., Aliyev, T., 2018. Human mobility and early sedentism: the late Neolithic landscape of southern Azerbaijan. Antiquity 92 (366), 1445-1461. https://doi.org/10.15184/aqy.2018.230.

Rivera, D., Matilla, G., Obon, C., Alcaraz, F., 2011. Plants and Humans in the Near East and the Caucasus. Ancient and Traditional Uses of Plants as Food and Medicine. An Ethnobotanical Diachronic Review. Université de Murcia, Murcia.

Rosenberg, D., 2010. Early maceheads in the southern Levant: a "chalcolithic" hallmark in Neolithic context. J. Field Archaeol. 35 (2), 204-216.

Skourtanioti, E., Erdal, Y., Frangipane, M., Balossi Restelli, F., Yener, A., Pinnock, F., Matthiae, P., Özbal, R., Schoop, U.D., Guliyev, F., Akhundov, T., Lyonnet, B., Hammer, E., Nugent, S., Burri, M., Neumann, G., Penske, S., Ingman, T., Akar, M., Shafiq, R. Palumbi, G., Eisenmann, S., D’Andrea, M., Rohrlach, A., Warinner, C., Jeong, C.,
Stockhammer, P., Haak, W., Krause, J., 2020. Genomic history of Neolithic to bronze age Anatolia, Northern Levant, and Southern Caucasus. Cell 181, 1158-1175.

Thomas, J., 1999. Understanding the Neolithic. Routledge, London.

Weaver, T.D., Boyko, R.H., Steele, T.E., 2011. Cross-platform program for likelihood-

based statistical comparisons of mortality profiles on a triangular graph. J. Archaeol. Sci. 38, 2420-2423.

Wedepohl, K.H., 1995. The composition of the continental crust. Geochimica and Cosmochimica Acta 59, 1217-1232.

Willcox, G., 2012. Searching for the origins of arable weeds. Veg. Hist. Archaeobotany 21, 163-167.

Zvelebil, M., 2001. The agricultural transition and the origins of Neolithic society in Europe. Documenta Praehistorica XXVIII 1-26. 